\title{
Review
}

\section{Sulfonylurea Receptor 1 in Central Nervous System Injury: An Updated Review}

\author{
Ruchira M. Jha ${ }^{1,2,3,+}$, Anupama Rani ${ }^{2, \dagger}$, Shashvat M. Desai ${ }^{1}$, Sudhanshu Raikwar ${ }^{2}$, Sandra Mihaljevic ${ }^{2}$, \\ Amanda Munoz-Casabella ${ }^{2}$, Patrick M. Kochanek ${ }^{4,5,6,7}$, Joshua Catapano ${ }^{3}$, Ethan Winkler ${ }^{3}$, \\ Giuseppe Citerio ${ }^{8,9}{ }^{\mathbb{D}}$, J. Claude Hemphill ${ }^{10}$, W. Taylor Kimberly ${ }^{11}$, Raj Narayan ${ }^{12}$, Juan Sahuquillo ${ }^{13,14,15}$, \\ Kevin N. Sheth ${ }^{16}$ and J. Marc Simard $17,18,19, *$ (i)
}

\section{check for} updates

Citation: Jha, R.M.; Rani, A.; Desai, S.M.; Raikwar, S.; Mihaljevic, S.; Munoz-Casabella, A.; Kochanek, P.M.; Catapano, J.; Winkler, E.; Citerio, G.; et al. Sulfonylurea Receptor 1 in Central Nervous System Injury: An Updated Review. Int. J. Mol. Sci. 2021, 22, 11899. https://doi.org/10.3390/ ijms222111899

Academic Editors: Mootaz Salman, Philip Kitchen and Roslyn Bill

Received: 13 September 2021

Accepted: 26 October 2021

Published: 2 November 2021

Publisher's Note: MDPI stays neutral with regard to jurisdictional claims in published maps and institutional affiliations.

Copyright: (c) 2021 by the authors. Licensee MDPI, Basel, Switzerland. This article is an open access article distributed under the terms and conditions of the Creative Commons Attribution (CC BY) license (https:/ / creativecommons.org/licenses/by/ $4.0 /)$.
1 Department of Neurology, Barrow Neurological Institute and St. Joseph's Hospital and Medical Center, Phoenix, AZ 85013, USA; ruchiramjha@gmail.com (R.M.J.); shashvatdesaimd@gmail.com (S.M.D.)

2 Department of Translational Neuroscience, Barrow Neurological Institute and St. Joseph's Hospital and Medical Center, Phoenix, AZ 85013, USA; Anupama.Rani@Barrowneuro.org (A.R.); Sudhanshu.Raikwar@Barrowneuro.org (S.R.); sandra.mihaljevic@Barrowneuro.org (S.M.); Amanda.Munoz-Casabella@Barrowneuro.org (A.M.-C.)

3 Department of Neurosurgery, Barrow Neurological Institute and St. Joseph's Hospital and Medical Center, Phoenix, AZ 85013, USA; joshua.catapano@barrowbrainandspine.com (J.C.);

Ethan.Winkler@barrowbrainandspine.com (E.W.)

4 Clinical and Translational Science Institute, School of Medicine, University of Pittsburgh, Pittsburgh, PA 15213, USA; kochanekpm@pitt.edu

5 Department of Critical Care Medicine, University of Pittsburgh, Pittsburgh, PA 15213, USA

6 Department of Pediatrics, School of Medicine, University of Pittsburgh, Pittsburgh, PA 15213, USA

7 Safar Center for Resuscitation Research, School of Medicine, University of Pittsburgh, Pittsburgh, PA 15213, USA

8 School of Medicine and Surgery, University of Milan-Bicocca, 20126 Milan, Italy; giuseppe.citerio@unimib.it

9 Neurointensive Care Unit, Department of Neuroscience, San Gerardo Hospital, ASST—Monza, 20900 Monza, Italy

10 Department of Neurology, University of California, San Francisco, CA 94143, USA; claude.hemphill@ucsf.edu

11 Division of Neurocritical Care and Center for Genomic Medicine, Department of Neurology, Massachusetts General Hospital, Boston, MA 02114, USA; WTKIMBERLY@mgh.harvard.edu

12 Department of Neurosurgery, Donald and Barbara Zucker School of Medicine at Hofstra/Northwell, North Shore University Hospital, Manhasset, NY 11549, USA; RNarayan@northwell.edu

13 Neurotrauma and Neurosurgery Research Unit (UNINN), Vall d'Hebron Research Institute (VHIR), 08035 Barcelona, Spain; sahuquillo.juan@gmail.com

14 Neurotraumatology and Neurosurgery Research Unit, Universitat Autònoma de Barcelona (UAB), 08193 Barcelona, Spain

15 Department of Neurosurgery, Vall d'Hebron University Hospital, 08035 Barcelona, Spain

16 Division of Neurocritical Care and Emergency Neurology, Department of Neurology, School of Medicine, Yale University, New Haven, CT 06510, USA; kevin.sheth@yale.edu

17 Department of Neurosurgery, University of Maryland School of Medicine, Baltimore, MD 21201, USA

18 Department of Pathology, University of Maryland School of Medicine, Baltimore, MD 21201, USA

19 Department of Physiology, University of Maryland School of Medicine, Baltimore, MD 21201, USA

* Correspondence: MSimard@som.umaryland.edu

+ Joint first authors.

Abstract: Sulfonylurea receptor 1 (SUR1) is a member of the adenosine triphosphate (ATP)-binding cassette $(\mathrm{ABC})$ protein superfamily, encoded by $\mathrm{Abcc} 8$, and is recognized as a key mediator of central nervous system (CNS) cellular swelling via the transient receptor potential melastatin 4 (TRPM4) channel. Discovered approximately 20 years ago, this channel is normally absent in the CNS but is transcriptionally upregulated after CNS injury. A comprehensive review on the pathophysiology and role of SUR1 in the CNS was published in 2012. Since then, the breadth and depth of understanding of the involvement of this channel in secondary injury has undergone exponential growth: SUR1TRPM4 inhibition has been shown to decrease cerebral edema and hemorrhage progression in multiple preclinical models as well as in early clinical studies across a range of CNS diseases including ischemic stroke, traumatic brain injury, cardiac arrest, subarachnoid hemorrhage, spinal cord injury, intracerebral hemorrhage, multiple sclerosis, encephalitis, neuromalignancies, pain, liver 
failure, status epilepticus, retinopathies and HIV-associated neurocognitive disorder. Given these substantial developments, combined with the timeliness of ongoing clinical trials of SUR1 inhibition, now, another decade later, we review advances pertaining to SUR1-TRPM4 pathobiology in this spectrum of CNS disease-providing an overview of the journey from patch-clamp experiments to phase III trials.

Keywords: sulfonylurea receptor; edema; cellular swelling; traumatic brain injury; stroke; SUR 1; TRPM4; clinical trials

\section{Introduction}

Sulfonylurea receptor 1 (SUR1) is a member of the adenosine triphosphate (ATP)binding cassette $(\mathrm{ABC})$ protein superfamily, which encompasses a large group of membrane proteins that assist in and regulate the transport of ions and molecules across lipid bilayers $[1,2]$. To mediate this action, ABC proteins use energy derived from ATP hydrolysis. The ABC transporter subfamily encoded by the $A b c c$ genes consists of three classes: multidrug resistance-associated proteins encoded by $A b c c 1-6$ and $A b c c 10-13$, the cystic fibrosis conductance regulator encoded by $A b c c 7$ and the sulfonylurea receptors (SUR) encoded by $A b c c 8$ and $A b c c 9$ [3]. The SUR proteins appear in several isoforms with variable tissuepredominant expression patterns: for example, SUR1 is expressed in pancreatic $\beta$-cells and neurons, SUR2A is expressed in cardiac and skeletal muscle, and SUR2B is expressed in vascular smooth muscle [4].

Discovered approximately two decades ago, an octameric channel regulated by SUR1 is now increasingly recognized as a key mediator of central nervous system (CNS) cellular swelling via the association of four SUR1 subunits with four subunits of an ATP and calcium-sensitive non-selective cation pore-forming subunit, formerly known as $\mathrm{NC}_{\mathrm{Ca}-\mathrm{ATP}}$ and subsequently identified as transient receptor potential melastatin 4 (TRPM4) [5-8]. The SUR1-TRPM4 channel, when open, results in sodium influx, cell depolarization, intracellular edema, and, ultimately, oncotic cell death [5,6,9-12]. This channel is not present in the normal CNS but is transcriptionally upregulated after various forms of CNS injury, and contributes to cerebral edema.

Cerebral edema, an accumulation of intracerebral fluid that increases the net braintissue water mass, is a key detrimental hallmark of various CNS injuries including ischemic stroke, traumatic brain injury (TBI), subarachnoid hemorrhage (SAH), intracerebral hemorrhage $(\mathrm{ICH})$, cardiac arrest (CA), spinal cord injury (SCI), intracranial tumors, infections, autoimmune processes, and systemic conditions such as liver failure and sepsis [12-14]. In the context of a rigid skull, by increasing brain-tissue volume, cerebral edema often lowers brain-tissue perfusion, thereby causing cellular distress/injury. This also increases the risk of herniation and death [10]. This relationship between intracranial pressure (ICP) and cerebral edema was first described in 1783 by the Scottish Surgeon Alexander Monro, and is now well known as the Monro-Kellie hypothesis [15]. The increased pressure can also limit cerebral perfusion, and further perpetuate secondary injury. Mechanistically, oncotic edema of endothelial cells and breakdown of the blood-brain barrier (BBB) further contribute to other forms of secondary injury such as hemorrhage progression [16]. Currently, cerebral edema and resultant intracranial hypertension are treated with non-specific therapies such as hyperosmolar agents and, when severe, decompressive craniectomy. Although these therapies can be life-saving, they do not always improve functional outcomes, nor do they target or prevent the underlying pathobiological mechanisms [17-20]. Advances in precision medicine have led to an increasing recognition of the fact that a 'one-size -fits-all' approach is likely suboptimal [20-23], and the potential benefits of a targeted approach.

SUR1-TRPM4 expression and contribution to cerebral edema and secondary injury has been demonstrated across several types of CNS injury. SUR1-TRPM4 inhibition decreases cerebral edema and hemorrhage progression in multiple preclinical models, as well as 
some early clinical studies across a spectrum of CNS injury $[9,11,24-50]$. These studies underscore its potential as a translatable therapeutic target and biomarker after CNS injury. A comprehensive review on the pathophysiology and role of SUR1 in the CNS was published in 2012, approximately 10 years after the channel's discovery [6]. Now, another decade later, we review advances in the depth and breadth of understanding of the role of SUR1-TRPM4 in CNS disease and provide an overview of the journey from patch-clamp experiments to phase III clinical trials. Here, we outline the reported roles of SUR1-TRPM4 in different types of CNS injury, as well as the current progress and challenges in therapeutic inhibition.

\section{SUR1-TRPM4}

\subsection{SUR1-TRPM4 Structure}

SUR1, encoded by $A B C C 8$, is a transmembrane protein in the $A B C$ transporter superfamily [6]. Like other proteins in that family, SUR1 has a core structure comprised of two sets of transmembrane domains (TMD1 and TMD2), each containing six transmembrane $\alpha$-helices, and two cytosolic nucleotide-binding domains (NBDs) [2,51-53] (Figure 1). The characteristic feature of SUR1 is an additional set of five N-terminal transmembrane helices (TMD0) which is connected to TMD1 via a long cytosolic CL3 linker loop. SUR1 contains two functionally distinct nucleotide binding sites (NBS): the degenerate NBS1, and the consensus NBS2 - which has greater ATPase activity [54].
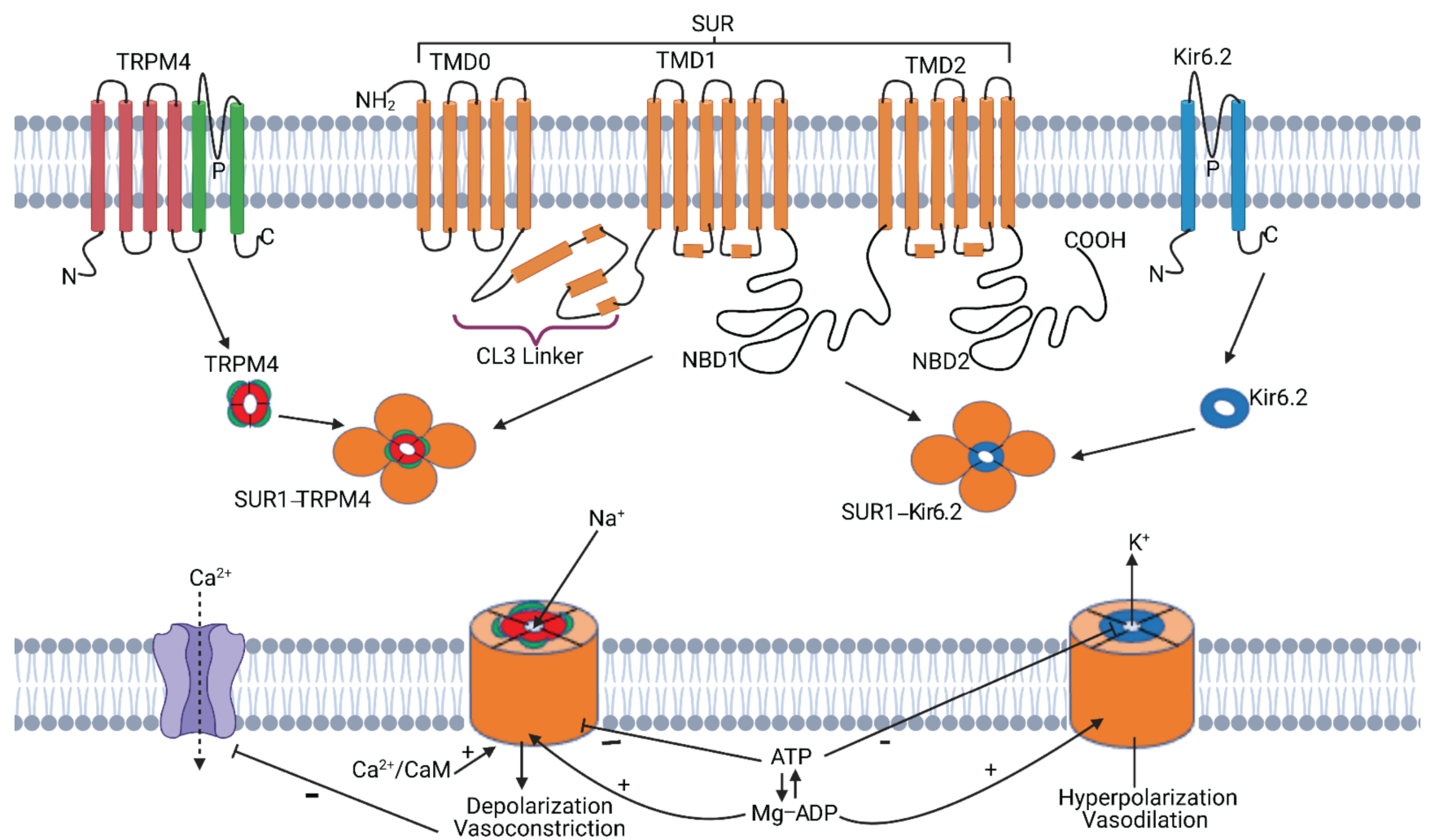

Figure 1. Schematic depiction of SUR1, TRPM4, and Kir6.2 topology. TRPM4 monomers consist of six transmembrane helices with a pore region (P). SUR1 is composed of two interacting six-helix trans-membrane domains (TMD1 and TMD2), each containing a nucleotide binding domain NBD1 and NBD2. TMD0 interacts directly with Kir6.2. Four TRPM4 subunits oligomerize with four SUR1 subunits to form the functional SUR1-TRPM4 octameric channel. Influx of $\mathrm{Na}^{+}$via the nonselective monovalent cation pore-forming subunit TRPM4 leads to depolarization. Figure created with BioRender.com (2021).

TRMP4 belongs to a superfamily of membrane proteins that includes 28 non-selective cation channels. Most proteins belonging to this group conduct both monovalent and 
divalent cations, including $\mathrm{Ca}^{2+}$ [55-57]. TRPM4 is $\mathrm{Ca}^{2+}$ activated, and is one of only two known ion channels in the mammalian genome that exclusively and non-selectively conducts monovalent cations [5,58]. TRPM4 is an independently functional ion channel, whereas SUR1 requires binding to a pore-forming subunit for functional capability $[59,60]$.

SUR1 co-associates with TRPM4 (previously SUR1-regulated NC Ca-ATP channels/SUR1$\left.\mathrm{NC}_{\mathrm{Ca}-\mathrm{ATP}}\right)$ and forms a hetero-octameric structure comprised of four SUR1 subunits and four TRPM4 subunits (the pore-forming complex), as schematized in Figure $1[5,11]$. The association of SUR1 with TRPM4 doubles the affinity of TRPM4 for $\mathrm{Ca}^{2+}$-calmodulin and its sensitivity to intracellular $\mathrm{Ca}^{2+}[5]$.

SUR1 also co-associates with the pore-forming subunit, KIR6.2/Kcnj11, an ATPsensitive potassium channel, to form $\mathrm{K}_{\text {ATP }}$ channels, whose role has historically been extensively studied in pancreatic $\beta$ cells and diabetes mellitus [2,61,62]. Although both SUR1-Kir6.2 and SUR1-TRPM4 channels are both regulated by SUR1, these two associations have opposite functional effects in CNS injury: $\mathrm{K}_{\mathrm{ATP}}$ channel opening leads to potassium efflux and hyperpolarization of cells $[2,6,11,63,64]$, whereas SUR1-TRPM4 channel opening leads to influx of monovalent cations, resulting in depolarization of the cell, cytotoxic edema, blebbing, and oncotic cell death (Section 2.2) $[6-8,11,65]$. SUR1 can also associate with the inwardly rectifying potassium channel, Kir6.1/Kcnj8 [66,67], but this combination has not been reported in nature.

\subsection{SUR1-TRPM4-Discovery and Function}

Alone, SUR proteins do not perform any recognized function; rather, they act as regulatory subunits for pore-forming subunits that together form multiple ion channels [2]. In 2001, Chen and Simard first reported a novel SUR1-regulated non-selective ATP and $\mathrm{Ca}^{2+}$-sensitive cation channel (subsequently identified as TRPM4) in adult rat reactive astrocytes isolated from the hypoxic inner zone of the gliotic capsule [6-8]. In these seminal patch-clamp experiments, channel opening and cell depolarization were mediated by nanomolar concentrations of intracellular $\mathrm{Ca}^{2+}$ and ATP depletion (Figure 2A) $[7,8]$. This resulted in cell swelling and blebbing (Figure 2B).

A
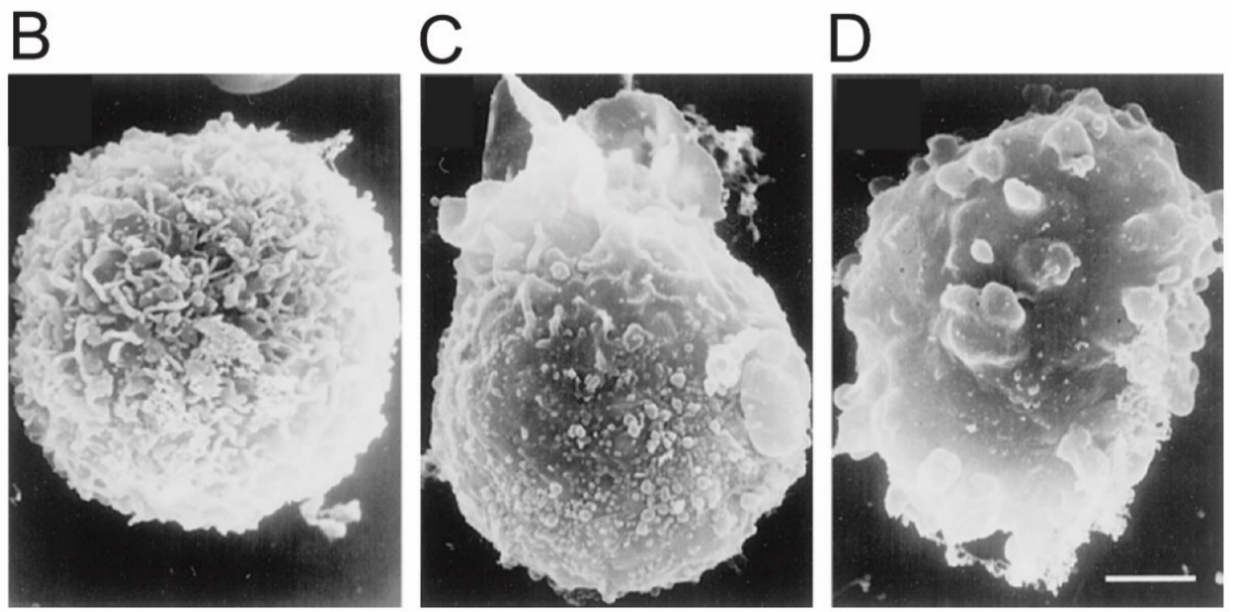

Figure 2. (A) Sodium azide induced ATP depletion, resulting in cellular depolarization. Current clamp recording demonstrating cellular resting potential $(\sim 60 \mathrm{mV})$. After exposure to $1 \mathrm{mM}$ oubain (downward arrow), cell depolarization was $<5 \mathrm{mV}$ with rapid recovery after washout. Conversely, $3 \mathrm{~min}$ exposure to $1 \mathrm{mM}$ sodium azide induced ATP depletion and resulted in a depolarizing inward current with cell depolarization to almost $0 \mathrm{mV}$. Scanning electron micrograph of a freshly isolated reactive astrocyte under control conditions (B), $5 \mathrm{~min}$ after exposure to $1 \mathrm{mM}$ sodium azide (C) and $25 \mathrm{~min}$ after exposure to $1 \mathrm{mM}$ sodium azide (D). Scale bar is $12 \mu \mathrm{m}$. Adapted with permission from Ref. [7].

After CNS injury, SUR1 undergoes obligate association with the pore-forming cation subunit, TRPM4 [5,6]. SUR1-TRPM4 is not expressed in normal CNS tissue [6] but is upregulated de novo in different cells including astrocytes, neurons, endothelial cells, macrophages 
and microglia after forms of CNS injury including ischemic stroke $[6,65,68]$, SAH [36,40], TBI [26], SCI [27,28], CNS metastases [41], and others [6,26,29,36,65,68-70]. SUR1-TRPM4 plays a crucial role in the formation of cerebral edema across the spectrum of cellular swelling, and what has traditionally been referred to as vasogenic edema $[11,12,15,16,20,71]$. Depleted ATP levels or nanomolar changes of $\mathrm{Ca}^{2+}$ concentration result in SUR1-TRPM4 channel opening, facilitating sodium entry into the cell, depolarization, and an oncotic gradient-ultimately producing cell swelling and accidental (non-programmed) cell death $[65,72,73]$. SUR1 contains high-affinity binding sites for sulfonylurea drugs and related compounds including glibenclamide (US adopted name, glyburide) and repaglinide, which bind with nanomolar or sub-nanomolar affinity and pharmacologically modulate SUR1-regulated channel activity [6]. This represents the basis for preclinical and clinical studies evaluating SUR1-TRPM4 inhibition in CNS injury, as discussed later.

Besides its role in channel formation/regulation, SUR1 also acts as a chaperone, and traffics functional channels to the plasma membrane [74-76]. The trafficking and cell surface expression of $\mathrm{K}_{\mathrm{ATP}}$ channels are regulated by an endoplasmic reticulum (ER)retention signal (RKR), present in both the SUR1 and Kir6.2 subunits. Association of SUR1 and Kir6.2 results in shielding of the ER-retention signal, permitting the trafficking of the channel complex to the cell surface [76].

\subsection{SUR1-TRPM4: Biophysical and Pharmacological Properties}

The original patch-clamp experiments that led to the discovery of SUR1-TRPM4 channels showed that the channel is permeable to all inorganic monovalent cations $\left(\mathrm{Na}^{+}\right.$, $\mathrm{K}^{+}, \mathrm{Cs}^{+}, \mathrm{Li}^{+}$, and $\mathrm{Rb}^{+}$) with a single channel conductance of 25 to 35 picosiemens (pS), but impermeable to divalent cations including $\mathrm{Ca}^{2+}$ and $\mathrm{Mg}^{2+}$ [7]. Experiments using a series of organic monovalent cations with increasing cation size showed that the channel had a pore radius of approximately $4.1 \mathrm{~nm}$. A nanomolar concentration of cytoplasmic $\mathrm{Ca}^{2+}$ induced channel opening, and was blocked by intracellular ATP $\left(\mathrm{EC}_{50}, 0.79 \mu \mathrm{mol} / \mathrm{L}\right)$, but was unaffected by ADP or AMP.

SUR1-TRPM4 is blocked by first- and second-generation sulfonylureas, tolbutamide $\left(\mathrm{EC}_{50}, 16.1 \mu \mathrm{mol} / \mathrm{L}\right.$ at $\left.\mathrm{pH} 7.4\right)$, and glibenclamide $\left(\mathrm{EC}_{50}, 48 \mathrm{nmol} / \mathrm{L}\right.$ at $\left.\mathrm{pH} 7.4\right)$, respectively $[6,8]$. Channel inhibition by glibenclamide is the consequence of the prolonged and increased probability of long closed state of the channel, with no effect on open channel dwell times or channel conductance [8]. In vitro experiments revealed effective prevention of SUR1-TRPM4-regulated $\mathrm{Na}^{+}$influx, cytotoxic edema, and oncotic cell death with glibenclamide administration [7]. In the presence of ATP, diazoxide and NN414 (SUR1 activators) increase SUR1-TRPM4 opening [6,8]. Sulfonylurea and related drugs access SUR1 binding sites via the lipid layer. The active un-ionized form of weak-acid drugs like tolbutamide, glibenclamide ( $\mathrm{pKa}=6.3)$, and repaglinide [77], result in increased drug binding [78], and more effective channel blockade for both $\mathrm{K}_{\text {ATP }}$ and SUR1-TRPM4 channels at acidic $\mathrm{pH}$ [77]. The magnitude of channel blockade in neurons from ischemic core brain tissue with $50 \mathrm{nM}$ glibenclamide doubled when $\mathrm{pH}$ was decreased from 7.4 to 6.8 [65]. This $\mathrm{pH}$-dependent drug potency enhances drug effects at the acidic $\mathrm{pH}$ characteristic of ischemic or injured CNS tissues [79]. In addition to its action on the closed/open state of SUR1-TRPM4, glibenclamide may also decrease surface expression of channel complexes; this has been noted for $\mathrm{K}_{\mathrm{ATP}}$ channels, apparently due to abnormal trafficking induced by the drug [80].

\subsection{SUR1-TRPM4: Transcriptional Regulation}

Prior to the report of SUR1-TRPM4 in the CNS, SUR1 (encoded by $A B C C 8$ ) had been extensively studied with regards to its role in regulating the $\mathrm{K}_{\text {ATP }}$ channel involved in insulin secretion in pancreatic $\beta$-cells. Earlier studies regarding transcriptional regulation of $A b c c 8$ were performed in models of diabetes [81,82]. In pancreatic $\beta$-cells, several transcription factors including Sp1, FoxA2/HNF3 $\beta$, Beta2/NeuroD, and STAT3 have been reported to regulate the transcription of $A b c c 8$; Sp1 in particular appears to play a critical role in the basal 
expression of the gene [81-85]. This section discusses key transcriptional upregulators of $A b c c 8$ and/or Trpm 4 that have been evaluated in CNS cells or models of CNS injury.

\subsubsection{Hif1a and Sp1}

In the CNS, $A b c c 8$ upregulation reported during hypoxia/ischemia is regulated via a complex mechanism of sequential gene activation involving hypoxia-inducible factor $1 \alpha(H i f 1 \alpha)[5,6,86]$. In human brain microvascular endothelial cells, Hif1 $\alpha$ expression during hypoxia increased luciferase reporter activity driven by the $A b c c 8$ promoter [86]. A series of luciferase reporter assays further revealed that activation of $A b c c 8$ transcription by Hif1 $\alpha$ required binding sites for Sp1 (and not Hif1) [86]. Further examination of the Sp1 promoter using luciferase reporter assays and chromatin immunoprecipitation after cerebral ischemia revealed that Hif binds to Hif-binding sites on the rat Sp1 promoter to stimulate transcription of the $S p 1$ gene [86]. Sp1, in turn, has been shown to induce $A b c c 8$ transcription in mice, humans, and rats $[81,82,86]$. These data, combined with earlier work in cerebral ischemia [65], suggest the crucial role of Sp1 in the regulation of $A b c c 8$ expression across species $[81,82,86]$. Pharmacological inhibition and gene suppression of Hif is protective in cerebral ischemia/hypoxia, which corresponds with the role of Hif1 in upregulation of SUR1 in focal ischemia [87-89]. Similar results were found in the Rice-Vannucci model of neonatal hypoxia-ischemia, confirming neuroprotection [90,91].

\subsubsection{TNFa and NF- $\mathrm{KB}$}

TNFa and NF- $\mathrm{kB}$ are also important transcriptional regulators of $A b c c 8$. The $5^{\prime}$ flanking region of both rat and human $A b c c 8$ promoter sites contains at least two consensus NF- $\mathrm{kB}$ binding sites [40]. In cultured brain endothelial (bEnd.3) cells, a $6 \mathrm{~h}$ exposure to TNFa (an activator of NF-kB), increased $A b c c 8$ mRNA and SUR1 protein levels [92]. Exposure of $\mathrm{bEnd} .3$ cells to TNFa resulted in nuclear accumulation of the p65 NF- $\mathrm{kB}$ subunit. An electrophoretic mobility shift assay in bEnd.3 cells further demonstrated a physical interaction between the rat $A b c c 8$ promoter and NF- $\kappa B$ [40]. Additionally, the functionality of NF- $\kappa B$ binding sites in the $A b c c 8$ promotor was confirmed in studies using a luciferase reporter plasmid in the rat $A b c c 8$ promotor encompassing the recognized NF- $\mathrm{kB}$ binding site. TNFa stimulated luciferase activity $\sim 2.3 \times$, driven by NF- $\mathrm{kB}$ binding sites; rat $A b c c 8$ promotor activity also increased $\sim 2 \times$ with TNFa [40]. Both Sp1 and NF- $\mathrm{kB}$ play an important role in transcriptional upregulation of $A b c c 8$ in trauma [30].

\subsubsection{Toll-like Receptor (TLR)-4}

TLR4 has increasingly been recognized as initiating harmful neuro-inflammatory cascades, including via microglial activation [92-94]. In rats, TLR4-activated P2Y12 ${ }^{+}$microglia have shown markedly increased mRNA expression for both $A b c c 8$ and Trpm4, with similarly enhanced immunolabeling for the SUR1 and TRPM4 proteins [92]. These results were corroborated in vitro, and in addition to $A b c c 8$ and Trpm 4 mRNA upregulation (at 6 and $24 \mathrm{~h}$ after TLR4 ligation), Il-1b mRNA was also upregulated [92]. Changes in Kcnj11 mRNA were not observed at either timepoint, suggesting that the $\mathrm{K}_{\text {ATP }}$ channel (SUR1-KIR6.2) is not involved in TLR4-activated microglia. Similar findings were also reported in N9 microglia where TLR4 activation resulted in a switch from a quiescent to an activated phenotype associated with upregulation of Abcc8/Trpm4 mRNA and SUR1-TRPM4 channels [92].

\subsection{SUR1 Pathways}

The SUR1-TRPM4 channel interfaces with several other key secondary injury pathways [11], including those involved with cerebral edema (AQP4) [95], BBB integrity (matrix metalloproteinase-9 (MMP9), zona-occludens-1 (ZO-1)) [36,40,44,96], neuroinflammation (nitric oxide synthase-2 (NOS2), nuclear factor of activated T-cells (NFAT), calcineurin, calmodulin-dependent protein kinase II (CAMK-II) $[36,40,45,92,97,98]$, and celldeath-including apoptotic pathways (Bcl-associated X protein (BAX), caspase-3; Table 1 and Figure 3). 


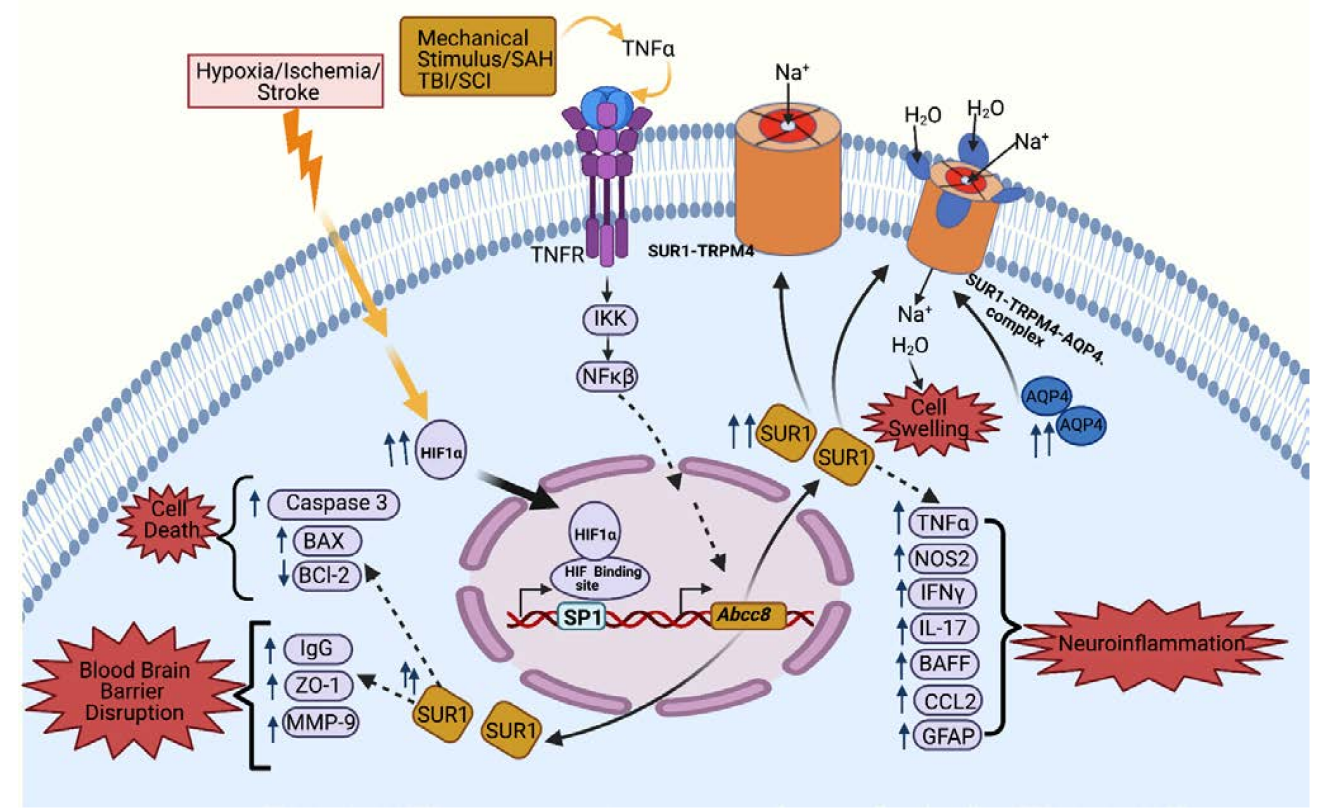

(A)

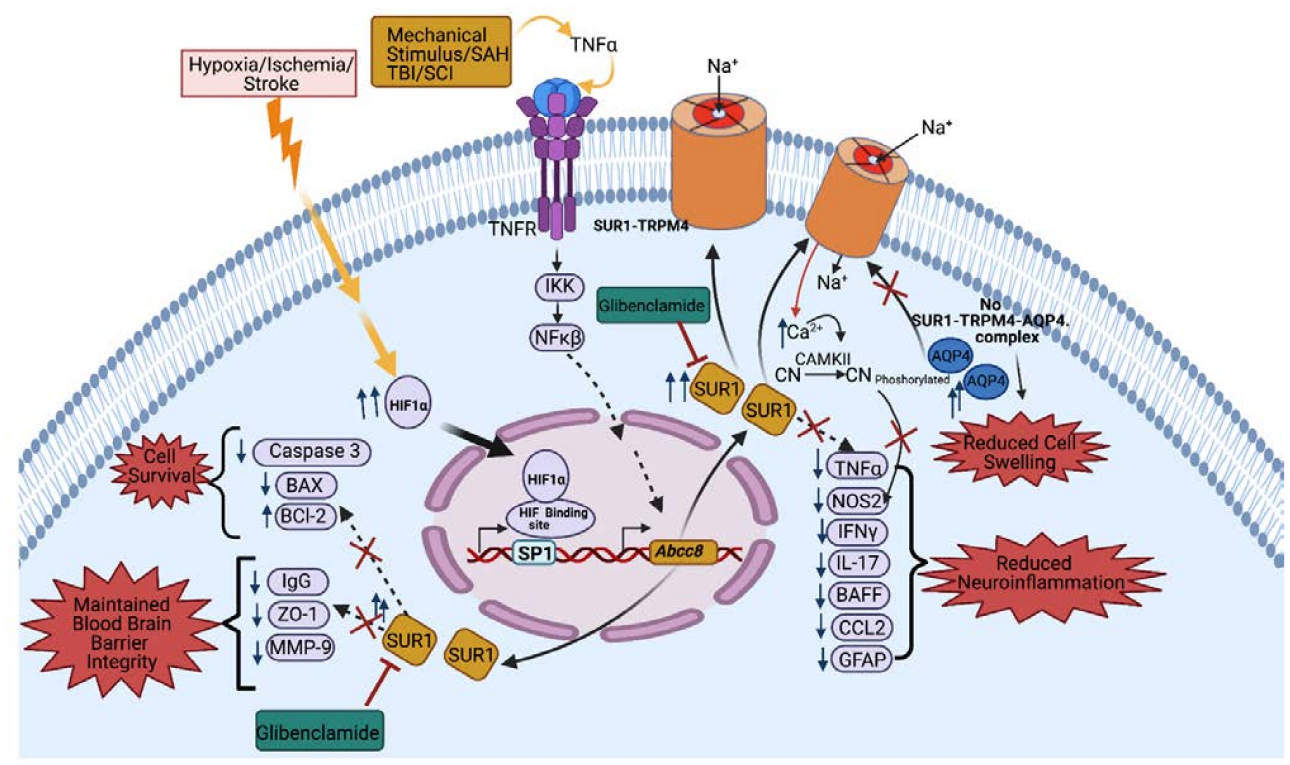

(B)

Figure 3. (A) Schematic depiction of upregulated pathways after CNS injury related to SUR1-TRPM4. Hypoxia/ischemia results in upregulation of HIF1 $\alpha$, which is transported to the nucleus where it binds with the HIF-binding site, leading to the upregulation of SP1-which in turn leads to the upregulated transcription of $A b c c 8$ (SUR1). Mechanical stimuli after traumatic brain injury or spinal cord injury results in increased levels of TNF $\alpha$, which is an upstream regulator of Abcc8 (SUR1). Increased levels of TNF $\alpha$ lead to upregulation of IKK and NF- $\mathrm{B}$, ultimately resulting in transcriptional activation of $A b c c 8$ (SUR1). Upregulation of SUR1 leads to increased association of SUR1-TRPM4 on the plasma membrane. An open SUR1-TRPM4 channel results in $\mathrm{Na}^{+}$influx, leading to depolarization and an oncotic gradient. Association of the SUR1-TRPM4-AQP4 complex results in increased influx of water into the cell (following the oncotic gradient), ultimately leading to cell swelling. Increased SUR1 may contribute to neuroinflammation (by activating NOS2, INF $\gamma$, IL-17, BAFF, CCL2, GFAP), disruption of the blood brain barrier (by activating IgG, MMP-9 and ZO-1), and cell death (via upregulation of caspase 3 and BAX). (B) Schematic representation of the signaling effects of SUR1 inhibition via genetic $A b c c 8$ knockout or pharmacological inhibition by glibenclamide. Edema is reduced via channel blockade. Neuroinflammation is decreased (lower levels of TNF $\alpha$, NOS2, INF $\gamma$, IL-17, BAFF, CCL2, GFAP); the blood-brain barrier disruption is minimized (downregulated ZO-1, MMP-9), and cell death reduced (upregulation BCL-2, downregulation of BAX and caspase 3). Figure created with BioRender.com (2021). 
Table 1. Key SUR1 signaling pathways.

\begin{tabular}{|c|c|c|c|c|}
\hline Study Title & Disease and Model Details & $\begin{array}{c}\text { Regulation/ } \\
\text { Inhibition/Interaction }\end{array}$ & Signaling Pathway Proteins & Authors/ Year \\
\hline $\begin{array}{l}\text { Glibenclamide reduces } \\
\text { inflammation, vasogenic edema, } \\
\text { and caspase-3 activation after } \\
\text { subarachnoid hemorrhage }\end{array}$ & SAH (rat, filament puncture) & Inhibition of SUR1 by GLI & $\begin{array}{ll}\text { - } & \text { Treatment } \downarrow \text { IgG extravasation } \\
\text { Treatment } \downarrow \text { ZO- } 1 \text { expression } \\
\text { and prevention of } \\
\text { redistribution with significant } \\
\quad \downarrow \text { in cytoplasmic localization } \\
\text { and restored intracellular } \\
\text { localization } \\
\text { - } \\
\text { Treatment } \downarrow \text { endothelial } \\
\text { caspase } 3 \text { expression } \\
\quad \text { Treatment } \downarrow \text { GFAP expression }\end{array}$ & Simard et al., 2009 [40] \\
\hline $\begin{array}{l}\text { Inhibition of the Sur1-Trpm4 } \\
\text { channel reduces neuroinflammation } \\
\text { and cognitive impairment in } \\
\text { subarachnoid hemorrhage }\end{array}$ & $\begin{array}{l}\text { SAH (rat, filament puncture and } \\
\text { entorhinal injection) }\end{array}$ & $\begin{array}{l}\text { Gene suppression of } A b c c 8 / \text { Inhibition of } \\
\text { SUR1 by GLI }\end{array}$ & $\begin{array}{l}\text { - Inhibition/treatment } \downarrow \mathrm{TNF} \alpha \\
\text { expression }\end{array}$ & Tosun et al., 2013 [36] \\
\hline $\begin{array}{c}\text { Glibenclamide Attenuates } \\
\text { Blood-Brain Barrier Disruption in } \\
\text { Adult Mice after Traumatic Brain } \\
\text { Injury }\end{array}$ & TBI (mouse, CCI) & Inhibition of SUR1 by GLI & $\begin{array}{ll}\text { - } & \text { Treatment } \downarrow \text { AQP4 expression } \\
\text { - } & \text { Treatment } \downarrow \text { ZO- } 1 \text { expression } \\
\text { - } & \text { Treatment } \downarrow \text { BAX expression } \\
\text { - } & \text { Treatment } \uparrow \text { Bcl- } 2 \text { expression }\end{array}$ & Xu et al., 2017 [44] \\
\hline $\begin{array}{l}\text { SUR1-TRPM4 channel activation } \\
\text { and phasic secretion of MMP-9 } \\
\text { induced by tPA in brain endothelial } \\
\text { cells }\end{array}$ & $\begin{array}{l}\text { Cerebral ischemia/ } \\
\text { reperfusion (in vitro, and rat } \\
\text { ischemia-reperfusion) }\end{array}$ & $\begin{array}{l}\text { NF- } k \text { B activation/ } \\
\text { SUR1-TRPM4 channel opening by tPA }\end{array}$ & $\begin{array}{ll}- & \text { De novo expression of SUR1 } \\
- & \downarrow \text { phasic MMP9 secretion }\end{array}$ & Gerzanich et al., 2018 [96] \\
\hline $\begin{array}{l}\text { Glibenclamide reduces } \\
\text { hippocampal injury and preserves } \\
\text { rapid spatial learning in a model of } \\
\text { traumatic brain injury }\end{array}$ & TBI (rat, cortical impact) & Inhibition of SUR1 by GLI & $\begin{array}{l}\text { - } \quad \text { Treatment } \downarrow \text { caspase } 3 \\
\text { expression }\end{array}$ & Patel et al., 2010 [30] \\
\hline $\begin{array}{l}\text { Silencing of } A b c c 8 \text { or inhibition of } \\
\text { newly upregulated Sur1-Trpm } 4 \\
\text { reduce inflammation and disease } \\
\text { progression in experimental } \\
\text { autoimmune encephalomyelitis }\end{array}$ & EAE (mouse EAE, $\mathrm{MOG}_{33-55}$ peptide) & $\begin{array}{c}A b c c 8^{-/-} \text {mice/Inhibition of SUR1 by } \\
\text { GLI }\end{array}$ & $\begin{array}{l}\text { - Treatment } \downarrow \mathrm{TNF} \alpha, \text { IFN } \gamma, \text { IL-17 } \\
\text { expression }\end{array}$ & Makar et al., 2015 [97] \\
\hline
\end{tabular}


Table 1. Cont

\begin{tabular}{|c|c|c|c|c|}
\hline Study Title & Disease and Model Details & $\begin{array}{l}\text { Regulation/ } \\
\text { Inhibition/Interaction }\end{array}$ & Signaling Pathway Proteins & Authors/ Year \\
\hline $\begin{array}{l}\text { Salutary effects of glibenclamide } \\
\text { during the chronic phase of murine } \\
\text { experimental autoimmune } \\
\text { encephalomyelitis }\end{array}$ & EAE (mouse EAE, MOG $_{33-55}$ peptide) & Inhibition of SUR1 by GLI & $\begin{array}{l}\text { - Treatment } \downarrow \text { TNF } \alpha, \text { BAFF, } \\
\text { CCL2, NOS2 expression }\end{array}$ & Gerzanich et al., 2017 [98] \\
\hline $\begin{array}{l}\text { Glibenclamide pretreatment } \\
\text { protects against chronic memory } \\
\text { dysfunction and glial activation in } \\
\text { rat cranial blast traumatic brain } \\
\text { injury }\end{array}$ & TBI (rat, direct cranial blast) & Inhibition of SUR1 by GLI & $\begin{array}{l}\text { - Treatment } \downarrow \text { GFAP and Iba-1 } \\
\text { expression }\end{array}$ & Stokum et al., 2017 [45] \\
\hline $\begin{array}{c}\text { The Sur1-Trpm4 channel regulates } \\
\text { NOS2 transcription in } \\
\text { TLR4-activated microglia }\end{array}$ & $\begin{array}{l}\text { Activation of TLR4 by LPS (primary } \\
\text { culture, adult rat microglia) }\end{array}$ & $A b c c 8^{-/-}$mice/Inhibition of SUR1 by & - $\quad$ Treatment $\downarrow$ NOS2 expression & Kurland et al., 2016 [92] \\
\hline
\end{tabular}




\subsubsection{Cerebral Edema Pathways}

AQP4 is a key mediator of CNS water influx and efflux, with a complex effect on cerebral edema, given its role in both edema formation and clearance [99-104]. AQP4 expression in astrocytes (especially in perivascular endfeet) has been shown to mediate water flux across the bloo-brain barrier-this increases in response to hypoxia-induced cell swelling, possibly in a calmodulin-dependent manner $[105,106]$. AQP4 channels on astrocyte vascular endfeet have recently been identified as central to the glymphatic system pathway of cerebral edema [102-104,107-109]. More comprehensive reviews focusing on AQP4's role in cerebral edema have been reviewed elsewhere [105,107-109]. SUR1TRPM4 has been shown to physically co-assemble with astrocytic AQP4 to form a novel hetero-multimeric water/ion channel complex [95]. In experiments using COS-7 cells, SUR1-TRPM4 co-immunoprecipitated with AQP4-both the M1 and M23 isoforms. FRET analyses showed that AQP4 directly co-associated with SUR1-TRPM4 to form a heteromeric channel complex [95]. Further in vitro studies in primary astrocytes demonstrated that close co-localization of TRPM4 and AQP4 leads to synergistically mediated, fast, highcapacity water influx resulting in astrocytic swelling [95]. This was validated in vivo, in a murine model of cerebellar cold injury [95]. Furthermore, it was noted that the co-assembly of SUR1-TRPM4 and AQP4 may amplify the role of TRPM4 as a negative regulator of $\mathrm{Ca}^{2+}$ influx, given the dilutional effects of water influx (in addition to the already increased TRPM4 $\mathrm{Ca}^{2+}$ sensitivity and reduced inward driving force/electrochemical gradient with SUR1-TRPM4 co-assembly) [95]. In a recent study of a rat model of SAH (Section 3.4.2), pituitary adenylate cyclase-activating polypeptide (PACAP38)-mediated downregulation of SUR1 also attenuated AQP4-mediated glymphatic dysfunction [110].

\subsubsection{BBB Permeability Pathways}

MMP-9, tissue plasminogen activator (tPA) $[6,96,111]$, and ZO-1 [44] have been implicated in BBB disruption and mechanistically overlap with SUR1-TRPM4 [11,44,96,111]. In NF- $\mathrm{kB}$-activated brain endothelial cells, tPA induced SUR1-TRPM4 channel opening and MMP-9 secretion; both processes were dependent on protease-activated receptor 1 (PAR1) [96]. tPA converts plasminogen to plasmin, which in turn induces canonical activation of PAR1. Surprisingly, SUR1-TRPM4 inhibition (by glibenclamide and shRNA against $A b c c 8)$ reduced tPA-induced phasic MMP-9 secretion from activated endothelial cells. The precise relationship underlying this is unknown but it is speculated to be due to increased phosphorylated CamKII leading to desensitization and internalization of PAR1 [96].

The protective effect of glibenclamide in BBB permeability has also been studied in a mouse model of TBI [44]. TBI was induced in C57Bl/ 6 mice using controlled cortical impact (CCI). After controlled cortical impact (CCI) in mice, $10 \mu \mathrm{g}$ of glibenclamide was given intra-peritoneally for 3 days. This showed a significant reduction in brain water content $(p<0.05)$, Evans blue extravasation $(p<0.01)$, and tissue hemoglobin levels $(p<0.05)$. Attenuation of apoptosis was observed with the glibenclamide treatment via the JNK/c-jun signaling pathway, ultimately resulting in elevated ZO-1 expression-thereby possibly preventing/minimizing BBB disruption.

\subsubsection{Neuroinflammation Pathways}

The expression of pro-inflammatory cytokines (TNF $\alpha$, IFN $\gamma$ and IL-17) in models of SAH and experimental autoimmune encephalomyelitis (EAE) is decreased with both pharmacological inhibition of SUR1 or Abcc8 gene suppression [36,97]. In EAE [98], global $A b c c 8$ deletion or pharmacological inhibition of SUR1 further reduced the inflammatory burden of several additional markers, as measured by the decreased expression of CD45, CD20, CD3, p65, TNF $\alpha$, BAFF, CCL2, and NOS2.

In vivo and in vitro studies on microglia showed that activation of TLR4 by LPS led to de novo upregulation of SUR1-TRPM4 channels as well as CN/NFAT-dependent upregulation of Nos 2 mRNA and NOS2 protein [92]. In this study, it was shown that either 
gene silencing of $A b c c 8$ or Trpm 4 or pharmacological inhibition of SUR1 by glibenclamide, and of TRPM4 by 9-phenanthrol, resulted in downregulation of NOS2 expression.

In a rat model of blast traumatic brain injury, GFAP and Iba-1 were upregulated, indicating reactive astrogliosis and microglial activation [45]. In this study, pretreatment with glibenclamide led to downregulation of GFAP and lba-1 expression.

\subsubsection{Cell Death Pathways}

The role of SUR1 as it pertains to cell death pathways has predominantly been reported in SAH (caspase-3) and TBI (BAX-6/Bcl2). In a rat model of SAH, TNF $\alpha$ induced apoptosis through the activation of caspase 3-an effect that was reversed with glibenclamide, where treatment improved cell survival [40]. After murine CCI, the expression of the pro-apoptotic protein BAX was significantly upregulated, while that of the anti-apoptotic protein Bcl-2 was downregulated [44]. Glibenclamide treatment reversed these expression patterns.

\section{SUR1-TRPM4 Expression and Inhibition in CNS injury}

\subsection{Ischemic Stroke}

In the CNS, SUR1-TRPM4 (and its inhibition) has been most extensively studied in the context of ischemic injury, both in preclinical models as well as in human cohorts. These studies are summarized in Tables 2 and 3. 
Table 2. Pre-clinical and clinical studies evaluating SUR1 inhibition for ischemic stroke.

\begin{tabular}{|c|c|c|c|c|c|}
\hline Authors, Year & Study Title & Model & Species & Drug Details & Results \\
\hline \multicolumn{6}{|c|}{ In vitro studies: ischemic stroke } \\
\hline Chen et al., 2001 [7] & $\begin{array}{c}\text { Cell swelling and a nonselective cation } \\
\text { channel regulated by internal } \mathrm{Ca}^{2+} \text { and } \\
\text { ATP in native reactive astrocytes from } \\
\text { adult rat brain }\end{array}$ & $\begin{array}{l}\text { Chemically induced hypoxia } \\
\text { in non-reactive isolated } \\
\text { astrocytes using } 1 \mathrm{nM} \mathrm{NaN}_{3}\end{array}$ & NA & NA & 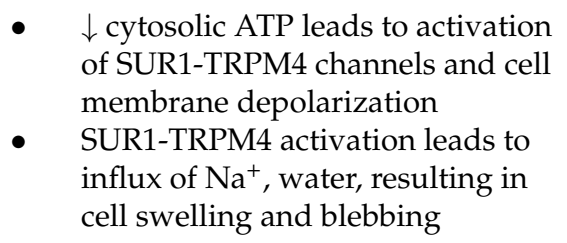 \\
\hline Chen et al., 2003 [8] & $\begin{array}{l}\text { Functional coupling between } \\
\text { sulfonylurea receptor type } 1 \text { and a } \\
\text { nonselective cation channel in reactive } \\
\text { astrocytes from adult rat brain }\end{array}$ & $\begin{array}{c}\text { Chemically induced hypoxia } \\
\text { in non-reactive astrocytes } \\
\text { using } 1 \mathrm{nM} \mathrm{NaN}_{3}\end{array}$ & NA & GLI & $\begin{array}{l}\text { - SUR1 is functionally coupled to the } \\
\text { pore-forming portion of the } \\
\text { NC Ca-ATP channel } \\
\text { Inhibition of SUR1 by GLI } \\
\text { prevented cell blebbing }\end{array}$ \\
\hline \multicolumn{6}{|c|}{ In vivo studies: ischemic stroke } \\
\hline Simard et al., 2006 [65] & $\begin{array}{l}\text { Newly expressed SUR1-regulated } \\
\text { NC(Ca-ATP) channel mediates } \\
\text { cerebral edema after ischemic stroke }\end{array}$ & $\begin{array}{c}\text { Massive middle cerebral } \\
\text { artery (MCA) infarction } \\
\text { associated with malignant } \\
\text { cerebral edema }\end{array}$ & Rat & $\begin{array}{c}\text { GLI } \\
\text { Infusion rate: } 75 \mathrm{ng} / \mathrm{h} \\
\text { Infusion time: } 2-3 \mathrm{~min} \text { after } \\
\text { MCAo }\end{array}$ & 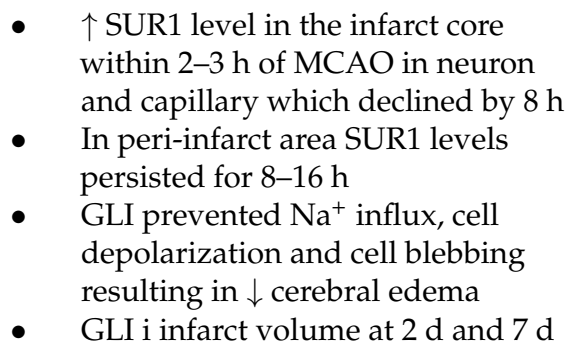 \\
\hline Simard et al., 2009 [112] & $\begin{array}{l}\text { Protective effect of delayed treatment } \\
\text { with low-dose glibenclamide in three } \\
\text { models of ischemic stroke }\end{array}$ & $\begin{array}{c}3 \text { models } \\
\text { Thromboembolic MCA } \\
\text { occlusion (MCAo), Transient } \\
\text { MCAo and Permanent MCAo }\end{array}$ & Rat & $\begin{array}{c}\text { GLI } \\
\text { Time: variable } \\
\text { Loading dose: } 3.3-10 \mathrm{mg} / \mathrm{kg} \\
\text { Infusion rate: } 75-200 \mathrm{ng} / \mathrm{h}\end{array}$ & $\begin{array}{l}\text { - In thromboembolic MCAo at } 6 \mathrm{~h} \text {, } \\
\text { GLI treatment i total lesion volume } \\
\text { by } 53 \% \\
\text { - } \mathrm{GLI} \downarrow \text { cortical lesion volume by } 41 \% \\
\text { in transient MCAo at } 5.75 \mathrm{~h} \\
\text { - } \quad \text { GLI } \downarrow \text { cortical lesion volume by } 51 \% \\
\text { in permanent MCAo at } 4 \mathrm{~h}\end{array}$ \\
\hline
\end{tabular}


Table 2. Cont.

\begin{tabular}{|c|c|c|c|c|c|}
\hline Authors, Year & Study Title & Model & Species & Drug Details & Results \\
\hline Simard et al., 2010 [113] & $\begin{array}{l}\text { Glibenclamide is superior to } \\
\text { decompressive craniectomy in a rat } \\
\text { model of malignant stroke }\end{array}$ & $\begin{array}{l}\text { MCAo severe ischemia } \\
\text { reperfusion }\end{array}$ & Rat & $\begin{array}{l}\text { GLI } \\
\text { Time: } 15 \mathrm{~min} \text { before MCAo } \\
\text { Loading dose: } 10 \mathrm{mg} / \mathrm{kg} \text { i.p. } \\
\text { Infusion rate: } 200 \mathrm{ng} / \mathrm{h}\end{array}$ & $\begin{array}{l}\text { - } 6 \mathrm{~h} \text { after onset of ischemia, GLI } \\
\text { treatment was as effective as } \\
\text { immediate decompressive } \\
\text { craniectomy in } \downarrow \text { mortality }\end{array}$ \\
\hline $\begin{array}{l}\text { Abdallah et al., } \\
\quad 2011[114]\end{array}$ & $\begin{array}{c}\text { Glibenclamide ameliorates } \\
\text { ischemia-reperfusion injury via } \\
\text { modulating oxidative stress and } \\
\text { inflammatory mediators in the rat } \\
\text { hippocampus }\end{array}$ & Ischemia reperfusion & Rat & $\begin{array}{l}\text { GLI } \\
\text { Time: } 10 \text { min before } \\
\text { ischemia/reperfusion } \\
\text { Dose: } 1 \mathrm{mg} / \mathrm{kg} \text { i.p. }\end{array}$ & $\begin{array}{l}\text { - GLI treatment } \downarrow \text { neutrophil } \\
\text { recruitment, ameliorated TNF } \alpha \text {, } \\
\text { prostaglandin E2 and boosted } \\
\text { anti-inflammatory cytokines }\end{array}$ \\
\hline Simard et al., 2012 [115] & $\begin{array}{l}\text { Glibenclamide } 10 \mathrm{~h} \text { treatment window } \\
\text { in a clinically relevant model of stroke. }\end{array}$ & Intra-arterial occluder MCAo & Rat & $\begin{array}{c}\text { GLI } \\
\text { Time: } 4.5 \text { vs. } 10 \mathrm{~h} \text { post MCAo } \\
\text { Loading dose: } 10 \mu \mathrm{g} / \mathrm{kg} \\
\text { Infusion rate: } 200 \mathrm{ng} / \mathrm{h}\end{array}$ & $\begin{array}{l}\text { - GLI treatment improved } \\
\text { hemispheric swelling, neurological } \\
\text { outcome and } 48 \mathrm{~h} \text { mortality }\end{array}$ \\
\hline Ortega et al., 2012 [116] & $\begin{array}{l}\text { ATP-dependent potassium channel } \\
\text { blockade strengthens microglial } \\
\text { neuroprotection after } \\
\text { hypoxia-ischemia in rats }\end{array}$ & Transient MCAo & Rat & $\begin{array}{c}\text { GLI } \\
\text { Time: } 6,12,24 \mathrm{~h} \text { after MCAo } \\
\text { Doses: } 0.06 \mu \mathrm{g}, 0.6 \mu \mathrm{g}, 6 \mu \mathrm{g}\end{array}$ & $\begin{array}{l}\text { GLI treatment improved } \\
\text { neurological score and preserved } \\
\text { neurons in the lesioned core } 3 \mathrm{~d} \\
\text { after reperfusion }\end{array}$ \\
\hline Wali et al., 2012 [117] & $\begin{array}{l}\text { Glibenclamide administration } \\
\text { attenuates infarct volume, hemispheric } \\
\text { swelling, and functional impairments } \\
\text { following permanent focal cerebral } \\
\text { ischemia in rats }\end{array}$ & Permanent MCAo & Rat & $\begin{array}{c}\text { GLI } \\
\text { Time: } 5 \text { min after MCAo } \\
\text { Loading dose: } 10 \mathrm{mg} / \mathrm{kg} \text {, } \\
\text { Infusion rate: } 200 \mathrm{ng} / \mathrm{h}\end{array}$ & $\begin{array}{l}\text { - GLI treatment significantly } \downarrow \text { infarct } \\
\text { volume, hemispheric swelling, grip } \\
\text { strength and lowered neurological } \\
\text { severity scores }\end{array}$ \\
\hline Ortega et al., 2013 [118] & $\begin{array}{l}\text { Glibenclamide enhances neurogenesis } \\
\text { and improves long-term functional } \\
\text { recovery after transient focal cerebral } \\
\text { ischemia }\end{array}$ & Transient MCAo & Rat & $\begin{array}{c}\text { GLI } \\
\text { Time: } 6 \mathrm{~h}, 12 \mathrm{~h}, 24 \mathrm{~h} \text { after } \\
\text { reperfusion } \\
\text { Dose: } 0.6 \mathrm{mg}\end{array}$ & $\begin{array}{l}\text { - Migration of double cortin-positive } \\
\text { cells were observed within } 72 \mathrm{~h} \text { of } \\
\text { GLI treatment } \\
\text { GLI treatment continued } \\
\text { neurogenesis even after } 30 \mathrm{~d} \text { of } \\
\text { MCAo, and also yielded both } \\
\text { cognitive and sensorimotor } \\
\text { improvement }\end{array}$ \\
\hline
\end{tabular}


Table 2. Cont.

\begin{tabular}{|c|c|c|c|c|c|}
\hline Authors, Year & Study Title & Model & Species & Drug Details & Results \\
\hline Arikan et al., 2017 [119] & $\begin{array}{l}\text { Malignant infarction of the middle } \\
\text { cerebral artery in a porcine model. A } \\
\text { pilot study }\end{array}$ & $\begin{array}{l}\text { Malignant infarction of the } \\
\text { middle cerebral artery }\end{array}$ & Pig & NA & $\begin{array}{l}\text { - } \quad \text { SUR1-TRPM4 in core, penumbra } \\
\text { and contralateral neurons and } \\
\text { microvessels } 5 \mathrm{~h} \text { after ischemia }\end{array}$ \\
\hline $\begin{array}{l}\text { Alquisiras et al., } \\
\quad 2020[120]\end{array}$ & $\begin{array}{l}\text { Resveratrol reduces cerebral edema } \\
\text { through inhibition of de novo SUR1 } \\
\text { expression induced after focal ischemia }\end{array}$ & MCAo & Rat & NA & $\begin{array}{ll}\text { - } & \text { Resveratrol treatment } \downarrow A b c c 8 \\
\text { mRNA and SUR1 protein } \\
\text { expression } \\
\text { - } \\
\text { eesveratrol treatment } \downarrow \text { cerebral } \\
\text { expression and improved } \\
\text { neurological outcome and survival } \\
\text { (by } \sim 40 \%)\end{array}$ \\
\hline Woo et al., 2020 [121] & $\begin{array}{l}\text { SUR1-TRPM4 channels, not } \mathrm{K}_{\mathrm{ATP}} \\
\text { mediate brain swelling following } \\
\text { cerebral ischemia }\end{array}$ & Permanent MCAo & Rat & $\begin{array}{l}\text { Abcc8 antisense ODN } \\
\text { Trpm4 antisense ODN }\end{array}$ & - $\quad \downarrow$ hemispheric swelling \\
\hline \multicolumn{6}{|c|}{ Human expression studies: ischemic stroke } \\
\hline Mehta et al., 2015 [68] & $\begin{array}{l}\text { Sur1-Trpm } 4 \text { cation channel expression } \\
\text { in human cerebral infarcts }\end{array}$ & Post-mortem brain specimen & 14 patients & NA & $\begin{array}{ll}\text { - } & \text { TRPM4 } \uparrow \text { and persisted even at } 1 \mathrm{~m} \\
\text { - } & \text { post-infarct } \\
\text { FRET analysis showed } \\
\text { co-localization of TRPM4 with } \\
\text { SUR1 in neurons, endothelial cells } \\
\text { and astrocytes }\end{array}$ \\
\hline
\end{tabular}


Table 2. Cont.

\begin{tabular}{|c|c|c|c|c|c|}
\hline Authors, Year & Study Title & Model & Species & Drug Details & Results \\
\hline \multicolumn{6}{|c|}{ Clinical retrospective studies: ischemic stroke } \\
\hline Kunte et al., 2007 [123] & $\begin{array}{l}\text { Sulfonylureas improve outcome in } \\
\text { patients with type } 2 \text { diabetes and acute } \\
\text { ischemic stroke }\end{array}$ & Acute ischemic stroke & 61 patients & Oral sulfonylurea & $\begin{array}{l}\text { - Sulfonylurea treatment leads to } \\
>4 \text { point reduction in NIHSS score } \\
\text { in } 36.4 \% \text { patients (vs. } 7.1 \% \text { in } \\
\text { untreated) } \\
\text { - Sulfonylurea treatment showed an } \\
\text { improved modified Rankin scale } \\
\text { score of } \leq 2\end{array}$ \\
\hline Favilla et al., 2011 [124] & $\begin{array}{l}\text { Sulfonylurea use before stroke does } \\
\text { not influence outcome }\end{array}$ & $\begin{array}{l}\text { Patients enrolled in } \\
\text { non-reperfusion ischemic } \\
\text { stroke trials }\end{array}$ & 1050 patients & Oral sulfonylurea & $\begin{array}{l}\text { Post-stroke sulfonylurea treatment } \\
\text { showed a trend toward benefit }\end{array}$ \\
\hline Kunte et al., 2012 [125] & $\begin{array}{l}\text { Hemorrhagic transformation of } \\
\text { ischemic stroke in diabetics on } \\
\text { sulfonylureas }\end{array}$ & $\begin{array}{l}\text { Diabetic patients with acute } \\
\text { ischemic stroke }\end{array}$ & 220 patients & Oral sulfonylurea & $\begin{array}{l}\text { Sulfonylurea i post-stroke } \\
\text { symptomatic hemorrhagic } \\
\text { transformation and mortality }\end{array}$ \\
\hline $\begin{array}{l}\text { Horsdal et al., } \\
2012[126]\end{array}$ & $\begin{array}{l}\text { Type of preadmission antidiabetic } \\
\text { treatment and outcome among } \\
\text { patients with ischemic stroke: a } \\
\text { nationwide follow-up study }\end{array}$ & $\begin{array}{l}\text { Diabetic patient with acute } \\
\text { ischemic stroke }\end{array}$ & 4817 patients & Oral sulfonylurea & $\begin{array}{l}\text { - No association between } \\
\text { preadmission use of sulfonylurea } \\
\text { use and clinical outcome after } \\
\text { ischemic stroke }\end{array}$ \\
\hline \multicolumn{6}{|c|}{ Clinical trials: ischemic stroke } \\
\hline Sheth et al., 2014 [117] & $\begin{array}{l}\text { Pilot study of intravenous glyburide in } \\
\text { patients with a large ischemic stroke }\end{array}$ & Large hemispheric infarction & 10 patients & $\begin{array}{l}\text { Intravenous glyburide } \\
\text { (RP-1127) }\end{array}$ & $\begin{array}{l}\text { Drug well tolerated without any } \\
\text { safety concerns or hypoglycemia }\end{array}$ \\
\hline Sheth et al., 2016 [47] & $\begin{array}{l}\text { Safety and efficacy of intravenous } \\
\text { glyburide on brain swelling after large } \\
\text { hemispheric infarction (GAMES-RP): a } \\
\text { randomized, double-blind, } \\
\text { placebo-controlled phase } 2 \text { trial }\end{array}$ & Large hemispheric infarction & 86 patients & $\begin{array}{l}\text { Intravenous glyburide } \\
\text { (RP-1127) } \\
\text { Phase II double-blind } \\
\text { (GAMES-RP) }\end{array}$ & $\begin{array}{l}\text { - } \quad \text { Drug is safe and well tolerated } \\
\text { Did not meet primary composite } \\
\text { endpoint of mRS 0-4 at } 90 \mathrm{~d} \\
\text { without decompressive } \\
\text { craniectomy } \\
\text { - } \quad \text { Improved midline shift } \\
\text { - } \quad \text { Reduced plasma MMP-9 } \\
\text { Trend towards survival benefit }\end{array}$ \\
\hline
\end{tabular}


Table 3. Ongoing Clinical Trials for Glyburide.

\begin{tabular}{|c|c|c|c|c|}
\hline NCT Identifier & Phase & Drug & Studied Population & Outcome/References \\
\hline NCT03741530 & $\begin{array}{c}\text { Phase I } \\
\text { (GATE-ICH) }\end{array}$ & $\begin{array}{l}\text { Oral glyburide } \\
\quad(1.25 \mathrm{mg})\end{array}$ & $\mathrm{ICH}$ & $\begin{array}{l}\text { Completed, results not } \\
\text { yet reported [127] }\end{array}$ \\
\hline NCT02864953 & Phase III (CHARM) & $\begin{array}{l}\text { BIIB093 (newest name } \\
\text { for RP-1127) }\end{array}$ & $\begin{array}{l}\text { Large hemispheric } \\
\text { infarction including } \\
\text { thrombectomy }\end{array}$ & Recruiting [46] \\
\hline NCT03954041 & $\begin{array}{l}\text { Phase II } \\
\text { (ASTRAL) }\end{array}$ & $\begin{array}{c}\text { Intravenous glyburide } \\
\text { (RP-1127) }\end{array}$ & Brain contusion & Recruiting [46] \\
\hline NCT02524379 & $\begin{array}{l}\text { Phase I } \\
\text { (SCING) }\end{array}$ & $\begin{array}{l}\text { Oral glyburide } \\
\text { (3.125-2.5 mg on } \\
\text { days } 1-3)\end{array}$ & $\begin{array}{l}\text { Acute cervical } \\
\text { traumatic SCI }\end{array}$ & $\begin{array}{l}\text { Active, not } \\
\text { recruiting [46] }\end{array}$ \\
\hline NCT03569540 & $\begin{array}{l}\text { Phase IV } \\
\text { (GASH) }\end{array}$ & Oral glyburide $(0.5 \mathrm{mg})$ & SAH & Unknown [128] \\
\hline
\end{tabular}

\subsubsection{Ischemic Stroke-Preclinical Studies}

Ischemic Stroke-In Vitro Studies

The original in vitro patch-clamp studies described earlier (Sections 2.2 and 2.3) were performed on freshly isolated rat brain astrocytes after chemically induced hypoxia; these experiments demonstrated that depletion of cytosolic ATP resulted in activation of SUR1TRPM4 channels and cell membrane depolarization [7]. The activation and opening of SUR1-TRPM4 resulted in an influx of $\mathrm{Na}^{+}$and water into the cell, ultimately leading to osmotic gradient-driven cell swelling and blebbing $[7,129]$. These effects were reproduced in the absence of ATP depletion by treatment of reactive astrocytes with the SUR1 activator diazoxide, which resulted in channel activation; inhibitors such as glibenclamide and tolbutamide were protective [8].

\section{Ischemic Stroke-In Vivo Expression Patterns}

A subsequent seminal study by the same group was the first to demonstrate that this channel was upregulated in vivo in two rat models of ischemic stroke, and mediated cerebral edema in both models: massive middle-cerebral artery (MCA) infarction with malignant cerebral edema (MCE), as well as a non-lethal thromboembolic infarction [65]. In this work, SUR1 protein levels were increased in the infarct core within 2-3 h of MCA occlusion (MCAO) in "virtually every" neuron and capillary, and declined by $\sim 8 \mathrm{~h}$ [65]. In the peri-infarct region, SUR1 levels increased later, but persisted for longer (8-16 h), with as much as a 3-fold elevation (vs. control) in several cell types including neurons, astrocytes, and endothelial cells. The elevated protein levels were corroborated by corresponding increases in $A b c c 8$ mRNA transcripts. A pilot porcine study after malignant MCA infarction also demonstrated elevated SUR1 and TRPM4 expression in the core (highest levels) and penumbra, as well as in contralateral neurons and microvessels $5 \mathrm{~h}$ after ischemia [119].

\section{Ischemic Stroke-In Vivo Channel Blockade}

In the MCE rat model, treatment with glibenclamide $(75 \mathrm{ng} / \mathrm{h})$ decreased mortality from $65 \%$ to $24 \%$, with a significant reduction in peri-infarct edema (Figure 4 ). In the non-lethal thromboembolic model, glibenclamide reduced infarct volume at 2 days and 7 days [65]. This study was also the first to demonstrate preferential uptake of glibenclamide into ischemic tissue, as noted in Section 2.3-a finding that has since been confirmed [116]. Further evaluations of glibenclamide in different models of non-lethal stroke confirmed protection [112]. Delayed administration of glibenclamide, up to $6 \mathrm{~h}$ postMCAO, still reduced total and/or corrected cortical lesion volumes by $41-53 \%$ measured at $48 \mathrm{~h}$ in thromboembolic MCAO, transient MCAO, and permanent MCAO models [112]. 
Doses used in these studies ranged from a loading dose of $3.3-10 \mathrm{mg} / \mathrm{kg}$, and infusion doses of 75-200 ng/h.

A

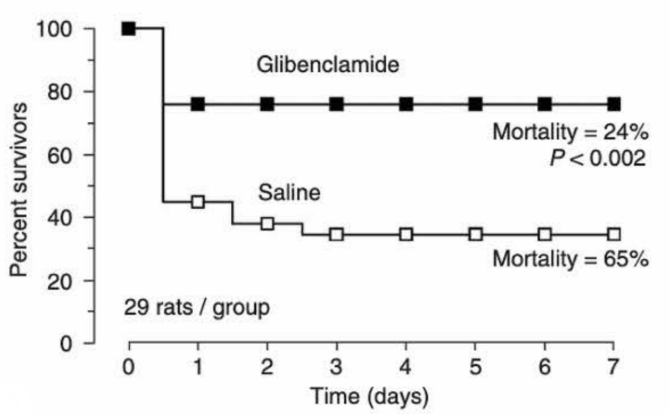

B

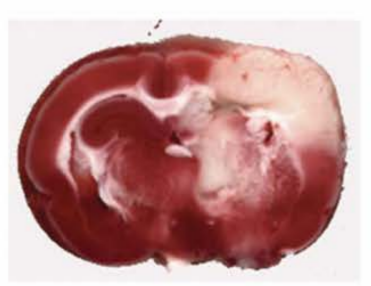

C

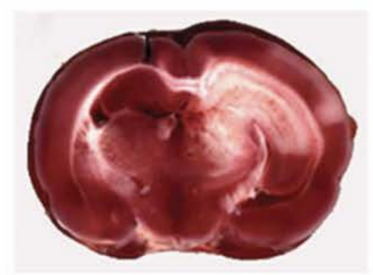

Figure 4. (A) Graph showing percent survival of rats over 7 days after middle cerebral artery occlusion (MCAO, malignant cerebral edema model) when treated by saline (open squares) vs. glibenclamide (filled black squares). At 7 days, mortality was significantly different in the glibenclamide group $(24 \%)$ vs. vehicle group $(65 \%, p<0.002)$. Representative TTC-stained coronal sections 2 days after MCAO (thromboembolic model) in a rat treated with saline (B) vs. glibenclamide (C) showing cortical sparing in the latter. Adapted with permission from Ref. [65].

The same investigative group further evaluated the in vivo benefits of glibenclamide in clinically relevant rodent models of stroke treatment, including decompressive craniectomy and recombinant tissue plasminogen activator (rtPA) [111,113,115]. In a model of severe ischemia/reperfusion, where reperfusion and glibenclamide treatment were initiated $6 \mathrm{~h}$ after the onset of ischemia, glibenclamide $(10 \mathrm{mg} / \mathrm{kg}$ plus $200 \mathrm{ng} / \mathrm{h})$ was as effective as decompressive craniectomy in reducing mortality, but was superior in preserving neurological function as well as watershed cortex and deep white matter [113]. Given the expression of SUR1-TRPM4 in the CNS microvascular endothelium, and the contribution to both cerebral edema and hemorrhage progression, glibenclamide was evaluated in a rat model of MCAO using an intra-arterial occluder followed by recanalization at $4.5 \mathrm{~h}$ and administration of $\mathrm{rtPA}(0.9 \mathrm{mg} / \mathrm{kg} \times 30 \mathrm{~min}$, identical to the human dose $)$ [115]. Glibenclamide treatment at either $4.5 \mathrm{~h}$ or $10 \mathrm{~h}$ post-recanalization $(10 \mathrm{mg} / \mathrm{kg}$ followed by $200 \mathrm{ng} / \mathrm{h}$ ) improved hemispheric swelling, $48 \mathrm{~h}$ mortality (by $>30 \%$ ), and improved neurological outcomes as measured by Garcia scores. Interestingly, there was no difference in hemorrhagic transformation or $48 \mathrm{~h}$ infarct volume; the authors postulated that there was minimal opportunity for reducing infarct volume after a $4.5 \mathrm{~h}$ duration of ischemia-by which point the maximal ischemic insult had already occurred. The robust improvement in neurological outcomes with delayed glibenclamide treatment (as much as $10 \mathrm{~h}$ ) further added to the growing body of evidence that glibenclamide is a promising therapeutic agent, and may provide benefits independently from the final infarct volume-possibly via effects on swelling or alternative neuroprotective pathways.

Independent groups have subsequently validated the protective effects of glibenclamide in preclinical models [116-118]. Wali et al. evaluated the same dose of glibenclamide as previously tested (10 mg/kg plus $200 \mathrm{ng} / \mathrm{h}$ infusion) in a permanent MCAO rat model [117]. Confirming the previous results, glibenclamide treatment significantly reduced infarct volume, hemispheric swelling, lowered neurological severity scores, and improved grip strength as compared to control rats [117]. Ortega et al. performed studies in transient MCAO rat models. They reported that treatment with different doses of glibenclamide (0.06 mg vs. $0.6 \mathrm{mg}$ vs. $6 \mathrm{mg}$ vs. vehicle) at $6 \mathrm{~h}, 12 \mathrm{~h}$ and $24 \mathrm{~h}$, resulted in neuronal preservation within the infarct core ( 3 days after reperfusion), and improved neurological outcomes [116]. The dose of $0.6 \mathrm{mg}$ had greater neuronal sparing vs. both $0.06 \mathrm{mg}$ and vehicle, whereas $6 \mathrm{mg}$ was only beneficial vs. vehicle but not the other doses. In this study, the beneficial effects of glibenclamide did not extend to the whole lesion volume (measured by MRI), nor did it protect against astroglial reaction. Immunolabeling studies identified a predominance of amoeboid reactive microglia within the necrotic core, co-expressing 
Kir6.2, SUR1 and SUR2B (at the time of this study's publication, TRPM4 had not yet been identified as the $\mathrm{NC}_{\mathrm{Ca}-\mathrm{ATP}}$ inner pore, thereby precluding immunolabelling). This group also tested long-term effects of low dose glibenclamide (total $=0.6 \mathrm{mg}$ ) in rat transient MCAO [118]. Within $72 \mathrm{~h}$ of glibenclamide treatment, doublecortin-positive cells were noted to be migrating towards the ischemic cortex (increased vs. control); 30 days after $\mathrm{MCAO}$, glibenclamide continued to enhance cortical neurogenesis, as evidenced by an increase in 5-bromo-2-deoxyuridine (BrdU) and NeuN labeling around the infarct. Given these histopathological findings, it is not surprising that glibenclamide was associated with behavioral improvement in both cognitive and sensorimotor functions up to 1 month [118].

Of note, in a rat model of ischemia/reperfusion $(15 \mathrm{~min} / 60 \mathrm{~min})$, glibenclamide treatment reduced neutrophil recruitment, ameliorated inflammatory mediators (TNFa, prostaglandin E2), and boosted anti-inflammatory cytokine profiles [114]. However, involvement of SUR1-TRPM4 was not demonstrated in these studies and is thought to be unlikely, since the timepoints measured were insufficient for channel upregulation [6].

Glibenclamide has also been evaluated in combination with other therapeutic approaches in in vivo stroke models. In a rat MCAO model, glibenclamide and therapeutic hypothermia performed synergistically with multifactorial benefits [130]. Individual treatment with either glibenclamide or therapeutic hypothermia significantly reduced infarct volume. However, combination therapy was associated with greater edema reduction, less tight-junction loss, lower inflammatory cytokines (iNOS, COX2), and ultimately, higher performance on neurobehavioral tests vs. either therapy alone.

A recent report suggests that the antioxidant resveratrol may be a potentially novel therapy that targets SUR1 to provide benefit ischemic stroke; male rats were subjected to $2 \mathrm{~h}$ MCAO followed by intravenous resveratrol treatment $(1.9 \mathrm{mg} / \mathrm{kg}$ ) [120]. Resveratrol decreased $A b c c 8$ mRNA and SUR1 protein expression in MCAO and reperfusion, possibly by decreasing Sp1 binding activity. Resveratrol significantly reduced cerebral edema (water content), BBB disruption (Evans blue extravasation), and improved neurological outcome (limb-use asymmetry test) and survival (by $\sim 40 \%$ ). Resveratrol also reduced AQP4 expression in this study.

\subsubsection{Ischemic Stroke-Human Studies}

Ischemic Stroke-Human Expression Patterns

The first systematic evaluation of SUR1 expression in brains from ischemic stroke patients was reported in 2013 [122]. In this study, postmortem tissue was obtained from 13 patients within the first 31 days after an ischemic stroke and evaluated for SUR1 expression using in situ hybridization and immunohistochemistry. SUR1 levels were elevated in all cases, with important temporal differences in cell-type-specific expression. Both neurons and endothelial cells were most elevated within the first week; expression was detected as early as $24 \mathrm{~h}$ after stroke onset, and persisted for 7-10 days. Conversely, both microglial and astrocytic cells showed a progressive increase in expression over the first month. Neutrophilic expression in peri-infarct regions remained prominent with no noticeable temporal changes. A subsequent study of post-mortem brain specimens from 15 patients (again, using both immunohistochemistry and in situ hybridization) confirmed TRPM4 elevation in all adult human brains [68]. TRPM4 upregulation persisted at 1 month post-infarction. FRET analysis confirmed the formation of SUR1-TRPM4 heteromers in neurons, endothelial cells, and astrocytes in human cerebral infarcts [68].

\section{Ischemic Stroke-Clinical Retrospective Studies}

Retrospective studies have evaluated the use of oral sulfonylureas (such as glibenclamide) in diabetic patients with ischemic stroke [123-126]. Given that SUR1-TRPM4 is upregulated after CNS injury, mechanistically it should be less likely that pre-treatment with glibenclamide would confer significant benefits. It is therefore not surprising that a Danish study of 4817 diabetics did not find an association between pre-admission sulfonylurea use and clinical outcome after ischemic stroke [126]. No pharmacokinetic values 
were available to evaluate the bioavailability of pre-treatment glibenclamide. In the VISTA (Virtual International Stroke Trials Archive), an analysis of 1050 patients identified 298 that were on pre-existing sulfonylurea medications [124]. Again, no association was noted between sulfonylureas and overall outcome, although there was a trend towards benefit in all 28 patients who were continued on sulfonylureas post-stroke. Of note, this cohort consisted of patients enrolled in non-reperfusion ischemic stroke trials, and stroke subtypes were not reported. In contrast, studies where sulfonylurea administration was continued post-stroke have indicated potential benefits. In acute ischemic stroke patients treated with sulfonylureas (from admission through discharge) $36.4 \%$ had a $>4$ point lower NIHSS score (National Institutes of Health Stroke Scale) at discharge vs. 7.1\% in untreated patients $(p=0.007)]$. Treated patients were also more likely to attain an improved modified Rankin Scale score of $\leq 2(81.8 \%$ vs. $57 \%, p=0.035)$. A separate analysis of 220 diabetic patients with acute ischemic stroke reported that sulfonylureas reduced post-stroke symptomatic hemorrhagic transformation ( 0 vs. $11 \%, p=0.016)$ and mortality $(0 \%$ vs. $10 \%, p=0.027)$ [125]. Brain tissue from one of the patients with symptomatic hemorrhagic transformation in this study demonstrated upregulated neuronal and microvascular SUR1.

\section{Ischemic Stroke-Clinical Trials}

RP-1127 (also known as Cirara) is an intravenous formulation of glyburide developed by Remedy Pharmaceuticals. After the RP-1127 program was purchased by Biogen, the drug was renamed BIIB093. This intravenous formulation was first evaluated in the field of ischemic stroke-specifically large hemispheric infarction, since this subtype is at highest risk for malignant cerebral edema.

A phase I trial (NCT01132703) in 34 healthy human volunteers [131] assessed the safety, tolerability and pharmacokinetics of RP-1127 at three doses: 3.0, 6.0, and $10.0 \mathrm{mg} / \mathrm{day}$. No serious adverse events were reported. Although blood glucose levels $\geq 80 \mathrm{mg} / \mathrm{dL}$ were more common in the placebo group, there was no significant difference in levels $\leq 70 \mathrm{mg} / \mathrm{dL}$ with a dose of $3 \mathrm{mg} /$ day, which was associated with steady-state drug levels of $27.3 \mathrm{ng} / \mathrm{mL}$ (higher than the $16 \mathrm{ng} / \mathrm{mL}$ required for efficacy in preclinical studies).

The safety profile of RP-1127 led to a phase IIa Glyburide Advantage in Malignant Edema and Stroke (GAMES-Pilot; NCT01268683) study. In this open-label, feasibility study with no control arm, a $72 \mathrm{~h}$ infusion of RP-1127 was tested at $3 \mathrm{mg} /$ day in 10 patients with large hemispheric infarctions of $82-210 \mathrm{~cm}^{3}$ [132]. The drug was well tolerated without any safety concerns, symptomatic hypoglycemia, or adverse events requiring discontinuation or dose reduction. An exploratory analysis comparing these patients vs. historical untreated controls suggested improved clinical outcomes $(p=0.049)$ and a trend towards reduced mortality with treatment, although this was not statistically significant [49]. A case-control evaluation comparing the GAMES-Pilot patients with placebo-treated subjects in the Normobaric Oxygen Therapy in Acute Ischemic Stroke trial, revealed reduced vasogenic edema with RP-1127 treatment as measured by FLAIR ratio $(p<0.01)$, that persisted over time up to $80 \mathrm{~h}(p<0.005)$ [25]. Compared with historical controls, RP-1127 also reduced MMP-9 levels at $48 \mathrm{~h}$ post-stroke onset as measured by quantitative sandwich ELISA $(54 \pm 17 \mathrm{ng} / \mathrm{mL}$ vs. $212 \pm 151 \mathrm{ng} / \mathrm{mL}, p<0.01)$ and proMMP-9 enzyme levels (as measured by zymography; $p<0.01$ ) [25]. Both FLAIR ratio and MMP-9 levels are associated and known markers of BBB integrity [133].

The subsequent phase IIb study, GAMES-RP, was a randomized, multicenter, prospective, double-blind placebo-controlled trial that evaluated the same dose of RP-1127 as the GAMES-Pilot in 86 patients with large hemispheric infarction (lesion volumes $82-300 \mathrm{~cm}^{3}$ ) [47] Treatment had to be initiated within $\leq 10 \mathrm{~h}$ of symptom onset, given the underlying biology of channel upregulation and preclinical data; 41 patients received RP-1127 and 36 received placebo. Overall infarct volumes (150-160 cc) were larger than in the GAMES-Pilot. The primary clinical outcome of mRS 0-4 without decompressive craniectomy was not different between groups, potentially due to widely variable surgical practice across centers. However, mortality at 30 days (regardless of craniectomy) was reduced in the treated 
group $(15 \%$ vs. $36 \%, p=0.03)$, with a trend towards reduction at 90 days $(17 \%$ vs. $36 \%$, $p=0.06)$. Measures of cerebral edema and BBB stability also showed a promising response to treatment: midline shift observed on MRI at 72-96 h was almost half in the treatment group vs. controls (4.6 mm vs. $8.5 \mathrm{~mm}, p=0.0006$; Figure 5A). Plasma MMP-9 levels also were lower in the treatment vs. placebo groups $(211 \mathrm{ng} / \mathrm{mL}$ vs. $346 \mathrm{ng} / \mathrm{mL} ; p=0.006)$. No differences were noted in serious adverse events. A subsequent publication of pre-specified edema-adjudicated endpoints highlighted that treatment with RP-1127 resulted in a lower proportion of edema-related deaths $(2.4 \%$ vs. $22.2 \%, p=0.01)$ and other markers of clinical worsening, e.g., as measured by NIHSS increases of $\geq 4$ (37\% vs. 71\%, $p=0.043)$ [134]. An exploratory post-hoc study of 65 patients from the GAMES-RP cohort who were $\leq 70$ years of age identified lower mortality at all timepoints in RP-1127-treated patients (hazards ratio $0.34, p=0.04)$. Although the trend towards benefit in functional outcome as measured by the modified Rankin Scale was not significant $(p=0.07)$, there were other significant treatment effects, including on the Barthel index $(p=0.03)$, a reduced plasma level of MMP-9 (189 vs. $376 \mathrm{mg} / \mathrm{mL}, p<0.001)$, and decreased midline shift (4.7 vs. $9 \mathrm{~mm} ; p<$ 0.001) [48]. A separate post-hoc exploratory analysis of the GAMES-RP cohort reported that treatment with $\mathrm{RP}-1127$ reduced net water uptake $(\mathrm{b}=-2.80 ; p=0.016)$; gray matter net water uptake contributed to a greater proportion of midline shift vs. white matter $(p=$ 0.001).

A
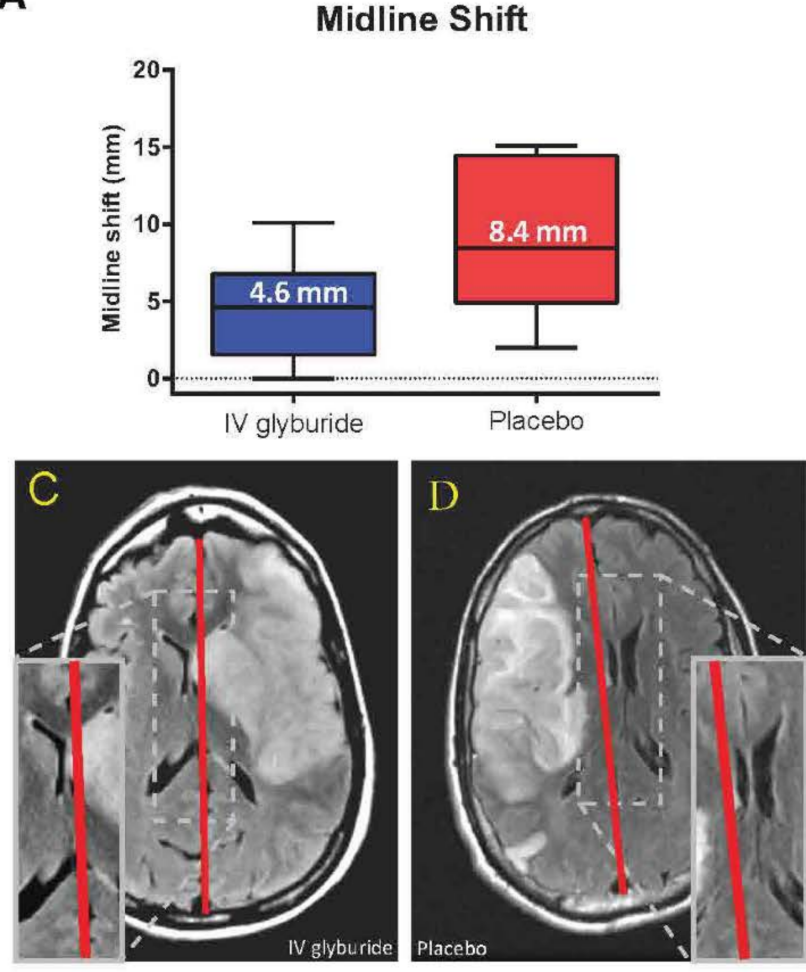

B

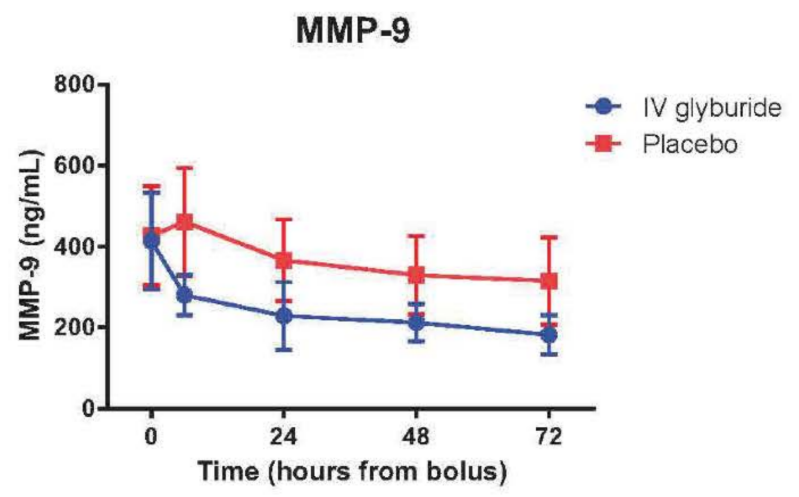

\begin{tabular}{|l|l|l|l|l|l|l|}
\hline & Treatment & $0 \mathrm{hr}$ & $4 \mathrm{hr}$ & $24 \mathrm{hr}$ & $48 \mathrm{hr}$ & $72 \mathrm{hr}$ \\
\hline $\begin{array}{l}\text { No. of } \\
\text { IV glyburide }\end{array}$ & 40 & 41 & 41 & 39 & 39 \\
\hline patients & Placebo & 35 & 36 & 36 & 32 & 31 \\
\hline
\end{tabular}

Figure 5. Figures from the GAMES-RP clinical trial demonstrating the effect of glyburide on midline shift (A,C,D) and plasma MMP-9 levels (B). (A) Boxplot showing the median midline shift (horizontal line, box = interquartile range, whiskers $=10-90$ percentile) in each treatment group in the per-protocol sample. (B) Temporal profile of mean total plasma MMP9 levels for the per-protocol sample (error bars are 95\% confidence intervals at the specific timepoint shown). (C,D) Representative examples of median extent of midline shift on follow-up brain MRI with a patient treated with intravenous glyburide $(5 \mathrm{~mm})$ vs a placebo-treated patient $(9 \mathrm{~mm})$. The redline is a reference showing the brain midline. Adapted with permission from Ref. [47].

These findings led to the ongoing a phase III clinical trial of RP-1127 or Cirara (now, BIIB093) in large hemispheric infarction, sponsored by Biogen. CHARM (Ciara in large Hemispheric infarction Analyzing modified Rankin and Mortality; NCT02864953), is a 
randomized, double-blind, placebo-controlled, parallel-group, multicenter international study designed to evaluate the efficacy and safety of BIIB093 for severe cerebral edema [46]. Inclusion requires infarctions measuring $80-300 \mathrm{~cm}^{3}$ on either MRI (diffusion weighted imaging), or CT perfusion, or an Alberta Stroke Program Early CT Score, (ASPECTS) of 1-5. Patients undergoing thrombectomy are included in this study, provided that the post-procedure infarct volume is within the required parameters. The planned primary outcome is the percentage of patients with improvements in 90-day functional outcome assessed via the modified Rankin scale score. The trial is actively enrolling; interim results are not yet available.

\section{2. $T B I$}

Scientific research into the role of SUR1-TRPM4 in secondary injury processes after TBI is rapidly evolving with insights from preclinical and clinical studies (Table 4) [11,24,26,29-35,38,42-44,135-139].

\subsubsection{TBI-Preclinical Studies}

TBI-In Vivo Expression Patterns

Expression of SUR1 and/or TRPM4 (henceforth, SUR1 \pm TRPM4) has been evaluated in rat models of TBI, with all but one study being performed in models of focal cortical impact $[26,29,30,140]$. In all reports, regardless of injury severity or specific model-type, SUR1 \pm TRPM4 was consistently upregulated in multiple cell-types of the neurovascular unit. The spatio-temporal patterns described in the studies below were previously reported [11], and are re-summarized here (Figure 6).

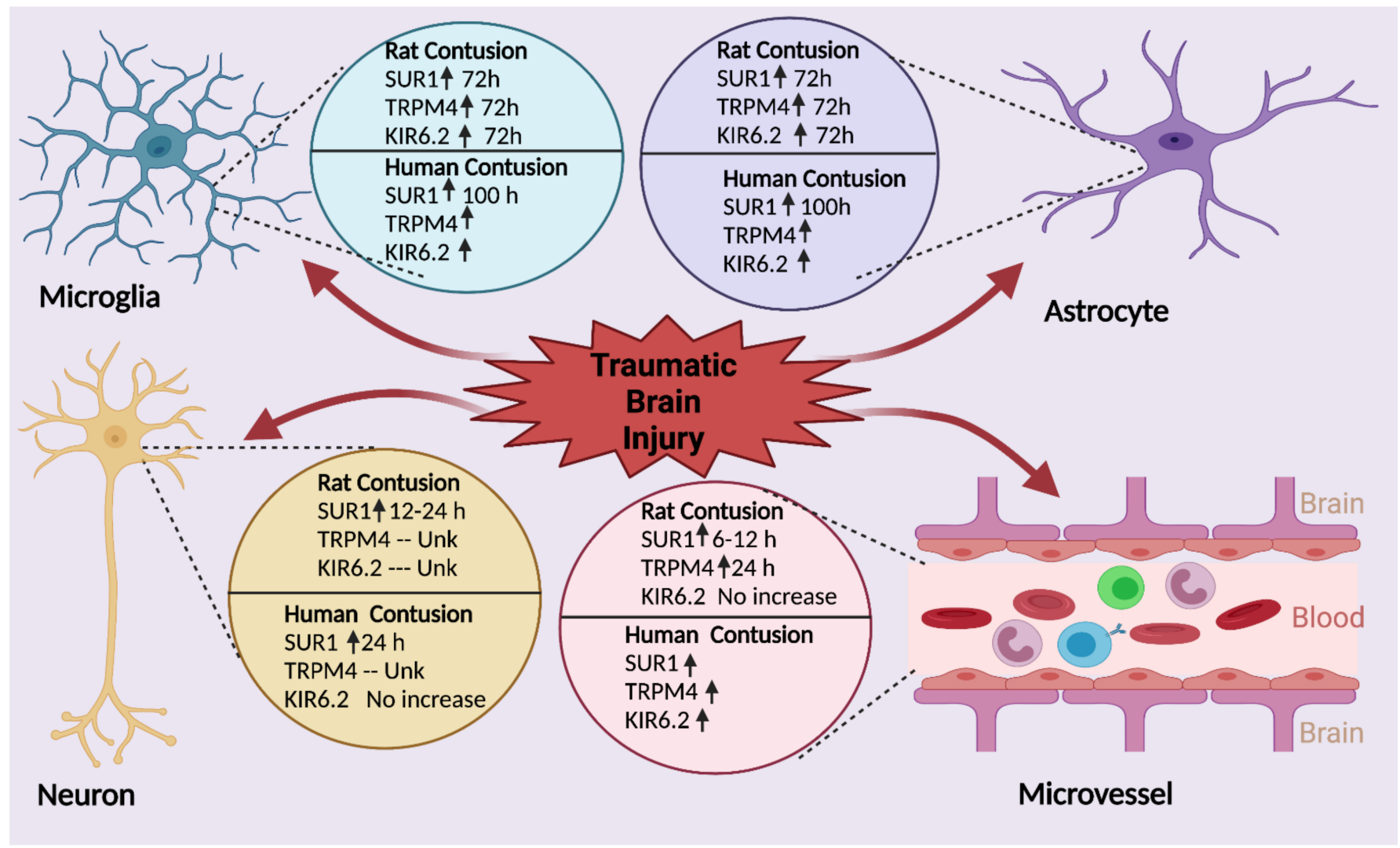

Figure 6. Schematic representation of SUR1, TRPM4, and KIR6.2 expression and timelines in neuron, microglia, astrocytes, and microvessels after TBI in rodents and humans. Figure created with BioRender.com (2021). 
Table 4. Pre-clinical and clinical studies evaluating SUR1 inhibition for traumatic brain injury (TBI).

\begin{tabular}{|c|c|c|c|c|c|}
\hline Authors, Year & Study Title & Model & Species & Drug Details & Results \\
\hline \multicolumn{6}{|c|}{ In vivo studies: TBI } \\
\hline Simard et al., 2009 [26] & $\begin{array}{l}\text { Key role of sulfonylurea } \\
\text { receptor } 1 \text { in progressive } \\
\text { secondary hemorrhage after } \\
\text { brain contusion }\end{array}$ & $\begin{array}{l}\text { Weight-drop model of focal } \\
\text { cortical contusion }(10 \mathrm{~g} \\
\text { dropped from } 5 \mathrm{~cm} \\
\text { velocity }=1 \mathrm{~m} / \mathrm{s})\end{array}$ & Rat & $\begin{array}{l}\text { GLI } \\
\text { Time: } 10 \mathrm{~min} \text { of injury } \\
\text { Loading dose: } 10 \mathrm{mg} / \mathrm{kg} \text { i.p, } \\
\text { Infusion rate: } 200 \mathrm{ng} / \mathrm{h}\end{array}$ & $\begin{array}{l}\text { - } \quad \text { SUR1 } \mathrm{h} \text { as early as } 3 \mathrm{~h} \text { after injury. } \\
\text { SUR1 upregulation was } \\
\text { predominantly } \mathrm{h} \text { in microvessels } \\
\text { and remained elevated up to } 24 \mathrm{~h} \\
\text { - } \quad \text { After } 24 \mathrm{~h} \text {, SUR1 expression was } \mathrm{h} \\
\text { in thalamus and hippocampus } \\
\text { BBB integrity was maintained with } \\
\text { reduced blood extravasation at } 3 \mathrm{~h} \text {, } \\
6 \mathrm{~h} \text { and maximal benefit at } 12 \mathrm{~h} . \\
\text { - Hemorrhage progression was } \\
\text { reduced by } 45 \text { min in GLI-treated } \\
\text { rats }\end{array}$ \\
\hline Patel et al., 2010 [30] & $\begin{array}{l}\text { Glibenclamide reduces } \\
\text { hippocampal injury and } \\
\text { preserves rapid spatial } \\
\text { learning in a model of } \\
\text { traumatic brain injury. }\end{array}$ & $\begin{array}{l}\text { Milder injury weight drop } \\
\text { model }(10 \mathrm{~g} \text { dropped from } \\
3 \mathrm{~cm} \text {, velocity }=0.77 \mathrm{~m} / \mathrm{s})\end{array}$ & Rat & $\begin{array}{l}\text { GLI } \\
\text { Time: } 10 \mathrm{~min} \text { of injury } \\
\text { Loading dose: } 10 \mathrm{mg} / \mathrm{kg} \text { i.p, } \\
\text { Infusion rate: } 200 \mathrm{ng} / \mathrm{h}\end{array}$ & $\begin{array}{l}\text { - } \quad \text { S SUR1 protein and } A b c c 8 \text { mRNA } \\
\text { expression in hippocampal neurons } \\
\text { at } 6 \mathrm{~h} \text { and peaks at } 24 \mathrm{~h} \\
\text { h } \mathrm{Sp} 1 \text { expression preceded SUR1 } \\
\text { expression }\end{array}$ \\
\hline Zweckberger et al., 2014 [43] & $\begin{array}{c}\text { Glibenclamide reduces } \\
\text { secondary brain damage after } \\
\text { experimental traumatic brain } \\
\text { injury }\end{array}$ & $\begin{array}{c}\mathrm{CCI}(1.5 \mathrm{~mm} \text { tissue } \\
\text { displacement, velocity }= \\
7.5 \mathrm{~m} / \mathrm{s}, \text { dwell time }=300 \mathrm{~ms})\end{array}$ & Rat & $\begin{array}{c}\text { GLI } \\
\text { Time: } 15 \mathrm{~min} \text { after CCI } \\
\text { Loading dose } 10 \mathrm{mg} / \mathrm{kg} \text { i.p, } \\
\text { Infusion rate } 10 \mathrm{~mL} / \mathrm{h}\end{array}$ & $\begin{array}{l}\text { - } \quad \text { GLI i brain water content } \\
\text { i contusion volume } 8 \mathrm{~h}, 24 \mathrm{~h}, 72 \mathrm{~h} \\
\text { and } 7 \mathrm{~d} \text { post-CCI }\end{array}$ \\
\hline Xu et al., 2017 [44] & $\begin{array}{l}\text { Glibenclamide attenuates } \\
\text { blood-brain barrier } \\
\text { disruption in adult mice after } \\
\text { traumatic brain injury }\end{array}$ & $\begin{array}{c}\text { CCI }(1.5 \mathrm{~mm} \text { tissue } \\
\text { displacement, velocity }= \\
1.5 \mathrm{~m} / \mathrm{s} \text {, dwell time }=100 \mathrm{~ms})\end{array}$ & Mouse & $\begin{array}{c}\text { GLI } \\
\text { Time: immediately after CCI } \\
\text { Dose:10 mg i.p. }\end{array}$ & $\begin{array}{l}\text { - } \quad \text { GLI i loss of ZO-1 and occludin } \\
\text { GLI i brain water content, i BBB } \\
\text { permeability, apoptosis (JNK/c-jun } \\
\text { signaling) }\end{array}$ \\
\hline Jha et al., 2018 [24] & $\begin{array}{l}\text { Glibenclamide produces } \\
\text { region-dependent effects on } \\
\text { cerebral edema in a combined } \\
\text { injury model of traumatic } \\
\text { brain injury and hemorrhagic } \\
\text { shock in mice }\end{array}$ & $\begin{array}{l}\mathrm{CCI}(5 \mathrm{~m} / \mathrm{s}, 1 \mathrm{~mm} \text { depth})+ \\
\text { hemorrhagic shock }(\mathrm{HS})\end{array}$ & Mouse & $\begin{array}{l}\text { GLI } \\
\text { Time: } 10 \mathrm{~min} \text { after CCI } \\
\text { Loading dose: } 20 \mathrm{mg} / \mathrm{kg} \text { i.v. } \\
\text { Infusion rate: } 0.4 \mathrm{mg} / \mathrm{h}\end{array}$ & $\begin{array}{l}\text { - Low dose GLI did not reduce } \\
\text { ipsilateral edema } \\
\text { - Low dose GLI normalized } \\
\text { contralateral edema in CCI + HS. }\end{array}$ \\
\hline
\end{tabular}


Table 4. Cont.

\begin{tabular}{|c|c|c|c|c|c|}
\hline Authors, Year & Study Title & Model & Species & Drug Details & Results \\
\hline Gerzanich et al., 2019 [29] & $\begin{array}{c}\text { Sulfonylurea receptor 1, } \\
\text { transient receptor potential } \\
\text { cation channel subfamily } \mathrm{M} \\
\text { member 4, and kir6.2: role in } \\
\text { hemorrhagic progression of } \\
\text { contusion }\end{array}$ & $\begin{array}{c}\text { CCI } \\
(4.5 \mathrm{~mm} \text { tissue displacement, } \\
\text { velocity }=1 \mathrm{~m} / \mathrm{s} \text {, dwell time } \\
=200 \mathrm{~ms})\end{array}$ & Rat & $\begin{array}{l}\text { GLI } \\
\text { Time: } 10 \mathrm{~min} \text { after CCI } \\
\text { Loading dose: } 10 \mathrm{mg} / \mathrm{kg} \text { i.p., } \\
\text { Infusion rate: } 400 \mathrm{ng} / \mathrm{h}\end{array}$ & $\begin{array}{l}\text { - SUR1 expression in the core tissue } \\
\text { peaked at } 6 \mathrm{~h} \text {, remained elevated at } \\
12 \mathrm{~h} \text {, decreased at } 24 \mathrm{~h} \text { and } \\
\text { upregulated again at } 72 \mathrm{~h} \\
\text { - SUR1 expression was h at } 24 \mathrm{~h} \\
\text { predominantly in microvessels but } \\
\text { at } 72 \mathrm{~h} \text { SUR1 } \mathrm{h} \text { in microglia } \\
\text { - } \mathrm{Hemorrhage} \text { progression was i by } \\
60 \% \text { in GLI treated rats }\end{array}$ \\
\hline Jha et al., 2021 [33] & $\begin{array}{l}\text { Glibenclamide treatment in } \\
\text { traumatic brain injury: } \\
\text { operation brain trauma } \\
\text { therapy }\end{array}$ & $\begin{array}{c}\text { Fluid percussion injury (FPI), } \\
\mathrm{CCI}(4 \mathrm{~m} / \mathrm{s} ; 2.6 \mathrm{~mm} \text { depth), } \\
\text { penetrating ballistic like brain } \\
\text { injury }\end{array}$ & Rat & $\begin{array}{l}\text { GLI } \\
\text { Time: } 10 \mathrm{~min} \text { after injury } \\
\text { Loading dose: } 10 \mathrm{mg} / \mathrm{kg} \text { i.p., } \\
\text { Infusion rate: } 0.20 \mu \mathrm{g} / \mathrm{h}\end{array}$ & $\begin{array}{l}\text { GLI treatment improved lesion } \\
\text { volume and motor function in CCI } \\
\text { and did not show any benefit in FPI } \\
\text { or penetrating injury }\end{array}$ \\
\hline Tata et al., 2021 [35] & $\begin{array}{l}A b c c 8 \text { (Sulfonylurea } \\
\text { receptor-1) impact on brain } \\
\text { atrophy after TBI varies by } \\
\text { sex }\end{array}$ & $\begin{array}{c}\text { CCI } \\
\begin{array}{c}(1.2 \mathrm{~mm} \text { displacement, } \\
\text { velocity }=5 \mathrm{~m} / \mathrm{s}, \text { dwell time } \\
=50-60 \mathrm{~ms})\end{array}\end{array}$ & Mouse & $\mathrm{NA}\left(A b c c 8^{-/-}\right)$ & $\begin{array}{l}\text { Abcc8 KO mice had smaller } \\
\text { contusion volume and larger } \\
\text { normalized contralateral (right) } \\
\text { hemisphere volumes after injury vs. } \\
\text { wild type. }\end{array}$ \\
\hline \multicolumn{6}{|c|}{ Human expression and genetics studies: TBI } \\
\hline Martinez et al., 2015 [38] & $\begin{array}{l}\text { Sulfonylurea receptor } 1 \text { in } \\
\text { humans with post-traumatic } \\
\text { brain contusions }\end{array}$ & Contusional TBI & 26 patient samples & NA & $\begin{array}{l}\text { - SUR1 significantly upregulated in } \\
\text { all cell types } \\
\text { - } \quad \text { Neuronal SUR1 was detected by } \\
6 \mathrm{~h} \text { post TBI, with a peak at } 24 \mathrm{~h} \\
\text { - } \quad \text { In endothelial cells, h SUR1 level } \\
\text { persisted up to } 100 \mathrm{~h}\end{array}$ \\
\hline
\end{tabular}


Table 4. Cont

\begin{tabular}{|c|c|c|c|c|c|}
\hline Authors, Year & Study Title & Model & Species & Drug Details & Results \\
\hline Jha et al., 2017 [24] & $\begin{array}{l}\text { Sulfonylurea receptor-1: a } \\
\text { novel biomarker for cerebral } \\
\text { edema in severe traumatic } \\
\text { brain injury }\end{array}$ & CSF samples from severe TBI & $\begin{array}{l}28 \text { patients } \\
15 \text { controls }\end{array}$ & NA & $\begin{array}{l}\text { Level of SUR1 was } \mathrm{h} \text { in the CSF of } \\
\text { all patients } \\
\text { ICP trajectory mirrored SUR1 } \\
\text { expression after temporal delay } \\
\text { - } \quad \text { SUR1 level, radiographic CT edema } \\
\text { and initial degree of intracranial } \\
\text { hypertension were associated }\end{array}$ \\
\hline Jha et al., 2018 [120] & $\begin{array}{l}\text { Regionally clustered ABCC } 8 \\
\text { polymorphisms in a } \\
\text { prospective cohort predict } \\
\text { cerebral oedema and } \\
\text { outcome in severe traumatic } \\
\text { brain injury }\end{array}$ & $\begin{array}{l}\text { Tag-SNP study in severe TBI } \\
\qquad(A B C C 8)\end{array}$ & $\begin{array}{c}410 \text { patients } \\
\text { analyzed }\end{array}$ & NA & $\begin{array}{l}\text { rs7105832 and rs2237982 were } \\
\text { associated with intracranial } \\
\text { pressure and radiographic edema } \\
\text { rs2237982 was also associated with } \\
\text { 3-month GOS } \\
\text { Different SNPs (rs11024286, } \\
\text { rs4148622) were associated with } \\
\text { 3-month GOS. } \\
\text { Significant SNPs clustered } \\
\text { upstream (opposite end of the gene } \\
\text { vs. those significant in disorders of } \\
\text { glucose metabolism) } \\
\text { Significant SNPs spatially clustered } \\
\text { flanking exons encoding the } \\
\text { sulfonylurea receptor site and } \\
\text { transmembrane domain 0/loop } 0 \\
\text { (juxtaposing the channel } \\
\text { pore/binding site }\end{array}$ \\
\hline
\end{tabular}


Table 4. Cont.

\begin{tabular}{|c|c|c|c|c|c|}
\hline Authors, Year & Study Title & Model & Species & Drug Details & Results \\
\hline Castro et al., 2019 [139] & $\begin{array}{c}\text { Kir6.2, the pore-forming } \\
\text { subunit of ATP-sensitive } \mathrm{K}^{+} \\
\text {channels, is overexpressed in } \\
\text { human posttraumatic brain } \\
\text { contusions }\end{array}$ & Contusional TBI & 32 patients & NA & - $\quad$ KIR6.2 $\mathrm{h}$ in contusional astrocytes \\
\hline Gerzanich et al., 2019 [29] & $\begin{array}{l}\text { Sulfonylurea receptor 1, } \\
\text { transient receptor potential } \\
\text { cation channel subfamily } \mathrm{M} \\
\text { member } 4 \text {, and kir6.2: role in } \\
\text { hemorrhagic progression of } \\
\text { contusion }\end{array}$ & $\begin{array}{l}\text { Specimens from patients with } \\
\text { non-ballistic, closed head } \\
\text { injury or contusion-TBI who } \\
\text { underwent decompressive } \\
\text { craniectomy }\end{array}$ & 16 patients & NA & $\begin{array}{l}\text { - SUR1-TRPM4 co-localization and } \\
\text { co-assembly was observed in both } \\
\text { microvessels and microglia in the } \\
\text { GFAP }^{-} \text {contusion core } \\
\text { KIR6.2 expressed in CD68 }{ }^{+} \text {cells } \\
\text { but not co-localize with SUR1 } \\
\text { No neuronal SUR1-TRPM4 } \\
\text { expression in human contusion was } \\
\text { reported }\end{array}$ \\
\hline Jha et al., 2019 [122] & $\begin{array}{c}\text { Downstream TRPM4 } \\
\text { polymorphisms are } \\
\text { associated with intracranial } \\
\text { hypertension and statistically } \\
\text { interact with } A B C C 8 \\
\text { polymorphisms in a } \\
\text { prospective cohort of severe } \\
\text { traumatic brain injury }\end{array}$ & $\begin{array}{l}\text { Candidate gene study in } \\
\text { severe TBI (TRPM4) }\end{array}$ & $\begin{array}{l}385 \text { patients } \\
\text { analyzed }\end{array}$ & NA & $\begin{array}{l}\text { - } \quad \text { rs8104571 and rs150391806 were } \\
\text { associated with intracranial } \\
\text { hypertension } \\
\text { rs8104571 significantly interacted } \\
\text { with } A B C C 8 \text { SNPs to moderate } \\
\text { effect on intracranial hypertension } \\
\text { SNPs spatially clustered, flanking } \\
\text { the gene region encoding the } \\
\text { channel pore and interfacing with } \\
\text { SUR1 }\end{array}$ \\
\hline Zusman et al., 2021 [34] & $\begin{array}{l}\text { Cerebrospinal fluid } \\
\text { sulfonylurea receptor-1 is } \\
\text { associated with intracranial } \\
\text { pressure and outcome after } \\
\text { pediatric TBI: an exploratory } \\
\text { analysis of the cool kids trial }\end{array}$ & $\begin{array}{l}\text { CSF samples from pediatric } \\
\text { patients with severe TBI }\end{array}$ & $\begin{array}{l}16 \text { patients, } \\
7 \text { controls }\end{array}$ & NA & $\begin{array}{l}\text { - } \quad \text { SUR1 was h in CSF of } 9 \text { out of } 16 \\
\text { TBI patients and its elevation was } \\
\text { associated with increased ICP over } \\
7 \text { days } \\
\text { - } \quad \text { In patients with measurable SUR1 } \\
\text { after } 24 \mathrm{~h} \text {, ICP values were high } \\
\text { with worse functional outcome at } \\
12 \text { months }\end{array}$ \\
\hline
\end{tabular}


Table 4. Cont.

Authors, Year

Study Title
Model
Species

21 patients

analyzed
Drug Details
Candidate gene study of hemorrhage progression in severe TBI (ABCC8, TRPM4
Genetic variants associated

with intraparenchyma

traumatic brain injury.
NA
Oral GLI

glibenclamide in patients

with diffuse axonal injury

due to moderate to severe head trauma
Diffuse axonal injury

Randomized trial
40 patients

$1.25 \mathrm{mg}$ every $12 \mathrm{~h}$ for 1 week
Clinical trials: TB

Results

- Four $A B C C 8$ single nucleotide variants (rs2237982, rs2283261, rs3819521, rs819265) were associated with $\mathrm{h}$ hemorrhage progression

- $\quad$ Four TRPM4 single nucleotide variants (rs3760666, rs1477363, rs10410857, rs909010) were associated with i hemorrhage progression

- $\quad$ All SNPs were brain specific expression quantitative trait loci (eQTL)

- $\quad$ Regulatory annotations revealed promoter and enhancer marks and strong and/or active brain-tissue transcription, and eQTLs directionally and biologically consistent with $\mathrm{h}$ progression for $A B C C 8$ and i expression for TRPM4.

Zafardoost et al., 2016 [42] 
Table 4. Cont.

\begin{tabular}{|c|c|c|c|c|c|}
\hline Authors, Year & Study Title & Model & Species & Drug Details & Results \\
\hline Khalili et al., 2017 [138] & $\begin{array}{l}\text { Effects of oral glibenclamide } \\
\text { on brain contusion volume } \\
\text { and functional outcome of } \\
\text { patients with moderate and } \\
\text { severe traumatic brain } \\
\text { injuries: a randomized } \\
\text { double-blind } \\
\text { placebo-controlled clinical } \\
\text { trial }\end{array}$ & $\begin{array}{l}\text { Moderate to severe } \\
\text { contusional TBI } \\
\text { Randomized trial }\end{array}$ & 66 patients & $\begin{array}{c}\text { Oral GLI } \\
10 \mathrm{mg} \text { daily for } 10 \mathrm{~d}\end{array}$ & $\begin{array}{l}\text { Lower contusion expansion ratios } \\
\text { between baseline-day } 3 \text { and } \\
\text { baseline-day } 7\end{array}$ \\
\hline Eisenberg et al., 2020 [31] & $\begin{array}{l}\text { Magnetic resonance imaging } \\
\text { pilot study of intravenous } \\
\text { glyburide in traumatic brain } \\
\text { injury }\end{array}$ & $\begin{array}{l}\text { TBI with GCS 4-14 } \\
\text { Randomized Trial }\end{array}$ & 28 patients & $\begin{array}{c}\text { GLI total daily dose on D1 } \\
\text { was } 3.12 \mathrm{mg} \text {, on D2 and D3 } \\
\text { was } 2.67 \mathrm{mg} / \text { day }\end{array}$ & $\begin{array}{l}\text { - Lesion volume increased } 1036 \% \\
\text { with placebo and was } 136 \% \text { with } \\
\text { GLI (not significant) } \\
\text { - } 14 \text { patients had contusional TBI }\end{array}$ \\
\hline
\end{tabular}


The first report evaluating post-traumatic CNS SUR1 levels was in a rat weight-drop model of focal cortical contusion (10 gm dropped from $5 \mathrm{~cm}$, velocity $=1 \mathrm{~m} / \mathrm{s}$ ) [26]. SUR1 was upregulated immediately beneath the impact as early as $3 \mathrm{~h}$ after injury. Upregulated expression was noted predominantly in microvessels and remained elevated up to $24 \mathrm{~h}$ after injury [26]. By the $24 \mathrm{~h}$ timepoint, neuronal and microvascular SUR1 levels were increased in several regions beyond the injured cortex, including the thalamus and hippocampus [26]. In a milder injury model (CCI, 10 gm dropped from $3 \mathrm{~cm}$, velocity $=0.77 \mathrm{~m} / \mathrm{s}$ ), increased SUR1 protein and $A b c c 8$ mRNA expression was noted in hippocampal neurons, first at $6 \mathrm{~h}$, and peaking at $12 \mathrm{~h}$ [30]. This study also demonstrated that increased Sp1 expression (a transcription factor involved in $A b c c 8$ expression) preceded that of SUR1. The same group has demonstrated important spatiotemporal differences in SUR1-TRPM4 expression in contusion core vs. penumbra after controlled cortical impact ( $4.5 \mathrm{~mm}$ tissue displacement, velocity $=1 \mathrm{~m} / \mathrm{s}$ velocity, dwell time $=200 \mathrm{~ms}$ ) [29]. In that work, expression of SUR1 in core tissue varied temporally; it was highest at $6 \mathrm{~h}$, remained elevated at $12 \mathrm{~h}$, decreased at $24 \mathrm{~h}$, and was upregulated again at $72 \mathrm{~h}$. Further evaluation of specific cell-types of SUR1 upregulation in the core was informative. During the first $24 \mathrm{~h}$, SUR1 upregulation was predominantly in microvessels (with TRPM4 co-localization); however, at $72 \mathrm{~h}$, SUR1 expression was in small round cells (likely microglia/macrophages) with co-expression of both TRPM4 as well as KIR6.2 subunits. Penumbral expression at all time points was in GFAP+ glia, consistent with astrocytes-again with all three subunits present (SUR1, TRPM4, KIR6.2).

\section{TBI-In Vivo Channel Blockade}

SUR1-TRPM4 inhibition, most often with glibenclamide, reduced cerebral edema, BBB permeability, hemorrhage progression, and functional deficits in multiple independent studies of preclinical TBI models [29,30,32,33,35,43-45,112]. Benefits have been reported across different species (mice, rats), severities, and models of TBI including fluid percussion injury (FPI), cranial blast injury, and controlled cortical impact (CCI), although most studies were performed in CCI. The maximal benefit is likely also in CCI/contusional injury; Glibenclamide was one of only two drugs demonstrating benefit in Operation Brain Trauma Therapy (OBTT). The OBTT consortium evaluates promising preclinical therapies in TBI in a multi-center, randomized, blinded fashion across three different models: FPI, penetrating ballistic-like brain injury, and CCI [141,142]. In OBTT, glibenclamide significantly improved lesion volume as well as motor function in CCI, without any benefits noted in FPI or penetrating injury [33].

In two independent laboratories, glibenclamide reduced BBB breakdown at $24 \mathrm{~h}$ by approximately 2 -fold in both rat and mouse models of CCI [26,44]. A temporal analysis revealed a benefit of glibenclamide treatment on BBB integrity with reduced blood extravasation notable as early as $3 \mathrm{~h}$; this became statistically significant by $6 \mathrm{~h}$ post-injury, and had maximal benefit by $12 \mathrm{~h}$ [26]. Much like the results obtained in preclinical models of SAH (Section 3.4) and ICH (Section 3.6), treatment with glibenclamide was associated with decreased loss of ZO-1 and occludin in endothelial cells [44]. Cerebral edema, as measured by wet/dry weight, has also been reduced after glibenclamide treatment in CCI, by as much as $66 \%[26,43,143]$. Diffuse/contralateral edema that develops after CCI plus clinically relevant second insults such as hypotension (modeling hemorrhagic shock) has also been demonstrated to benefit from glibenclamide treatment [32].

Hemorrhage progression after CCI appeared to be halted/reduced by 45 min with no additional extravasated blood at $24 \mathrm{~h}$ compared with this hyperacute timepoint after glibenclamide treatment [26]. Similar results were observed with antisense oligodeoxynucleotides against $A b c c 8$ and Trpm4, with reduced hemispheric swelling and hemorrhage progression vs. controls after CCI [26,29]. Given the protective effects of glibenclamide on maintaining BBB integrity, it is not surprising that when hemorrhage progression after CCI was quantified, it was reduced by almost $60 \%$ in glibenclamide-treated rats [29]. In- 
deed, a third independent laboratory group demonstrated consistently reduced contusion volumes as measured by MRI at $8 \mathrm{~h}, 24 \mathrm{~h}, 72 \mathrm{~h}$, and 7 days post-injury in a rat model of CCI [43]. In mice with global genetic deletion of $A b c c 8$, contusion volumes were smaller, and hemispheres contralateral to injuries were larger (i.e., had less atrophy); this appeared to be influenced by sex, with less global atrophy in male but not female mice [35]. In vitro experiments suggest that these effects may be mediated by the SRY gene on the Y chromosome, and stimulation of $A B C C 8$ promoter activity [35]. This has not been reported with pharmacological channel blockade using glibenclamide, which may have different effects than constitutive, complete and global $A b c c 8$ knockout, including off-target actions that are not sex-dependent. Interestingly, in this study, $A b c c 8$ knockout naïve male mice had lower brain volumes, potentially suggesting a teleological role for SUR1 in CNS development that may be more important in males [35]. Further study of sex-based differences is warranted, particularly in the context of ongoing and future clinical trials (Section 3.2.2).

\subsubsection{TBI-Clinical Studies}

\section{TBI-Human Expression Patterns}

Human expression patterns of SUR1 \pm TRPM4 after TBI, particularly in contusional/ pericontusional tissue, are analogous to patterns reported in rodent models (Section 3.2.1, Figure 6) $[29,38,139]$. In a cohort of 26 patients with contusions, SUR1 expression was markedly higher compared with controls $(\sim 3 \times, p<0.001)$ [38]. Neuronal SUR1 was detected by $6 \mathrm{~h}$ post-TBI, peaking at $24 \mathrm{~h}$. In contrast, levels remained persistently elevated up to $100 \mathrm{~h}$ in $\mathrm{CD} 31^{+}$endothelial cells. SUR1 levels were also moderately elevated in astrocytes $\left(\mathrm{GFAP}^{+}\right)$, activated microglia, and neutrophils vs. control tissue. In a separate study of contusion specimens obtained from 32 patients, KIR6.2 was also found to be overexpressed in contusional astrocytes (consistent with findings in rodents) but not significantly elevated in either neurons or microglia vs. controls [139]. A nuanced map of regional SUR1, TRPM4 and KIR6.2 in the contusion core and penumbra was performed, analogous to the assessment in rodents by the same investigators (Section 3.2.1), and revealed a general consistency in results across species. SUR1-TRPM4 co-localization and co-assembly (by FRET imaging) was present in both microvessels and $\mathrm{CD} 68^{+}$round cells thought to be microglia/macrophages in the GFAP ${ }^{-}$contusion core [29]. KIR6.2 was also expressed in the small round $\mathrm{CD}^{+} 8^{+}$cells but did not co-localize with SUR1. SUR1 expression in the GFAP ${ }^{+}$penumbra was predominantly astrocytic rather than in microvessels/microglia, with heteromeric co-assembly of SUR1-TRPM4 as well as SUR1KIR6.2. Neuronal expression of SUR1-TRPM4 in human contusion was not reported in this study.

SUR1 levels have also been explored in the CSF of adult and pediatric TBI patients $[24,34]$. The utility of SUR1 \pm TRPM4 as a potential theragnostic biomarker is uniquely afforded by its de novo upregulation after CNS injury. Two small pilot studies have suggested markedly elevated CSF SUR1 levels in serial samples obtained from 28 adult [24] and 16 pediatric [34] patients with severe TBI. In adults, CSF SUR1 was elevated in all patients, vs. being undetectable in 15 controls with normal pressure hydrocephalus; in some patients, the ICP trajectory mirrored SUR1 expression after a temporal delay. Mean and peak SUR1 levels were associated with radiographic CT edema, and the initial degree of intracranial hypertension. Declining SUR1 levels between 48 and $72 \mathrm{~h}$ were associated with favorable prognosis: no patients had any intracranial hypertension or unfavorable outcomes [24]. In the pediatric cohort, samples (obtained from the "Cool Kids" randomized controlled trial), SUR1 expression was more nuanced: SUR1 was undetectable in all control CSF samples, and was elevated in 9 of the 16 patients with severe TBI. In this small sample, therapeutic hypothermia was not associated with SUR1 levels. CSF SUR1 was associated with increased ICP over 7 days $(p=0.004)$, and worse functional outcomes $(p=0.004)$. Patients who had SUR1 detected in any CSF sample after $24 \mathrm{~h}$ (regardless of level), had higher ICP values $(p=0.034)$ and worse functional outcomes at 12 months $(p=0.045)$ [34]. 


\section{TBI-Human Genetic Variation}

Based on the aforementioned biomarker studies, the same research group hypothesized potential genetic variation contributing to heterogeneity in SUR1 levels [135-137,144]. In a series of targeted investigations into the impact of $A B C C 8$ and TRPM4 genetic variability on secondary injury after TBI in a single-center cohort of 385-485 patients with severe TBI, they identified several regionally clustered polymorphisms in both genes that were consistently associated with measures of intracranial hypertension, radiographic edema, and hemorrhage progression. The effect sizes were large, and findings were biologically consistent $[135-137,144,145]$. Although only approximately $1 \%$ of polymorphisms in $A B C C 8$ (and TRPM4) are linked with brain-specific mRNA levels (i.e., brain-specific expression quantitative trait loci; eQTL), all the single nucleotide polymorphisms identified as significantly associated with hemorrhage progression after TBI were eQTLs with biologically concordant effects. For example, $A B C C 8$ eQTLs associated with increased brain-specific $A B C C 8 \mathrm{mRNA}$ levels were also associated with increased odds of hemorrhage progression [145]. Regulatory annotations of these regions further revealed promotor and enhancer marks, as well as active brain-tissue transcription start sites. Regions in linkage disequilibrium with these spatially clustered polymorphisms encoded both the SUR1 site, as well as the interface/juxtaposition between the two subunits (i.e., SUR1 and TRPM4), suggesting potential functional or splicing consequences. Interestingly, significant interactions between $A B C C 8$ and TRPM4 single nucleotide polymorphisms (SNPs) have also been reported, where certain genotype combinations containing risk alleles in both genes markedly and consistently increase the odds of several measures of intracranial hypertension [136]. The true consequences of these polymorphisms are yet to be evaluated in biological models, be it channel structure, function, regulation, expression, and/or post-translational modification. Nonetheless, identifying and validating patho-biologically relevant genetic variation in this pathway could have valuable implications for the design of future clinical trials, and could also inform novel targets and drug discovery (Figure 7). Given the small sample sizes available for genetic studies in TBI, unbiased genome-wide association studies have not yet validated these findings—but these important initiatives are ongoing in a large transatlantic multi-center effort known as GAIN (Genetic Associations in Neurotrauma). However, even such large-scale studies are limited in terms of severe TBI patients, and may be underpowered to detect contributions of ABCC8-TRPM4 genetic variation to secondary injury.

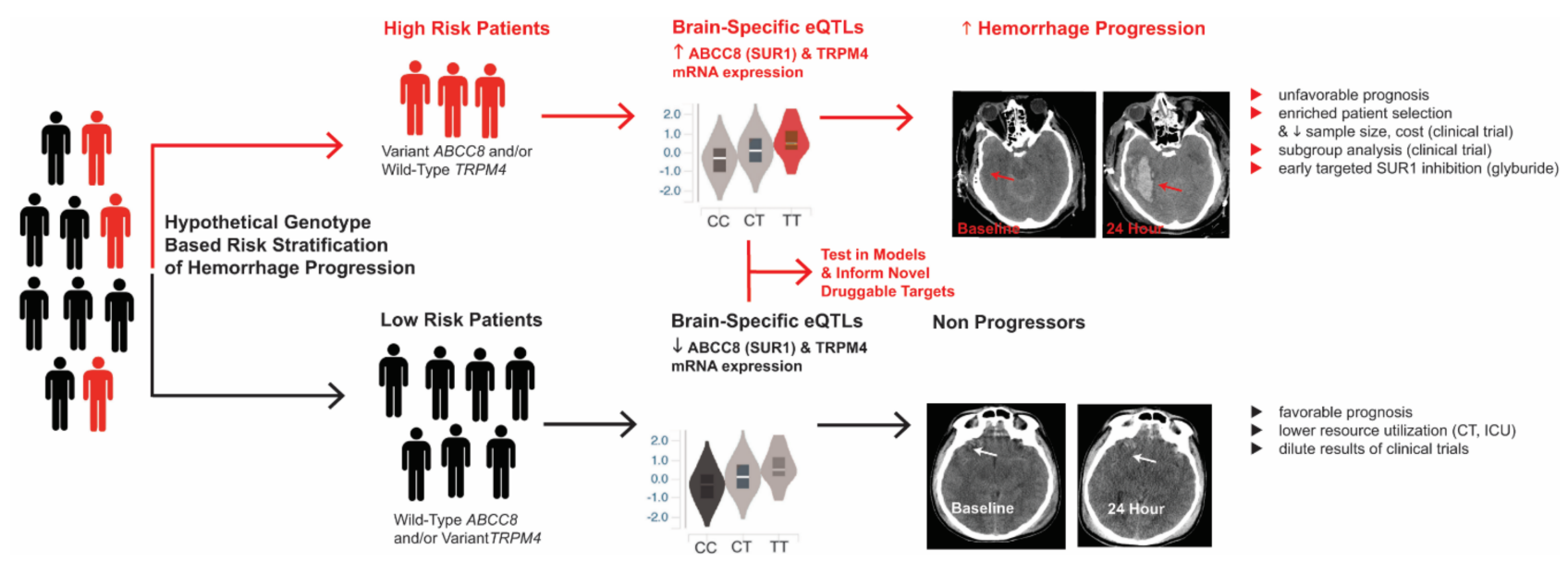

Figure 7. Hypothetical schematic example of precision medicine using genotype-based risk stratification of hemorrhage progression. Patients with high-risk genotypes of $A B C C 8$ or TRPM4 variants (red) may have higher levels of channel mRNA and/or protein expression and in turn be at higher risk of hemorrhage progression after traumatic brain injury. Genotype-based stratification could inform clinician prognostication, enrich patient selection/decrease sample size and cost of clinical trials, guide subgroup analyses, and also be valuable for discovery of novel therapeutic targets based on gene expression/regulation/post translational modifications in this pathway. 


\section{TBI-Clinical Trials}

Oral glibenclamide after TBI has been tested in two small randomized single-center clinical trials in Iran with encouraging results $[42,138]$. Randomization of 40 patients with diffuse axonal injury to $1.25 \mathrm{mg}$ glibenclamide every $12 \mathrm{~h}$ for 1 week (or until ICU discharge) resulted in improved functional outcomes at discharge in the treatment group vs. control, as measured by the Glasgow Coma Scale (GCS) scores, and Glasgow Outcome Scale scores (all $p<0.004$ ). In contusional TBI, randomization of 66 patients to either $10 \mathrm{mg}$ oral glibenclamide vs. placebo resulted in lower contusion expansion ratios between baseline to day $3(p<0.001)$ and baseline to day $7(p<0.003)$. However, no differences were reported with absolute contusion volumes or functional outcomes [138].

Given the pharmacokinetic variability with intermittent oral glibenclamide dosing (supratherapeutic peaks, subtherapeutic troughs, influence of stomach $\mathrm{pH}$ on plasma levels), the intravenous formulation BIIB093 (see Section 3.1.2) was also tested in a small phase II multicenter randomized TBI trial [31]; 28 patients with GCS 4-14 were randomized to $72 \mathrm{~h}$ of BIIB093 within $10 \mathrm{~h}$ of injury; 14 of these patients had contusional TBI. Although the difference was not statistically significant $(p=0.15)$, the 7 patients with contusion who received the placebo had an increase in lesion volume by $1036 \%$ from baseline vs. the 7 with contusional TBI who received BIIB093, in whom lesion volume increased by $136 \%$. The change in hemorrhage volumes was also not significant, likely due to the small sample size, but hemorrhage volumes in BIIB093 treated patients decreased $29.6 \%$ vs. increased by $11.6 \%$ with placebo. In MRI measures of edema, treated patients had no differences between lesional vs. uninjured white matter, unlike untreated patients, where increased edema was detected within the lesion $(p<0.02)$.

Driven by the promising preclinical and molecular data in contusional TBI, a larger Phase II trial (http://clinicaltrials.gov/: NCT03954041) entitled Antagonizing SUR1TRPM4 To Reduce the progression of intracerebral hematomA and edema surrounding Lesions (ASTRAL) is actively recruiting patients with contusional TBI to specifically evaluate effects of BIIB093 in this injury subgroup [11]. This is a multicenter, double-blind, multi-dose, placebo-controlled, randomized, clinical trial sponsored by Biogen. Enrollment in ASTRAL of 160 patients across multiple centers in North America, Europe, and Japan is planned. Two doses will be tested ( $3 \mathrm{mg} /$ day vs. $5 \mathrm{mg} /$ day for 4 days) with treatment initiation within $6.5 \mathrm{~h}$ of injury. The tighter treatment window (vs. in large hemispheric infarction) is in the context of the underlying biology based on the temporal course of microvascular SUR1-TRPM4 expression, as well as the known risk-window for contusion expansion. The primary outcome of this trial is radiographic: contusion expansion by $96 \mathrm{~h}$. Secondary outcomes include evaluating effects of BIIB093 on acute neurologic status, functional outcomes, and survival [11].

\subsection{SCI}

Traumatic spinal cord injury (SCI) is a devastating condition that results in blood vessel shearing and an immediate 'primary hemorrhage'. Over time, similar to hemorrhage progression in TBI, this initial lesion may evolve/progress, resulting in a phenomenon termed "progressive hemorrhagic necrosis" (PHN) $[6,9,146]$. Given the expression of SUR1TRPM4 in microvascular cells and their putative contributions to PHN, several studies have explored this channel and its inhibition in SCI with promising results $[27,28,147-150]$, and a clinical trial is recruiting [151].

\subsubsection{SCI-Preclinical Studies}

\section{SCI-In Vivo Expression Patterns}

In both mice and rat SCI models, SUR1 protein and $A b c c 8$ mRNA upregulation has been demonstrated in neurons, white matter, and microvascular cells using immunoblot analysis, immunohistochemistry, and in situ hybridization (Table 5) [27,28]. In severe unilateral SCI in rats (10 gm weight dropped from $2.5 \mathrm{~cm}$ ), SUR1 upregulation was prominent in tissues surrounding the necrotic lesion; by $24 \mathrm{~h}$, the lesion was larger, and SUR1 
upregulation extended to distant tissues including the contralateral hemicord [28]. In the core lesion, labeling was noted in both neuronal and capillary-like structures, but in the penumbra, upregulation appeared limited to the microvasculature. SUR1 upregulation after SCI has also been demonstrated in mice, again in several cell types including oligodendrocytes as well as neurons [27]. Similar expression patterns have been observed in mice, rats, and humans, indicating cross-species preservation of this pathway after spinal trauma [27]. Concurrent neuronal and microvascular upregulation of TRPM4 in SCI rodent models has also been demonstrated [5,28,152]. Co-immunoprecipitation experiments and FRET analyses have demonstrated the formation of abundant SUR1-TRPM4 heteromers in multiple cell-types, including those of the microvasculature [5]. In all the aforementioned studies, uninjured spinal cords had minimal labelling. 
Table 5. Pre-clinical and clinical studies evaluating SUR1 inhibition for spinal cord injury (SCI).

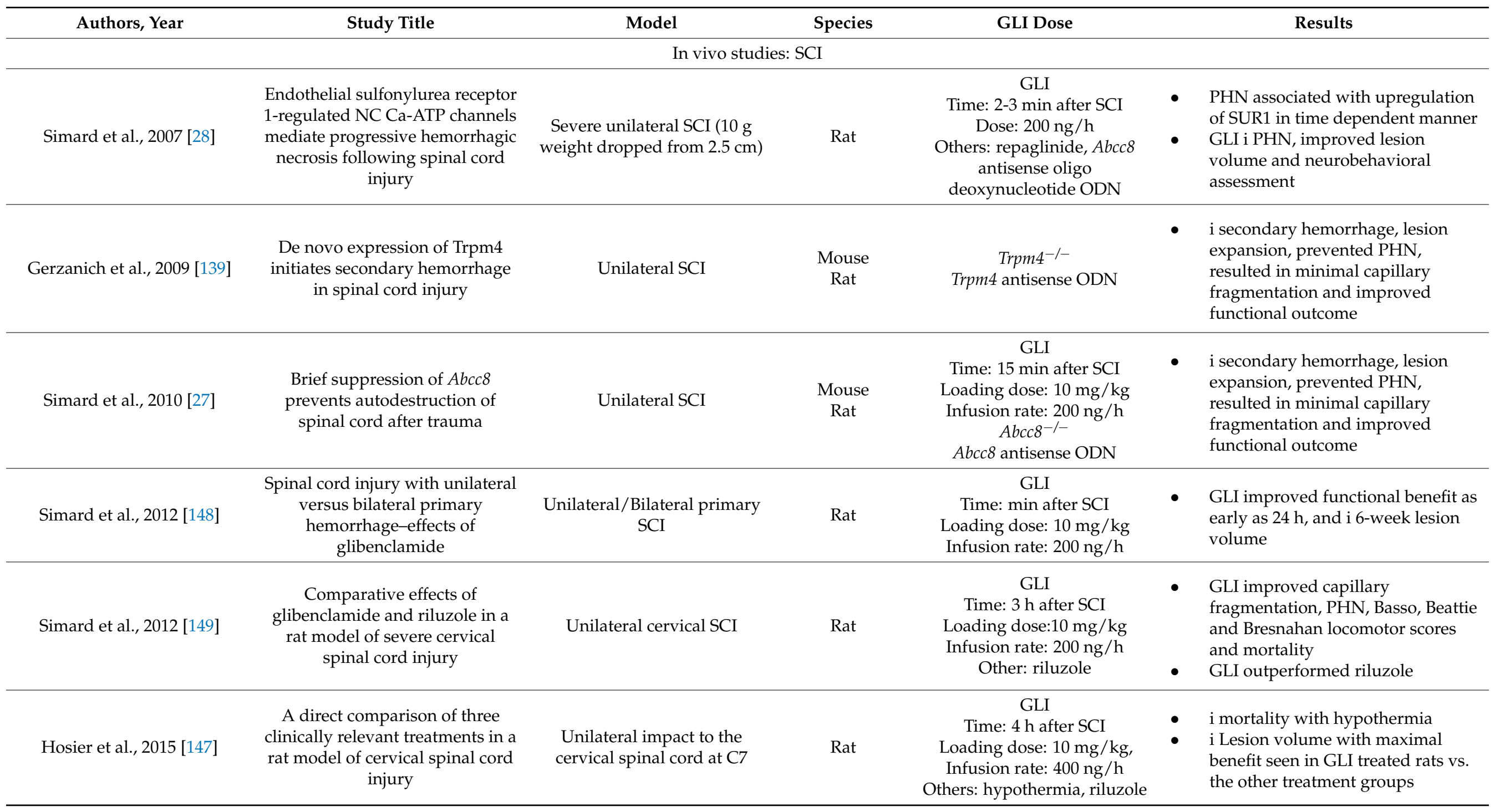


Table 5. Cont

\begin{tabular}{|c|c|c|c|c|c|}
\hline Authors, Year & Study Title & Model & Species & GLI Dose & Results \\
\hline Yao et al., 2018 [153] & $\begin{array}{c}\text { Flufenamic acid inhibits } \\
\text { secondary hemorrhage and BSCB } \\
\text { disruption after spinal cord } \\
\text { injury }\end{array}$ & Thoracic SCI & Mouse & Flufenamic acid & 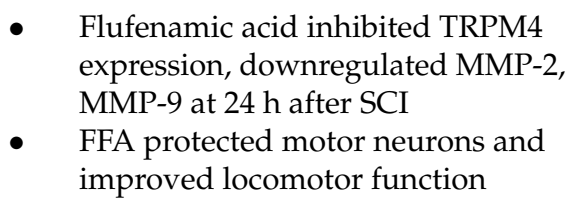 \\
\hline \multicolumn{6}{|c|}{ Human studies: SCI } \\
\hline Simard et al., 2010 [27] & $\begin{array}{l}\text { Brief suppression of } A b c c 8 \\
\text { prevents autodestruction of } \\
\text { spinal cord after trauma }\end{array}$ & $\begin{array}{c}\text { Autopsy sample from } \\
\text { patients with traumatic SCI }\end{array}$ & Human & NA & $\begin{array}{l}\text { - } \quad \text { Prominent penumbral SUR1 } \\
\text { expression } \\
\text { - } \quad \text { SUR1 in white matter and neurons }\end{array}$ \\
\hline
\end{tabular}




\section{SCI-In Vivo Channel Blockade}

The benefits of channel blockade in SCI have been demonstrated using several strategies including gene deletion, suppression (anti-sense oligodeoxynucleotides, ODN), and pharmacological inhibition of either the SUR1 or TRPM4 subunit [27,28,147-150,152]. All approaches have yielded similar histological and functional results.

Unilateral SCI in both $A b c c 8^{-/-}$mice and Trpm $4^{-/-}$mice reduced secondary hemorrhage and lesion expansion, prevented PHN, resulted in minimal capillary fragmentation, and improved functional outcomes at 1 week vs. wild-type $[27,152]$. These findings were corroborated in rats treated with anti-sense ODNs against $A b c c 8$; lesion volumes were reduced to $25 \%$ of controls [27]. Pharmacological inhibition of SUR1TRPM4 has been reported using SUR1-binding drugs (glibenclamide and repaglinide) or via targeting sodium currents and TRPM4 (riluzole, flufenamic acid), as shown in Table $5[5,27,28,147-150,152,154,155]$. However, specific pharmacological blockade of TRPM4 has not been reported, likely due to the non-specificity of drugs for this subunit in the context of structural similarities with other ion channels [9]. Riluzole, for example, also inhibits excitotoxicity - potentially via blocking glutamate release.

To date, seven studies of pharmacological SUR1-TRPM4 inhibition in SCI have been reported, six from the same group, with confirmatory findings from an independent laboratory - all of which have demonstrated benefits regardless of the laterality and initial severity of injury. One of the first reports was in a rat model of unilateral cervical spinal cord injury: here, PHN was associated with upregulation of SUR1 in a time-dependent manner in capillaries and post-capillary venules [28]. Glibenclamide reduced PHN and capillary fragmentation within $24 \mathrm{~h}$, spared both contralateral and ipsilateral white matter tracts, and improved both lesion volume and neurobehavioral assessments at 7 days [28]. Lesion volumes were reduced approximately 3 -fold compared to controls. In this study, the reduction in PHN was reproduced with in vivo gene suppression of $A b c c 8$ using antisense ODNs, which are taken up preferentially by penumbral microvessels in the spinal cord [28]. Similar results were obtained independently by another group, confirming the attenuation of PHN and improvement in functional outcomes after SCI with glibenclamide treatment [150]. The benefits of glibenclamide extended to bilateral primary SCI in a rat model: glibenclamide-treated rats had improved functional benefits as early as $24 \mathrm{~h}$, and reduced lesion volumes at 6 weeks. Nonetheless, the effect sizes were smaller compared to unilateral SCI. Lesion volumes after treatment with glibenclamide in bilateral SCI were $33 \%$ smaller than controls, vs. 57\% reduction after unilateral injury [148].

The benefits of glibenclamide after unilateral rat cervical SCI are measurable radiographically. T2 sequences on MRI proved to be an accurate, non-invasive imaging biomarker in a study of 28 female rats [154]. Here, an approximately 2.3-fold expansion in lesion volume was quantified within $24 \mathrm{~h}$ after injury in control rats, but only a $20 \%$ increase in those treated with glibenclamide. These values corresponded closely with measures of hemorrhagic contusion in tissue sections. This has important implications for future clinical trial design, including in terms of quantifying and endophenotyping the treatment effects of SUR1-TRPM4 inhibition.

Riluzole has been reported to significantly improve motor recovery, locomotion and functional neurological outcomes in a variety of SCI animal models [156]. Comparisons between glibenclamide $(200 \mathrm{ng} / \mathrm{h})$ vs. riluzole in a rat model of cervical SCI associated with high mortality, revealed similar acute improvement after either drug in terms of capillary fragmentation, PHN, Basso, Beattie and Bresnahan locomotor scores, and mortality [149]. However, glibenclamide resulted in better tissue sparing, as well as improved measures of complex function (grip strength, rearing, accelerating rotarod) [149]. Of note, both drugs were initiated at $3 \mathrm{~h}$ post-injury, and continued for 7 days. A subsequent study compared glibenclamide, riluzole, and systemic hypothermia after unilateral rat SCI, with further delayed administration of treatment at $4 \mathrm{~h}$ post-injury, as well as a higher dose of glibenclamide (400 ng/h) [147]. In this work, mortality was high without treatment (30\%), 
and also with riluzole (30\%). Reduced mortality was noted with hypothermia (12.5\%), and none of the rats in the glibenclamide-treated group died. Amongst the survivors, glibenclamide and hypothermia demonstrated similar efficacy, as measured by locomotor scores (modified Basso, Beattie and Bresnahan); riluzole was inferior to both treatments in the acute setting ( 2 weeks). However, all three treatments were similar by the last four weeks of the study. Lesion volumes vs. controls were reduced in all treatment groups, with the maximal benefit seen in glibenclamide-treated rats.

Drugs other than glibenclamide that impact MMP-9, SUR1 and/or TRPM4 have also been evaluated after SCI $[153,157,158]$. In a rat model of moderate thoracic SCI, immediate intraperitoneal treatment with ghrelin $(80 \mathrm{mg} / \mathrm{kg}$, followed by the same dose every $6 \mathrm{~h}$ for 1 day) decreased blood-spinal cord barrier (BSCB) dysfunction, reduced MMP-9, SUR1 and TRPM4 expression, and lessened macrophage and neutrophil infiltration after injury [158]. These effects were reported to be mediated by ghrelin receptor 1A; the benefit was lost when rats were administered a receptor antagonist. In a separate study using the same model of SCI, $150 \mathrm{mg} / \mathrm{kg}$ of immediate mithramycin A (MA) injection (followed by daily injections of the same dose for 5 days) decreased blood-spinal cord barrier breakdown, inhibited infiltration of neutrophils and macrophages, and decreased the expression of MMP-9, SUR1 and TRPM4 [157]. In this study, MA treatment reduced apoptosis and improved functional recovery. Recently, flufenamic acid (FFA) was evaluated in a thoracic SCI model using moderate contusion at T10; intraperitoneal FFA was injected $1 \mathrm{~h}$ after injury, and then dosed daily for 1 week [153]. Treatment with FFA inhibited TRPM4 expression (immunohistochemical localization, RT-PCR, western blot), secondary hemorrhage, and capillary fragmentation, and promoted angiogenesis (immunohistochemistry for vWF and KI-67 co-labeled vessel) [153]. FFA significantly downregulated the expression of MMP-2 and MMP-9 at $24 \mathrm{~h}$ after SCI, and significantly attenuated blood-spinal cord barrier (BSCB) disruption at 1 day and 3 days after injury. FFA treatment protected motor neurons and improved locomotor function following SCI.

Similar to TBI, the SUR1-TRPM4 pathway and its inhibition in traumatic SCI may have differential effects based on sex-in this case, hormonally mediated [159]. In a rat model of moderate thoracic SCI, immediate treatment of male rats with $17 \mathrm{~b}$-estradiol (E2, $300 \mathrm{mg} / \mathrm{kg}$, followed by the same dose at $6 \mathrm{~h}$ and $24 \mathrm{~h}$ post-injury) reduced BSCB breakdown, progressive hemorrhage, and infiltration of inflammatory cells such as neutrophils and macrophages. SUR1, TRPM4, MMP-9 and ZO-1 expression were also all reduced with E2 treatment. Functional improvement was also noted. All protective effects were negated with treatment by an estrogen receptor antagonist [159].

\subsubsection{SCI-Clinical Studies \\ SCI-Human Expression Patterns}

Autopsy samples from seven patients who died from traumatic SCI demonstrated prominent penumbral SUR1 expression that tapered distally from the epicenter [27]. Upregulation was noted for both SUR1 protein (immunofluorescence) and $A b c c 8$ mRNA (in situ hybridization) expression. Similar to findings in rodent models (Section 3.3.1), expression in humans was demonstrated in both white matter, microvascular endothelial cells, and neurons.

\section{SCI-Clinical Trials}

To date, no results from clinical trials testing glibenclamide or other pharmacological SUR1-TRPM4 inhibition in SCI have been reported. A pilot open label multicenter prospective evaluation of oral glyburide entitled SCING (Spinal Cord Injury Neuroprotection with Glyburide, NCT02524379) is active but not currently recruiting. The primary objective of this initial phase multi-center open-label pilot study is to enroll 10 patients with traumatic SCI to assess the feasibility and safety of receiving oral glyburide within $8 \mathrm{~h}$ of injury [151]. Secondary objectives include both radiographic and blood-based biomarker discovery, as well as impact on neurological recovery. 


\section{4. $S A H$}

Secondary brain injury after aneurysmal SAH involves cerebral edema, vasospasm, neuroinflammation, delayed cerebral ischemia and both early and delayed impairment in cognition. Emerging data suggest the involvement of the SUR1-TRPM4 channel in these processes after SAH (Table 6) [36,37,40,128].

\subsubsection{SAH-Preclinical Studies}

\section{SAH-In Vivo Expression Patterns}

In a rat model of mild-moderate SAH using a filament-based endovascular puncture of the internal carotid artery, in situ hybridization detected strong expression of $A b c c 8$ mRNA in neurons and microvessels in the inferomedial cortex (i.e., adjacent to the region of SAH) [40]. Immunoblot and immunohistochemistry demonstrated SUR1 protein upregulation at $24 \mathrm{~h}$-particularly in neurons and microvascular cells. This was noted both in the path of direct injury (inferomedial cortex) as well as in distal structures in the posterior cerebral artery territory. In vitro studies in the same report demonstrated that SUR1 transcription was activated by TNFa. Subsequent work from the same laboratory studied SUR1-TRPM4 expression 24-48 h after SAH. Both subunits were upregulated in cortical microvessels, neurons and astrocytes, with minimal expression of KIR6.2 [160]. Co-association of SUR1-TRPM4, but not KIR6.2, was confirmed using FRET analysis. Compared with controls, co-immunoprecipitation experiments revealed an 8-fold increase in co-associated SUR1-TRPM4.

\section{SAH-In Vivo Channel Blockade}

Both studies presented in Section 3.4.1 also evaluated SUR1-TRPM4 channel inhibition with glibenclamide after SAH. Treatment with a $10 \mu \mathrm{g} / \mathrm{kg}$ loading dose followed by $200 \mathrm{ng} / \mathrm{h}$ reduced BBB disruption, as measured by IgG extravasation, and decreased both local inflammation (TNFa and NF- $\mathrm{KB}$ immunolabeling) as well as reactive astrogliosis [40]. Moreover, in this study, rats treated with glibenclamide had minimal or no caspase-3 activation in the posterior cerebral artery territory, unlike untreated rats, suggesting that this drug may reduce TNFa induced apoptosis.

Two different rat models of SAH demonstrated similar benefits with SUR1 inhibition: the first with blood injection into the subarachnoid space of the entorhinal cortex, and the second with filament puncture of the internal carotid artery [36]. In both models, antisense ODN against $A b c c 8$ and glibenclamide reduced SAH-induced BBB disruption. These interventions also reduced TNFa expression in adjacent cortex by approximately 4-fold. The benefits of glibenclamide extended to tissue preservation as quantified by Black Gold II, Fluoro-Jade C, and DAPI staining of pyknotic nuclei. In models with entorhinal $\mathrm{SAH}$, glibenclamide-treated rats had improved functional outcomes, including platform search strategies and rapid spatial learning tasks.

The neuropeptide PACAP (pituitary adenylate cyclase-activating polypeptide) has recently demonstrated potential benefits in rat $\mathrm{SAH}$ via a mechanism that possibly involves SUR1 [110]. Exogenous PACAP38 treatment preserved BBB function, accelerated CSF movement/clearance, attenuated $24 \mathrm{~h}$ brain edema, and improved neurological functional deficits, as measured by modified Garcia scores and beam balance tests [110]. In this study, the PACAP receptor (PAC1) signaling pathway involving adenylate cyclase, cyclic AMP, and protein kinase $\mathrm{A}$ was thought to contribute to neuroprotection via phosphorylation and degradation of SUR1. Increased SUR1 expression after SAH was associated with MMP-9 elevation and ZO-1 reduction; PACAP38 reversed these effects-MMP-9, SUR1, and AQP4 expression were reduced, and ZO-1 expression was preserved [110]. 
Table 6. Pre-clinical and clinical studies evaluating SUR1 inhibition for subarachnoid hemorrhage (SAH).

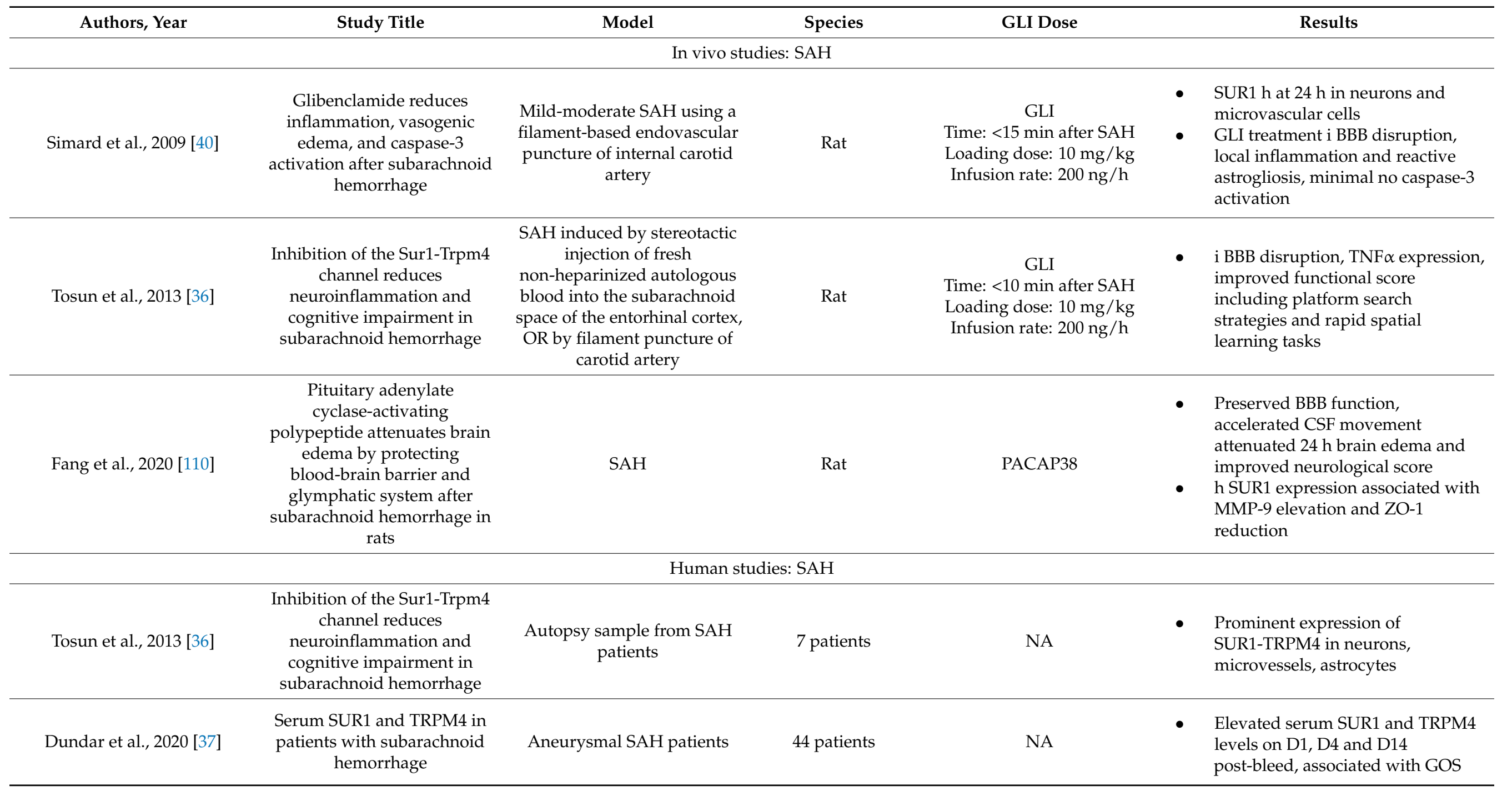




\subsubsection{SAH-Clinical Studies}

SAH-Human Expression Patterns

Human SUR1 expression has been evaluated by immunohistochemistry in autopsy specimens from seven patients with aneurysmal SAH and compared with five normal brains with documented absence of SAH, ischemia or identifiable CNS pathology [36]. In all cases of SAH, SUR1-TRPM4 was abundantly expressed in microvessels, neurons, and astrocytes; based on semi-quantitative analysis, expression was always greater than levels noted in control brains, although the relative abundance varied between cases. FRET analysis demonstrated formation of SUR1-TRPM4 heteromers in both neurons and microvessels. A prospective study of 44 consecutive patients with aneurysmal SAH reported elevated serum SUR1 and TRPM4 levels (on days 1, 4, and 14 post-bleed) vs. controls-the latter recruited from outpatient headache clinics with negative head imaging on CT and/or MRI [37]. In this pilot study, day 14 serum SUR1 $(p=0.001)$ and TRPM4 $(p=0.044)$ levels were correlated with the GOS score.

\section{SAH-Clinical Trials}

There are no reports of SUR1-TRPM4 inhibition in human SAH. A randomized doubleblind clinical trial, GASH (Glibenclamide in Aneurysmatic Subarachnoid Hemorrhage), is currently recruiting in São Paulo (NCT03569540). The investigators are evaluating the benefits of $5 \mathrm{mg}$ of oral glibenclamide for 21 days after aneurysmal SAH, with the goal of enrolling 50 patients [128].

\subsection{Cardiac Arrest}

Cerebral edema and neurological devastation are hallmarks of cardiac arrest, with no currently available pharmacological agents that proffer benefit. Varying degrees of hypothermia or targeted temperature management have shown promising results in clinical trials, but the data are nuanced and beyond the scope of this review [161-167]. The role of SUR1-TRPM4 in secondary injury after global ischemia from cardiac arrest has been reported, but is less well developed compared with focal ischemia from vessel occlusion.

\subsubsection{Cardiac Arrest-Preclinical Studies}

\section{Cardiac Arrest-In Vivo Expression Patterns}

In a 7 min murine model of asystolic cardiac arrest from $\mathrm{KCl}$ injection, $\mathrm{Abcc} 8$ and Trpm 4 mRNA levels were significantly upregulated at $6 \mathrm{~h}$ post-cardiopulmonary resuscitation; Trpm 4 levels remained elevated at $24 \mathrm{~h}$ [168]. In this model, hypothermia reduced $A b c c 8$ and Trpm 4 levels. Abcc 8 and Trpm 4 upregulation was accompanied by TNFa, IL-6, and NF-KB upregulation. Protein expression was not evaluated in this study. These findings were similar in rat models of asphyxial cardiac arrest. After 8 min asphyxial cardiac arrest, both $A b c c 8$ and Trpm 4 mRNA, as well as SUR1-TRPM4 protein (western blot), were upregulated in the cortex and hippocampus at $24 \mathrm{~h}$ after injury [169]. In a $10 \mathrm{~min}$ rat model of asphyxial cardiac arrest, both Abcc8 and Trpm 4 mRNA, as well as SUR1-TRPM4 protein (by western blot and immunohistochemistry), were upregulated at $6 \mathrm{~h}$ and peaked at $24 \mathrm{~h}$ [170]. Immunohistochemistry demonstrated that positive cells were predominantly in the cortex and CA1 hippocampal region; by $72 \mathrm{~h}$, SUR1 was expressed in several cell types including neurons, endothelial cells, microglia, and astrocytes.

\section{Cardiac Arrest-In Vivo Channel Blockade}

One of the first studies of glibenclamide in cardiac arrest was performed in a rat model of $8 \mathrm{~min}$ asphyxial cardiac arrest [169]. Glibenclamide treatment $(10 \mathrm{mg} / \mathrm{kg}$ loading dose, $1.2 \mathrm{mg}$ at $6,12,18$ and $24 \mathrm{~h}$ ) increased 7-day survival, reduced neurological deficit scores, and reduced hippocampal neuronal loss vs. the untreated vehicle group. This study also demonstrated histopathological evidence of neuroprotection (reduced apoptosis and neuronal necrosis) acutely, at $24 \mathrm{~h}$. Furthermore, glibenclamide reduced TNFa and 
monocyte chemokine protein 1 levels after return of spontaneous circulation. The same group compared the effects of glibenclamide with targeted temperature management after rat asphyxial cardiac arrest, and found similar levels of protection between the two treatment strategies in terms of reduced neuronal injury and neurological deficit compared to untreated rats at several time points up to 7 days [170]. A follow-up study by the same investigators utilized MRI parameters for quantification of benefits [171]. Here, cardiac arrest caused significant abnormalities with diffusion restriction, demonstrated by hyperintense diffusion weighted imaging at $72 \mathrm{~h}$. This corresponded with histopathological evidence of neuronal swelling, dendritic injury, and microglial/astrocytic activation. The abnormal diffusion restriction was alleviated by glibenclamide treatment within $72 \mathrm{~h}$. Glibenclamide also had a trend towards reducing neuronal loss at this time point, and significantly improved neurological deficit using the neurodeficit score.

An independent group evaluated the effects of glibenclamide after cardiac arrest in mice using a $\mathrm{KCl}$ injection model and evaluated the impact of the drug vs. the effects of hypothermia [168]. Similar findings were reported; glibenclamide significantly reduced brain water content at $24 \mathrm{~h}$ and improved BBB integrity with effects similar to those observed with hypothermia to $33^{\circ} \mathrm{C}$.

\subsubsection{Cardiac Arrest-Clinical Studies}

Cardiac Arrest-Human Expression Patterns

There are currently no studies reported of SUR1-TRPM4 expression after cardiac arrest in humans.

\section{Cardiac Arrest-Clinical Trials}

There are currently no reported or ongoing clinical trials of SUR1-TRPM4 inhibition after cardiac arrest.

\subsection{ICH}

The evaluation of SUR1 \pm TRPM4 and pharmacological inhibition of the channel by glibenclamide in primary ICH is less mature than current data in disease subtypes of ischemic stroke and TBI. Existing studies in ICH have yielded mixed results (Table 7) [143,160,172-177].

\subsubsection{ICH-Preclinical Studies \\ ICH-In Vivo Expression Patterns}

Aside from subarachnoid hemorrhage, two of the earliest studies evaluating this pathway in primary hemorrhagic disease were in hemorrhagic encephalopathy of prematurity/germinal matrix hemorrhage $[160,177]$. The first, studied in human infant tissue, is summarized below (Section 3.6.2). In the rat model of hemorrhagic encephalopathy of prematurity, $20 \mathrm{~min}$ of intrauterine ischemia followed by an intraperitoneal injection of glycerol (to elevate venous pressure) resulted in periventricular hemorrhages in rat pups [160]. Similar to the findings in human premature infants, SUR1 protein was upregulated in rat periventricular tissue by $24 \mathrm{~h}$ after intrauterine ischemia, and was negligible in control tissues. SUR1 upregulation was noted in several regions including the choroid plexus, ependymal lining of the lateral ventricles, internal capsule, subventricular zone, corpus callosum and hippocampus, but most prominently in microvascular cells. In an autologous blood-induced rat model of ICH, SUR1 but not KIR6.2 protein was found to be upregulated by immunofluorescence in perihematomal neurons and endothelial cells at $24 \mathrm{~h}$ [172]. No upregulation was noted in microglia at either $24 \mathrm{~h}$ or $72 \mathrm{~h}$ after ICH. 
Table 7. Pre-clinical and clinical studies evaluating SUR1 inhibition for other neurological diseases.

\begin{tabular}{|c|c|c|c|c|c|}
\hline Authors, Year & Study Title & Model & Species & GLI Dose & Results \\
\hline \multicolumn{6}{|c|}{ In vivo studies: Cardiac arrest } \\
\hline Huang et al., 2015 [169] & $\begin{array}{c}\text { Glibenclamide improves } \\
\text { survival and neurologic } \\
\text { outcome after cardiac arrest } \\
\text { in rats }\end{array}$ & 8 min asphyxia cardiac arrest & Rat & $\begin{array}{c}\text { GLI } \\
\text { Time: } 10 \mathrm{~min} \\
\text { Loading dose: } 10 \mu \mathrm{g} / \mathrm{kg} \\
\text { Maintenance dose: } 1.2 \mu \mathrm{g} \text { at } 6 \text {, } \\
12,18,24 \mathrm{~h}\end{array}$ & $\begin{array}{l}\text { - } \quad \text { h Abcc8 and Trpm4 mRNA and } \\
\text { SUR1/TRPM4 protein } \\
\text { Increased 7-day survival, reduced } \\
\text { neurological deficit scores and } \\
\text { reduced hippocampal neuronal loss }\end{array}$ \\
\hline Huang et al., 2016 [170] & $\begin{array}{l}\text { Glibenclamide is comparable } \\
\text { to target temperature } \\
\text { management in improving } \\
\text { survival and neurological } \\
\text { outcome after asphyxial } \\
\text { cardiac arrest in rats }\end{array}$ & $\begin{array}{c}10 \text { min asphyxia cardiac } \\
\text { arrest }\end{array}$ & Rat & $\begin{array}{c}\text { GLI } \\
\text { Time: at randomization } \\
\text { Loading dose: } 10 \mu \mathrm{g} / \mathrm{kg} \\
4 \text { maintenance doses of } 1.2 \mu \mathrm{g} \\
\text { per } 6 \mathrm{~h} \text { after ROSC }\end{array}$ & $\begin{array}{ll}\text { - } & \mathrm{h} A b c c 8 \text { and Trpm } 4 \text { mRNA and } \\
\text { - } & \text { RUR1/TRPM4 protein } \\
& \text { Reduced neuronal injury and } \\
\text { neuronal deficit }\end{array}$ \\
\hline Huang et al., 2018 [171] & $\begin{array}{l}\text { Glibenclamide prevents } \\
\text { water diffusion abnormality } \\
\text { in the brain after cardiac } \\
\text { arrest in rats }\end{array}$ & $\begin{array}{c}15 \text { min asphyxia cardiac } \\
\text { arrest }\end{array}$ & Rat & $\begin{array}{c}\text { GLI } \\
\text { Time: } 15 \text { min post-ROSC } \\
\text { Loading dose } 10 \mu \mathrm{g} / \mathrm{kg} \\
\text { Maintenance: four } \\
\text { maintenance doses of } 1.2 \mu \mathrm{g} \\
\text { at } 6,12,18 \text {, and } 24 \mathrm{~h} \text { after } \\
\text { ROSC }\end{array}$ & $\begin{array}{l}\text { - } \quad \text { Abnormal diffusion restriction was } \\
\text { alleviated by GLI treatment within } \\
72 \mathrm{~h} \\
\text { - } \quad \begin{array}{l}\text { Reduced neuronal injury and } \\
\text { neuronal deficit }\end{array}\end{array}$ \\
\hline Nakayama et al., 2018 [168] & $\begin{array}{l}\text { Glibenclamide and } \\
\text { therapeutic hypothermia } \\
\text { have comparable effect on } \\
\text { attenuating global cerebral } \\
\text { edema following } \\
\text { experimental cardiac arrest }\end{array}$ & $\begin{array}{l}\text { CA induced by IV injection of } \\
0.05 \mathrm{~mL} \text { cold } 0.5 \mathrm{~mol} / \mathrm{L} \mathrm{KCL}\end{array}$ & Mouse & $\begin{array}{c}\text { GLI } \\
\text { Loading dose: } 10 \mathrm{mg} / \mathrm{kg} \\
\text { Maintenance dose: } 4 \mathrm{mg} / \mathrm{kg} \\
6 \mathrm{~h} \text { and } 18 \mathrm{~h} \text { post ROSC }\end{array}$ & $\begin{array}{l}\text { - } \quad \text { Abcc } 8 \text { and Trpm } 4 \text { mRNA5 at } 6 \mathrm{~h} \\
\text { post cardiopulmonary resuscitation } \\
\text { - } \quad \text { i TNF } \alpha \text {, IL-6 and NFKB }\end{array}$ \\
\hline
\end{tabular}


Table 7. Cont.

\begin{tabular}{|c|c|c|c|c|c|}
\hline Authors, Year & Study Title & Model & Species & GLI Dose & Results \\
\hline \multicolumn{6}{|c|}{ In vivo studies: Intracerebral hemorrhage (ICH) } \\
\hline Tosun et al., 2013 [160] & $\begin{array}{l}\text { The protective effect of } \\
\text { glibenclamide in a model of } \\
\text { hemorrhagic encephalopathy } \\
\text { of prematurity }\end{array}$ & $\begin{array}{l}\text { Model of hemorrhagic } \\
\text { encephalopathy induced by } \\
20 \text { min of intrauterine } \\
\text { ischemia, followed by an } \\
\text { intraperitoneal injection of } \\
\text { glycerol }\end{array}$ & Rat & $\begin{array}{l}\text { GLI } \\
\text { Time: immediately before } \\
\text { closing the laparotomy } \\
\text { Loading dose: } 10 \mu \mathrm{g} / \mathrm{kg} \\
\text { Infusion rate } 400 \mathrm{ng} / \mathrm{h}\end{array}$ & $\begin{array}{l}\text { - SUR1 } \mathrm{h} \text { in periventricular tissue by } \\
24 \mathrm{~h} \text { after intrauterine ischemia } \\
\text { SUR1 } \mathrm{h} \text { was also observed in } \\
\text { choroid plexus, ependymal lining } \\
\text { of lateral ventricles, internal } \\
\text { capsule, subventricular zone, } \\
\text { corpus callosum and hippocampus }\end{array}$ \\
\hline Jiang et al., 2017 [172] & $\begin{array}{l}\text { Role of glibenclamide in } \\
\text { brain injury after } \\
\text { intracerebral hemorrhage }\end{array}$ & $\begin{array}{l}\text { Autologous blood infusion } \\
\text { ICH model }\end{array}$ & Rat & $\begin{array}{l}\text { GLI } \\
\text { Time: end of surgery } \\
\text { Loading dose: } 10 \mu \mathrm{g} / \mathrm{kg} \text {, } \\
\text { Infusion rate: } 200 \mathrm{ng} / \mathrm{h}\end{array}$ & $\begin{array}{l}\text { - SUR1 h in perihematomal neurons } \\
\text { and endothelial cells } \\
\text { - GLI treatment i brain water content, } \\
\text { MMP expression and restored BBB } \\
\text { integrity }\end{array}$ \\
\hline Zhou et al., 2018 [175] & $\begin{array}{l}\text { Neuroprotective potential of } \\
\text { glibenclamide is mediated by } \\
\text { antioxidant and } \\
\text { anti-apoptotic pathways in } \\
\text { intracerebral hemorrhage }\end{array}$ & $\begin{array}{l}\text { Collagenase induced ICH } \\
\text { model }\end{array}$ & Rat & $\begin{array}{c}\text { GLI } \\
\text { Time: } 30 \mathrm{~min} \text { before surgery } \\
\text { Loading dose: } 10 \mu \mathrm{g} / \mathrm{kg} \text { i.p } \\
\text { Maintenance: } 1 \mathrm{mg} / \mathrm{kg} \text { daily }\end{array}$ & $\begin{array}{l}\text { - GLI regulated iNOS level in } \\
\text { microglia, h BCL-2/BAX ratio, i } \\
\text { perihematomal caspase-3 } \\
\text { expression and apoptosis }\end{array}$ \\
\hline Xu et al., 2019 [143] & $\begin{array}{l}\text { Glibenclamide ameliorates } \\
\text { the disrupted blood-brain } \\
\text { barrier in experimental } \\
\text { intracerebral hemorrhage by } \\
\text { inhibiting the activation of } \\
\text { NLRP3 inflammasome }\end{array}$ & $\begin{array}{l}\text { Autologous blood infusion } \\
\text { ICH model }\end{array}$ & Mouse & $\begin{array}{c}\text { GLI } \\
\text { Time: immediately after ICH } \\
\text { Dose:10 } \mu \mathrm{g} / \mathrm{kg} \text { i.p. }\end{array}$ & $\begin{array}{l}\text { - GLI i perihematomal levels of } \\
\text { cytokines, IL1 } \beta, \text { IL18, IL6, TNF } \alpha \text {, } \\
\text { reduced apoptotic cells }\end{array}$ \\
\hline Wilkinson et al., 2019 [174] & $\begin{array}{c}\text { Glibenclamide, a Sur1-Trpm4 } \\
\text { antagonist, does not improve } \\
\text { outcome after } \\
\text { collagenase-induced } \\
\text { intracerebral hemorrhage }\end{array}$ & $\begin{array}{l}\text { Collagenase induced ICH } \\
\text { model }\end{array}$ & Rat & $\begin{array}{c}\text { GLI } \\
\text { Time: } 2 \mathrm{~h} \text { post-ICH } \\
\text { Loading dose: } 10 \mu \mathrm{g} / \mathrm{kg} \\
\text { Infusion rate: } 200 \mathrm{ng} / \mathrm{h}\end{array}$ & $\begin{array}{l}\text { - GLI did not improve edema, BBB } \\
\text { integrity, lesion volume } \\
\text { - GLI did not improved neurological } \\
\text { impairment }\end{array}$ \\
\hline
\end{tabular}


Table 7. Cont.

\begin{tabular}{|c|c|c|c|c|c|}
\hline Authors, Year & Study Title & Model & Species & GLI Dose & Results \\
\hline Kung et al., 2021 [173] & $\begin{array}{c}\text { Glibenclamide does not } \\
\text { improve outcome following } \\
\text { severe collagenase-induced } \\
\text { intracerebral hemorrhage in } \\
\text { rats }\end{array}$ & $\begin{array}{l}\text { Collagenase induced ICH } \\
\text { model }\end{array}$ & Rat & $\begin{array}{c}\text { GLI } \\
\text { Time: } 2 \mathrm{~h} \text { post-ICH } \\
\text { Loading dose } 10 \mu \mathrm{g} / \mathrm{kg} \\
\text { Infusion rate: } 200 \mathrm{ng} / \mathrm{h}\end{array}$ & $\begin{array}{l}\text { - GLI did not improve edema, } \\
\text { hematoma volume, or functional } \\
\text { outcome at any timepoint }\end{array}$ \\
\hline \multicolumn{6}{|c|}{ Human studies: ICH } \\
\hline Simard et al., 2008 [177] & $\begin{array}{l}\text { Sulfonylurea receptor } 1 \text { in the } \\
\text { germinal matrix of premature } \\
\text { infants }\end{array}$ & $\begin{array}{c}\text { Brain specimen from } \\
\text { pre-mature infants with } \\
\text { germinal matrix hemorrhage }\end{array}$ & 12 patients & NA & - $\quad \mathrm{h}$ SUR1 and HIF1 $\alpha$ expression \\
\hline \multicolumn{6}{|c|}{ In vivo studies: Multiple sclerosis (MS) and experimental autoimmune encephalitis (EAE) } \\
\hline Schattling et al., 2012 [178] & $\begin{array}{l}\text { TRPM4 cation channel } \\
\text { mediates axonal and } \\
\text { neuronal degeneration in } \\
\text { experimental autoimmune } \\
\text { encephalomyelitis and } \\
\text { multiple sclerosis }\end{array}$ & $\begin{array}{l}\text { EAE was induced using } \\
\text { myelin oligodendrocyte } \\
\text { glycoprotein } 35-55\end{array}$ & Mouse & $\begin{array}{c}\text { GLI } \\
\text { Dose: } 10 \mu \mathrm{g} \text { daily i.p }\end{array}$ & $\begin{array}{l}\text { - GLI i axonal and neuronal } \\
\text { degeneration }\end{array}$ \\
\hline Gerzanich et al., 2017 [98] & $\begin{array}{l}\text { Salutary effects of } \\
\text { glibenclamide during the } \\
\text { chronic phase of murine } \\
\text { experimental autoimmune } \\
\text { encephalomyelitis. }\end{array}$ & $\begin{array}{l}\text { EAE was induced using } \\
\text { myelin oligodendrocyte } \\
\text { glycoprotein } 35-55\end{array}$ & Mouse & $\begin{array}{c}\text { GLI } \\
\text { Dose: } 10 \mu \text { glibenclamide } \\
\text { daily i.p }\end{array}$ & $\begin{array}{l}\text { - GLI improved clinical scores, } \\
\text { reduced myelin loss, inflammation } \\
\text { (CD45, CD20, CD3, p65), and } \\
\text { reactive astrocytosis } \\
\text { i TNF, BAFF, CCL2 and NOS2 in } \\
\text { lumbar spinal cord white matter }\end{array}$ \\
\hline
\end{tabular}


Table 7. Cont.

\begin{tabular}{|c|c|c|c|c|c|}
\hline Authors, Year & Study Title & Model & Species & GLI Dose & Results \\
\hline \multicolumn{6}{|c|}{ Human studies: MS and EAE } \\
\hline Gerzanich et al., 2017 [98] & $\begin{array}{l}\text { Salutary effects of } \\
\text { glibenclamide during the } \\
\text { chronic phase of murine } \\
\text { experimental autoimmune } \\
\text { encephalomyelitis. }\end{array}$ & $\begin{array}{l}\text { Demyelinating lesions from } \\
\text { MS patients }\end{array}$ & 9 patients & NA & $\begin{array}{l}\text { - } \quad \text { h SUR1 expression in astrocyte like } \\
\text { GFAP+ cells } \\
\text { Co-expression of SUR1-TRPM4 in } \\
\text { stellate cells observed in } \\
\text { perivascular endfeet }\end{array}$ \\
\hline
\end{tabular}




\section{ICH-In Vivo Channel Blockade}

In the rat model of hemorrhagic encephalopathy of prematurity described above, a low non-hypoglycemic dose of glibenclamide $(10 \mathrm{mg} / \mathrm{kg}$ load plus $400 \mathrm{ng} / \mathrm{h}$ infusion $\times 1$ week) administered to the mother at the end of pregnancy protected the rat pups from insults of interuterine ischemia and postnatal glycerol-induced elevated venous pressure [160]. The number and extent/severity of brain hemorrhages were acutely reduced, and protection persisted into development; treatment of the mother decreased developmental delay in the pups and preserved brain and body mass.

Studies in adult models of primary ICH have yielded conflicting results. In the autologous blood-induced rat model of ICH where SUR1 upregulation was reported (Section 3.6.1), investigators reported that treatment with low-dose glibenclamide $(10 \mu \mathrm{g} / \mathrm{kg}$ load plus $200 \mathrm{ng} / \mathrm{h}$ infusion for an unreported length of time) resulted in marked benefits, both histopathologically as well as functionally [172]. Brain water content and MMP expression were reduced, and BBB integrity was restored (with less Evans Blue extravasation, less attenuation of ZO-1, vWF, and occludin vs. vehicle) with glibenclamide treatment. Additionally, treated mice showed improved performance in the Morris water maze [172]. These benefits on functional outcome, brain edema, and BBB integrity were independently corroborated by two groups: one in a model of autologous blood infusion [143], and the other in a collagenase-induced ICH model [175]. In the collagenase-induced ICH model, glibenclamide regulated iNOS levels in microglia, increased the BCL-2/BAX ratio, and also reduced perihematomal caspase-3 expression and apoptosis [175]. In the autologous blood infusion mouse model, glibenclamide appeared to act via the NLRP3 inflammasome, even at a single dose of $10 \mathrm{mg} /$ mouse [143]. In this study, treatment reduced perihematomal levels of several inflammatory cytokines (IL-1b, IL-18, IL-6, TNFa) vs. controls, and reduced the number of apoptotic cells (particularly microvascular/endothelial cells). Genetic deletion of NLRP3 eliminated the protective effects of glibenclamide on the BBB, suggesting that the NLRP3 inflammasome is involved in this pathway, and in mediating at least part of glibenclamide's benefit.

Two recent preclinical reports have suggested no benefit from glibenclamide treatment after ICH [173,174]. Both studies were performed in rats with collagenase-induced ICH; one involved severe ICH [173], and the other was more modest ICH without mortality [174]. In both reports, glibenclamide was well tolerated, but did not improve edema measures, hematoma volume, or functional outcomes at any timepoint. In the severe ICH model, glibenclamide may have demonstrated increased cytotoxic edema, with larger cell body volumes noted in the perihematomal at $24 \mathrm{~h}(p=0.001)$.

It is challenging to reconcile the discrepant results between these two studies and the previous body of work, particularly since both the species (rat) and the drug dosing $(10 \mathrm{mg} / \mathrm{kg}, 200 \mathrm{ng} / \mathrm{h}$ continuous infusion) appear to have been consistent across studies. One possibility is the timing of administration: in the studies demonstrating benefit $[143,172,175]$, glibenclamide was loaded either $30 \mathrm{~min}$ before or immediately after injury, whereas in those where no benefit was observed, drug was initiated $2 \mathrm{~h}$ after injury $[173,174]$. However, for ultra-early administration to be clinically translatable, it would require drug infusion in a prehospital setting. It is also possible that the collagenaseinduced ICH models did not activate pathways that upregulate/trigger SUR1-TRPM4. Indeed, in the severe ICH model, there was no increase in $A b c c 8$ or Trpm 4 mRNA in the perihematomal region (protein expression was not evaluated) [173]. Another possibility is that, particularly in severe $\mathrm{ICH}$, the injury is too overwhelming for any drug to demonstrate functional benefit, particularly if administration is delayed. Regardless, these studies cumulatively suggest that further preclinical investigation of SUR1-TRPM4 and glibenclamide is warranted in ICH. 


\subsubsection{ICH-Clinical Studies \\ $\mathrm{ICH}-$ Human Expression Patterns}

In brain specimens obtained from 12 premature infants ( 7 with histopathological evidence of germinal matrix hemorrhage), the most prominent expression of HIF1 $\alpha$ was noted in infants with frank germinal matrix hemorrhage [177]. SUR1 expression was strongly present in nearly all veins in specimens from infants with frank germinal matrix hemorrhage, but was minimal in veins from infants without this injury [177].

\section{ICH-Clinical Trials}

A randomized clinical trial across five centers in China evaluating the impact of low-dose oral glibenclamide has recently been completed (NCT03741530) [127]. The goal of this study entitled "Glibenclamide Advantage in Treating Edema After Intracerebral Hemorrhage (GATE-ICH) was to enroll 220 patients with primary ICH, and evaluate both safety and efficacy. Outcome measures included functional scores at day 3, 7, and 90, as well as secondary assessments of midline shift, change in hematoma volume, perihematomal edema, and mortality. Results from this study have not yet been reported.

\subsection{Multiple Sclerosis (MS) and Experimental Autoimmune Encephalitis (EAE)}

MS is an autoimmune disease characterized by chronic inflammation, demyelination, and neurodegeneration of the CNS, which leads to a neurological deficit in young and middle-aged adults $[179,180]$. There is no known cure for MS. The principal animal model for MS, EAE, is characterized by myelin-specific autoreactive T cells that enter the CNS and initiate inflammation and tissue damage, resulting in oligodendrocyte cell death, axonal demyelination, and neuronal degeneration $[97,181]$. In both MS and EAE, inflammation is perpetuated by both infiltrating immune cells and astrocytes (Table 7) [182-185]. The role of SUR1-TRPM4 in the inflammatory pathway as it pertains to models of MS/EAE is still being explored, but early work suggests its involvement.

\subsubsection{MS and EAE-Preclinical Studies}

\section{EAE-In Vivo Expression Patterns}

Upregulation of both SUR1 and TRPM4 have been reported in murine EAE induced by myelin oligodendrocyte glycoprotein 35-55 (MOG $35-55)[97,178]$. The earlier report focused on the TRPM4 subunit in both mice and humans (Section 3.7.2); here, by 14 days after immunization, murine TRPM4 expression was increased within axonal processes at the edge of EAE lesions (compared with healthy wildtype mice, $p=4.15 \times 10^{-13}$ ) [178]. Overall, TRPM4+ cells were noted to be irregularly shaped and fragmented. Minimal changes in TRPM4 expression were detected in neuronal somata. Expression of SUR1-TRPM4 heteromers in EAE mice was subsequently reported by an independent group [97]. Here, by post-induction day 10, modest immunolabelling of SUR1 was noted in the white matter of mice with EAE that was widespread by post-induction day 30; quantitative analyses revealed a progressive increase with time. Expression was predominantly seen in astrocytes, with minimal co-localization in microglia and oligodendrocytes. Consistent with the prior study, most neuronal cells showed minimal SUR1. SUR1 co-localized with TRPM4; the formation of heteromers was confirmed with immunoFRET and co-immunoprecipitation experiments. The channel was not detected in normal wildtype controls.

\section{EAE-In Vivo Channel Blockade}

The benefits of SUR1 \pm TRPM4 blockade in EAE have been demonstrated with genetic silencing as well as pharmacological inhibition using glibenclamide $[97,98,178]$. Compared with wild type untreated mice, in the $\mathrm{MOG}_{35-55}$ EAE model, both $A b c c 8^{-/-}$and glibenclamide treatment (on day 10) consistently resulted in improved clinical scores with robust effect sizes (Cohen's $d=1.2$ ) [97]. Treatment effects were similar between glibenclamide and $A b c c 8^{-/-}$, and persisted from post-induction days 10-30. No hypoglycemia was present in glibenclamide-treated mice. At post-induction day 30, sections from the lumbar spinal 
cord in $A b c c 8^{-/-}$mice were "indistinguishable" from normal wildtype controls, and had no evidence of constitutive inflammation [97]. The spinal cords of glibenclamide-treated and $A b c c 8^{-/}$mice with EAE had reduced meningeal, perivascular, and parenchymal inflammatory infiltrates vs. untreated EAE mice, including cells expressing CD45, CD3 ( $\mathrm{T}$ cells), CD20 (B cells), and CD11b (macrophages/microglia), as well as a reduced number of cells positive for pro-inflammatory cytokines such as TNFa, IL-17, and IFN-g [97]. Both genetic and pharmacological inhibition demonstrated improved myelin preservation, more mature and precursor oligodendrocytes, and protection against axonal damage in the EAE model. Subsequent work by the same group demonstrated that even later glibenclamide treatment, initiated during the chronic phase of EAE on post-induction day 24, demonstrated benefits, including reducing clinical severity, as well as decreasing the histopathological burden of demyelination and inflammation as measured by the same markers [98]. Mechanistically, in vivo effects of glibenclamide and global Abcc8 deletion both appeared linked to reduced expression of TNF, BAFF (B cell activating factor), CCL2 (chemokine C-C motif ligand 2) and NOS2 (nitric oxide synthase 2) vs. untreated mice [98]. Interestingly, although both axonal and neuronal injury were reduced and mean clinical scores were improved in Trpm $4^{-/-}$mice subjected to the MOG $_{35-55}$ EAE by an independent group, the autoimmune response was not modified by genetic Trpm4 deletion [178]. Much like the similar effects of $A b c c 8^{-/-}$and glibenclamide in the EAE model, this study also reported almost identical effects of Trpm4 genetic deletion and glibenclamide in terms of ameliorating EAE disability [178]. In vitro experiments by this group further showed that glibenclamide blocked TRPM4 currents and glutamate-mediated cytotoxicity, similar to Trpm4 genetic deletion.

\subsubsection{MS and EAE—Clinical Studies \\ MS-Human Expression Patterns}

Similar SUR1 \pm TRPM4 expression patterns described in the murine EAE models (Section 3.7.1) have been demonstrated in human tissue from MS patients [98,178]. TRPM4 expression in human brain MS samples (13 patients) revealed significantly more TRPM4 ${ }^{+}$ axons in active demyelinating lesions vs. controls $(p=0.006)$ [178]. As with the murine findings, TRPM $4^{+}$axons were irregular and often fragmented; uninflamed peri-plaque white matter (or inactive lesions) did not demonstrate significant increases in TRPM4 axonal expression. Neuronal expression was minimal. Subsequent work independently confirmed these findings and expanded the understanding of the role of SUR1-TRPM4 in MS using autopsy tissue from nine patients (and six controls) [98]. Again, no SUR1 labeling was noted in control white matter. However, in both active and chronic-active white matter lesions, widespread SUR1 immunolabeling was noted in astrocyte-like GFAP ${ }^{+}$ stellate cells, with the highest intensity noted in chronic-active lesions. Co-expression of SUR1-TRPM4 in these stellate cells was predominantly in the perivascular endfeet, and physical co-assembly was demonstrated using immunoFRET analysis. This study also demonstrated that SUR1-TRPM4-expressing astrocytes within human MS lesions also co-expressed other pathogenic molecules, including NOS2, BAFF, and CCL2, similar to the murine findings discussed above (Section 3.7.1).

\section{MS-Clinical Trials}

There are currently no reported or ongoing clinical trials of SUR1-TRPM4 inhibition in MS.

\subsection{Neuro-Oncology}

Cerebral edema is a frequent offender in the neurological morbidity and mortality caused by both primary brain tumors as well as metastatic CNS disease. Steroids remain a mainstay of treatment, although their use is accompanied by significant side-effects. Understanding the potential contributions of SUR1-TRPM4 to peritumoral edema may be valuable; currently there are two reports exploring this process. 


\subsubsection{Neuro-Oncology-Preclinical Studies \\ Neuro-Oncology-In Vivo Expression Patterns}

In a rat model of metastatic brain tumor, where small cell lung carcinoma or melanoma cells were intracerebrally implanted in nude rats, SUR1 protein expression was shown to be significantly increased compared with the contralateral basal ganglia $(p<0.05)$, measured by immunofluorescence and western blot [41]. Expression was increased in the peritumoral region in both glial and endothelial cells.

\section{Neuro-Oncology_In Vivo Channel Blockade}

In the same study and models described above (Section 3.10.1), treatment with glibenclamide (4.8 $\mu \mathrm{g}$ loading dose plus $400 \mathrm{ng} / \mathrm{h}$ continuous infusion) was compared with dexamethasone ( $0.35 \mathrm{mg}$ loading dose plus $3 \mathrm{mg} / \mathrm{h}$ continuous infusion) [41]. Interestingly, serum glucose measurements did not vary between the two groups, despite the clinical association of steroids being associated with hyperglycemia, and the potential opposite possibility with glibenclamide. Blood-tumor barrier permeability as measured by T1 post-contrast MRI sequences was significantly reduced after treatment with glibenclamide compared with control rats with small cell lung carcinoma metastases $(p<0.01)$, or melanoma metastases $(p<0.05)$. Similar findings were obtained with dexamethasone for small cell lung carcinoma. However, the difference vs. controls was not significant for melanoma. In both metastatic models, rats treated with glibenclamide had less ZO-1 gap distances vs. controls $(p<0.01)$. Despite the benefit on tumors, no differences were identified in median overall survival between vehicle, glibenclamide, or dexamethasone in either tumor model.

\subsubsection{Neuro-Oncology—Clinical Studies \\ Neuro-Oncology-Human Expression Patterns}

SUR1 expression has been demonstrated in post-mortem brain tissues from both adult and pediatric brain tumors [39]. SUR1 expression was present in all specimens from patients with IDH1 wild type glioblastoma (6 patients), cerebral metastases (12 patients), medulloblastoma (11 patients), supratentorial ependymoma (9 patients), and posterior fossa ependymoma (8 patients). As a percentage of total tissue area, the highest SUR1 expression was found in supratentorial ependymoma and medulloblastomas specimens. Depending on tumor subtype, SUR1 expression was variable in endothelial cells vs. glial cells vs. neurons; in glioblastomas, metastases, and posterior fossa ependymoma specimens, SUR1 expression had the greatest co-localization with $\mathrm{NeuN}^{+}$neurons.

\section{Neuro-Oncology-Clinical Trials}

There are currently no reported or ongoing clinical trials of SUR1-TRPM4 inhibition in either primary brain tumors or metastatic CNS disease.

\subsection{Acute Liver Failure (ALF)}

Cerebral edema remains a significant cause of morbidity and mortality in ALF, with particular pathology attributed to astrocyte swelling. There is currently one preclinical report of SUR1-TRPM4 and inhibition with glibenclamide in this disease process [186].

\subsubsection{ALF-Preclinical Studies}

\section{ALF-In Vitro Studies}

In cultured astrocytes exposed to ammonia, SUR1 protein and $A b c c 8$ mRNA were both markedly increased vs. controls [186]. Protein expression peaked at $24 \mathrm{~h}$, whereas mRNA expression had a bimodal peak ( 3 and $24 \mathrm{~h}$ ). Ammonia-treated astrocytes had increased NF$\kappa B$ activation (which was reduced by the NF- $\mathrm{KB}$ inhibitor BAY11-7082), suggesting that this mechanism may be relevant to astrocytic edema in ALF. In vitro, glibenclamide treatment (5-200 $\mathrm{nM}$ ) reduced $24 \mathrm{~h}$ cell volume, as measured by the 3-O-methyl- $\left[{ }^{3} \mathrm{H}\right]$-glucose method. 


\section{ALF-In Vivo Expression Pattern}

An in vivo rat model of ALF using thioacetamide treatment (TAA) by the same investigators demonstrated $1.5 \times$ SUR1 mRNA upregulation by $48 \mathrm{~h}$. SUR1 immunofluorescence in these mice was the most intense in cortical astrocytes.

\section{ALF-In Vivo Channel Blockade}

In the same study (Section 3.10.1), treatment of rats with $3 \mu \mathrm{g} / \mathrm{kg}$ (bodyweight) glibenclamide reduced brain water content by $48.7 \%$. Moreover, the increased SUR1 expression noted after TAA-induced ALF was attenuated by glibenclamide. Clinical grading of rat encephalopathy was also improved after glibenclamide treatment. Thus, early data from this single study suggest that this pathway may be relevant to ALF-related cerebral edema, and may warrant further evaluation.

\subsubsection{ALF-Clinical Studies}

There are currently no clinical studies of SUR1-TRPM4 and/or channel inhibition in ALF.

\subsection{Status Epilepticus}

Although cerebral edema after status epilepticus is less well studied than some of the aforementioned acute neurological conditions, it is an important cause of intracranial hypertension, morbidity, and even mortality in neuro-ICUs [187,188]. There is currently one preclinical study evaluating SUR1-TRPM4 and glibenclamide in an in vivo model of status epilepticus, the results of which suggest that inhibition is beneficial in treating cerebral edema as well as improving outcomes [188]. Additional studies may be informative.

\subsubsection{Status Epilepticus-Preclinical Studies}

Status Epilepticus-In Vivo Expression Patterns

In a rat model of status epilepticus, SUR1 and TRPM4 protein and Abcc8/Trpm 4 mRNA expression was increased within $6 \mathrm{~h}$ and persisted for 3 and 7 days, respectively [188]. On day 3, most SUR1 and TRPM4-positive cells localized to the hippocampal CA1 region and piriform cortex; co-labeling indicated expression in both neurons (NeuN) and endothelial cells (vWF).

\section{Status Epilepticus-In Vivo Channel Blockade}

In the same study (Section 3.10.1), glibenclamide treatment reduced SUR1 and TRPM4 upregulation 3 days after status epilepticus, including expression in the CA1 region and piriform cortex. Neuronal and dendritic loss in these regions was also mitigated with glibenclamide. Expectedly, glibenclamide did not affect seizure susceptibility, but both cerebral edema (brain water content), spontaneously recurring seizures, and mortality were significantly reduced. Moreover, cognitive neurological function was better in glibenclamidetreated rats. Gene knockdown of Trpm 4 had similar effects, with decreased BBB disruption and neuronal loss.

\subsubsection{Status Epilepticus-Clinical Studies}

There are currently no clinical studies of SUR1-TRPM4 and/or channel inhibition in status epilepticus.

\section{SUR1-TRPM4 Expression and Inhibition in Other Neurological Conditions \\ 4.1. Neuropathic Pain}

In neuropathic pain, responses to innocuous as well as noxious stimuli are magnified, and pain may also occur spontaneously [189]. After peripheral nerve injury (PNI), both peripheral and central inflammation may modulate neuropathic pain and influence pain hypersensitivity [190-192]. Given the overlay between pain and inflammation, the role of SUR1 \pm TRPM4 has been explored in preclinical models of chronic and neuropathic pain 
(Table 7) $[69,121]$. If this targeted therapy is able to clinically translate, it may provide an alternative, non-addictive approach towards neuropathic pain.

\subsubsection{Neuropathic Pain-Preclinical Studies}

Neuropathic Pain-In Vivo Expression Patterns

In a model of neuropathic pain, spinal cord tissues were harvested from wildtype mice 3-14 days after unilateral sciatic nerve cuffing. Quantitative analysis of SUR1 immunopositivity demonstrated a progressive increase in protein expression in the ipsilateral dorsal horn over 14 days, with minimal SUR1 labeling in normal wildtype controls [69]. The majority of SUR1 expression was in astrocytes (GFAP ${ }^{+}$stellate cells), with minimal colocalization of SUR1 with markers of other cell types such as oligodendrocytes or microglia. Double immunolabeling showed co-localization of SUR1-TRPM4 within astrocytes, and proximal ligation assays confirmed co-assembly of these heteromers in the dorsal horn [69].

Neuropathic Pain-In Vivo Channel Blockade

Several studies have evaluated the potential analgesic effects of glibenclamide and other SUR agonists / antagonists in conjunction with other analgesics vis-à-vis $\mathrm{K}_{\mathrm{ATP}}$ channels in neuropathic pain [193-200]. In these studies, single doses of glibenclamide did not influence pain thresholds but they did blunt the anesthetic effects of the analgesic being tested. Thus, $\mathrm{K}_{\text {ATP }}$ channels may be important to augment the analgesic effect of other compounds, but seem to be less important in basal conditions of neuropathic pain. In a chronic pain murine model of spinal nerve ligation (SNL) without other concurrent analgesics, Abcc8 (SUR1) and Kcnj11 (KIR6.2) mRNA was downregulated in the dorsal root ganglia and sciatic nerves 2 months after injury [121]. Administration of the SUR1 agonist diazoxide by intraplantar or intrathecal injection alleviated mechanical hypersensitivity after SNL. Mice lacking the SUR1 $\mathrm{K}_{\text {ATP }}$ channel subunit due to genetic modification, either by global knockout $(A b c c 8 \mathrm{KO})$ or intrathecal injection of short hairpin RNA ( $A b c c 8$ shRNA), displayed mechanical hypersensitivity when compared to wild type and control mice [121]. The role of SUR1-TRPM4, however, was not explored in this study.

Recently, neuropathic pain was induced by unilateral sciatic nerve cuffing in wild type mice and mice with global or $p$-Gfap-cre- or $p$ GFAP-cre/ERT2-driven Abcc8/SUR1 deletion or global Trpm4 deletion [69]. Wild type mice received prophylactic (starting on post-operative day [pod]-0) or therapeutic (starting on pod-21) administration of the SUR1 antagonist, glibenclamide (10 mg IP) daily. Wild type mice with sciatic nerve cuffing showed pain behavior (mechanical allodynia, thermal hyperalgesia) and newly upregulated SUR1-TRPM4 expression in dorsal horn astrocytes (Section 3.8.1). Global and p-Gfap-cre-driven $A b c c 8$ deletion as well as global Trpm 4 deletion prevented pain behaviors from developing. Abcc 8 silencing (by tamoxifen) in $p$-GFAP-cre/ERT2 mice, after pain behaviors had developed, was found to be beneficial, with continued improvement noted over the subsequent 14 days. Glibenclamide (both prophylactically and after allodynia was established) was similarly beneficial in terms of preventing or reducing allodynia. Glibenclamide administration was also associated with reduced astrocytic expression of IL-6, CCL2 and CXCL1, consistent with reduced neuroinflammation in the dorsal horn [69].

\subsubsection{Neuropathic Pain-Clinical Studies}

Neuropathic Pain-Human Expression Patterns

There are currently no reported studies of human SUR1-TRPM4 expression in neuropathic pain.

\section{Neuropathic Pain-Clinical Trials}

There are currently no reported or ongoing clinical trials of SUR1-TRPM4 inhibition in neuropathic pain. 


\subsection{HIV-Associated Neurocognitive Disorders (HAND)}

HIV-associated neurocognitive disorders (HAND) are characterized by glial activation, cytokine/chemokine dysregulation, and neuronal damage, thought to be a result of chronic neuroinflammation and neurotoxicity [201]. It has been speculated that HIV-1 viral protein $\mathrm{R}(\mathrm{Vpr})$, may contribute to HAND. A recently published single study has evaluated the role of SUR1-TRPM4 expression patterns and inhibition in a preclinical mouse models of HIV (Tg26) as well as postmortem human tissue [201].

\subsubsection{HAND—Preclinical Studies \\ HAND-In Vivo Expression Patterns}

In Tg26 mouse brain, HIV-1 infection increased several inflammatory markers in the hippocampus vs. wildtype controls [201]; these markers are known to upregulate SUR1 including TLR4, TNFa, and NF- $\mathrm{KB}$ (Section 2.4). This was also associated with upregulated expression of astrocytic SUR1-TRPM4 in the hippocampus of infected mice $(p<0.001$ vs. wildtype controls). Elevated SUR1 protein expression correlated with higher $A b c c 8$ mRNA levels.

\section{HAND—In Vitro Channel Blockade}

The benefits of glibenclamide in terms of blocking Vpr-induced apoptosis have been demonstrated in vitro, using cells from the human glioblastoma SNB19 cell line (of glial cell origin) [201]. In this study, a concentration-dependent inhibition of Vpr-induced apoptosis was observed at 2, 4 and $6 \mathrm{~h}$ post-infection using glibenclamide at increasing concentrations of 10,30 and $90 \mathrm{mM}$.

\subsubsection{HAND—Clinical Studies \\ HAND-Human Expression Patterns}

Similar to the murine findings (Section 3.9.1), in post-mortem brain tissue from HIVinfected patients, HIV-1 and Vpr expression was accompanied by increased expression of both SUR1 and TRPM4 in hippocampal astrocytes ( $p<0.01$ vs. non-infected patients) [201]. The two channel subunits co-localized, consistent with channel upregulation. Overexpression of other inflammatory markers such as TLR4, NF-kB, and TNFa was also noted in hippocampal astrocytes, although the difference between control vs. HIV infected NF- $\kappa B$ did not reach statistical significance. In vitro, in human glioblastoma SNB19 cells, expression of HIV-1 Vpr was also associated with increased SUR1 expression, as well as increased expression of the same set of proinflammatory markers [201].

HAND—Clinical Trials

There are currently no reported or ongoing clinical trials of SUR1-TRPM4 inhibition in HAND.

\subsection{Retinopathy}

Retinopathy can occur as a consequence of several different processes, with underlying mechanisms including neuroinflammation, metabolic disturbances, and possibly vasogenic edema. Indeed, diabetic retinopathy is a major cause of vision loss worldwide, and may be related to SUR1 regulation of both KIR6.2 as well as TRPM4. Although the data are limited to a single study, they support a potential role for SUR1 in excitotoxic retinal cell death, as well as a benefit of glibenclamide—as demonstrated in several rodent models [202].

\subsubsection{Retinopathy-Preclinical Studies \\ Retinal Preclinical SUR1 Expression Patterns}

SUR1 expression was demonstrated in non-human primate retinas with similar patterns noted in non-diabetic humans (Section 4.3.2) [202]. Expression was noted in all three retinal layers: ganglion cell layer (GCL), outer nuclear layer (ONL), and outer limiting membrane (OLM). SUR1 was enriched in the macula, and was also expressed in glial 
Müller cells and retinal vessels. In the fovea (responsible for visual acuity), SUR1 was expressed in the cone photoreceptors (blue, red/green) and the outer limiting membrane. In most cell types, particularly Müller glial cells and cones, SUR1 colocalized with both TRPM4 and KIR6.2.

\section{Retinopathy-In Vivo Channel Blockade}

In three rat models of retinopathy (adult diabetic retinopathy, NMDA-induced retinal excitotoxicity, and neonatal hyperglycemia-induced retinal neurodegeneration), intraocular glibenclamide improved retinal structure and function. Glibenclamide reduced cellular edema (Müller cells) and restored photoreceptor morphology without affecting glucose levels. Glibenclamide treatment also reduced apoptosis. These neuroprotective effects were abolished with pretreatment with siRNA directed against SUR1. Transcriptomic analysis revealed mRNA upregulation of known neuroprotective and antioxidant genes including lipocalin-2, osteopontin, clusterin, $\mathrm{C} 1 \mathrm{q}$ and $\mathrm{Bcl} 2 \mathrm{a}$ in glibenclamide-injected rat retinas.

\subsubsection{Retinal Expression-Clinical Studies}

In the same study as above (Section 4.3.1), human ocular tissue was obtained from a non-diabetic patient after enucleation for an untreated anterior uveal melanoma. The posterior retina was intact. In this patient, SUR1 was expressed in all retinal layers (GCL, OLM, ONL), retinal Müller glial cells, cone photoreceptors, and retinal vessels. It colocalized partially with TRPM4 in human retinal astrocytes in the GCL, OLM, and cone photoreceptors. KIR6.2 was also expressed in the inner nuclear layer, OLM, Müller cells, and around retinal vessels—but not in retinal astrocytes. Systematic study of SUR1 \pm TRPM4 \pm KIR6.2 expression in the healthy vs. diseased human retina has not yet been reported.

\section{Conclusions}

Advances over the past decade have broadened and deepened our understanding of the emerging role of SUR1-TRPM4 as a unifying mediator of secondary injury across a spectrum of ostensibly different CNS pathologies. De novo upregulation of this channel in all cells of the neurovascular unit has been shown to contribute to cerebral edema, hemorrhage progression, neuroinflammation and/or cell death in preclinical models of ischemic stroke, TBI, SCI, cardiac arrest, SAH, ICH, MS/EAE, neuropathic pain, HAND, and brain tumors. Patterns of channel expression in human patients with these diseases mimic those reported in rodent models. Across these conditions, genetic silencing or pharmacological inhibition of this channel with drugs-notably glibenclamide-has conferred protection, as shown in a growing body of preclinical models and early clinical trials. Findings have been robust and generally consistent across several independent laboratories despite the study nuances reviewed here. Although nature is notoriously conservative, it is rare for a uniquely upregulated molecular target to show such exciting potential, spanning not only acute ischemic and hemorrhagic CNS diseases, but also acute and chronic inflammatory CNS diseases.

The preponderance of research on SUR1-TRPM4 in CNS injury has been in ischemic stroke and TBI. Those findings have fueled the recent and ongoing clinical trials of SUR1TRPM4 inhibition with BIIB093, an intravenous formulation of glibenclamide. The phase II clinical trial of BIIB093 in large hemispheric infarction (GAMES-RP) yielded promising results. Both CHARM (phase III trial in large hemispheric infarction) and ASTRAL (phase II trial in contusional TBI) are enrolling, and their results are eagerly awaited. Future research on pharmacodynamic response, theragnostic biomarkers (including imaging, serum, CSF), endophenotyping intermediate/mechanistically relevant outcomes, and genetic variation in this pathway may further optimize the ability to harness this treatment by optimizing timing, dosing, or risk-stratification. This may be particularly important given the historical context of the struggle to translate neuroprotectants. While multifactorial, this has largely been attributed to challenges of patient and disease heterogeneity compounded by treatment homogeneity and lack of informative biomarkers for predictive and prog- 
nostic enrichment. The suggestion of genetic underpinnings driving the impact of the SUR1-TRPM4 pathway in different patients suggests that this may also represent a special opportunity to direct future precision-trial design.

Despite the ubiquitous devastation of secondary injury processes such as severe cerebral edema and hemorrhage progression across different types of acute brain injury, treatment options remain limited. Although therapies such as hyperosmolar agents and craniectomy may be lifesaving, they are reactive treatments only equipped only to deal with the downstream consequences of cerebral edema after it has already occurred, rather than addressing the root-cause. SUR1-TRPM4 is newly upregulated after CNS injury and may be pivotal in generating cerebral edema and hemorrhage progression. It also interfaces with several other key mediators of these secondary injury processes as well as neuroinflammation and cell death. This provides a unique opportunity to limit the development of cerebral edema. Based on the pathophysiology and mounting evidence in both preclinical models and clinical studies, targeting this channel has the potential for successful translation that would improve patients' lives after CNS injury.

Funding: No funding directly supported the writing of this review. R.M.J. is supported by grants from the National Institute of Neurological Disorders and Stroke (NINDS) (K23NS101036; R01NS115815), and the Barrow Neurological Foundation. J.M.S. is supported by grants from the Department of Veterans Affairs (I01RX003060; 1I01BX004652), the Department of Defense (SC170199), the National Heart, Lung and Blood Institute (R01HL082517) and the NINDS (R01NS102589; R01NS105633).

Institutional Review Board Statement: Ethical review and approval were waived for this study, since it is a review of existing literature.

Informed Consent Statement: Patient consent was waived due to no involvement of any patients.

Data Availability Statement: Not applicable.

Conflicts of Interest: R.M.J. provides consulting services for Biogen and is on the advisory board for ASTRAL. J.M.S. holds a US patent $(7,285,574)$, 'A novel non-selective cation channel in neural cells and methods for treating brain swelling'. J.M.S. is a member of the Board of Directors and holds shares in Remedy Pharmaceuticals and is a paid consultant for Biogen.

\section{Abbreviations}

$\begin{array}{ll}\text { ADC } & \text { Apparent Diffusion Coefficient } \\ \text { ALF } & \text { Acute Liver Failure } \\ \text { AQP4 } & \text { Aquaporin 4 } \\ \text { ASPECTS } & \text { Alberta Stroke Program Early CT Score } \\ \text { ASTRAL } & \text { Antagonizing SUR1-TRPM4 To Reduce the progression of intracerebral } \\ & \text { Hematoma and edema surrounding Lesions } \\ \text { ATP } & \text { Adenosine Triphosphate } \\ \text { BAX } & \text { Bcl-Associated X protein } \\ \text { BBB } & \text { Blood-Brain Barrier } \\ \text { BSCB } & \text { Blood-Spinal Cord Barrier } \\ \text { BTB } & \text { Brain-Tumor Barrier } \\ \text { CAMKII } & \text { Calmodulin-Dependent Protein Kinase II } \\ \text { CCI } & \text { Controlled Cortical Impact } \\ \text { CHARM } & \text { Ciara in Large Hemispheric Infarction Analyzing Modified Rankin and Mortality } \\ \text { CNS } & \text { Central Nervous System } \\ \text { COX2 } & \text { Cyclooxygenase 2 } \\ \text { CSF } & \text { Cerebrospinal Fluid } \\ \text { DC } & \text { Decompressive Craniectomy } \\ \text { FLAIR } & \text { Fluid-Attenuated Inversion Recovery } \\ \text { FPI } & \text { Fluid Percussion Injury } \\ \text { FRET } & \text { Förster Resonance Energy Transfer } \\ \text { GAIN } & \text { Genetic Association in Neurotrauma }\end{array}$




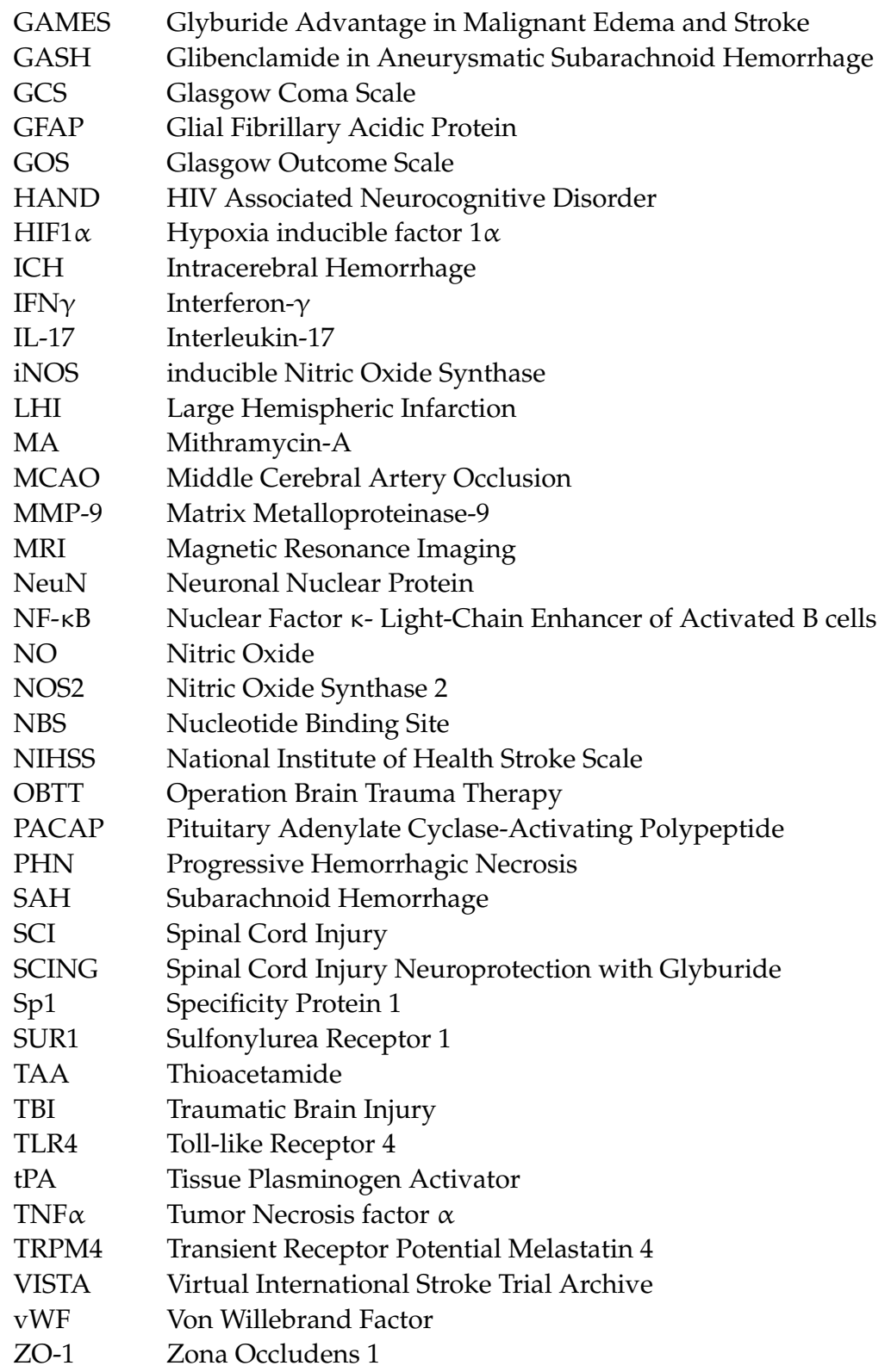

\section{References}

1. Shi, N.-Q.; Ye, B.; Makielski, J.C. Function and distribution of the SUR isoforms and splice variants. J. Mol. Cell. Cardiol. 2005, 39, 51-60. [CrossRef]

2. Aittoniemi, J.; Fotinou, C.; Craig, T.J.; de Wet, H.; Proks, P.; Ashcroft, F.M. SUR1: A unique ATP-binding cassette protein that functions as an ion channel regulator. Philos. Trans. R. Soc. B Biol. Sci. 2008, 364, 257-267. [CrossRef] [PubMed]

3. Deeley, R.G.; Westlake, C.; Cole, S.P.C. Transmembrane Transport of Endo- and Xenobiotics by Mammalian ATP-Binding Cassette Multidrug Resistance Proteins. Physiol. Rev. 2006, 86, 849-899. [CrossRef] [PubMed]

4. Seino, S.; Miki, T. Physiological and pathophysiological roles of ATP-sensitive $\mathrm{K}^{+}$channels. Prog. Biophys. Mol. Biol. 2003, 81, 133-176. [CrossRef]

5. Woo, S.K.; Kwon, M.S.; Ivanov, A.; Gerzanich, V.; Simard, J.M. The sulfonylurea receptor 1 (Sur1)-transient receptor potential me-lastatin 4 (Trpm4) channel. J. Biol. Chem. 2013, 288, 3655-3667. [CrossRef] [PubMed]

6. Simard, J.M.; Woo, S.K.; Schwartzbauer, G.T.; Gerzanich, V. Sulfonylurea Receptor 1 in Central Nervous System Injury: A Focused Review. Br. J. Pharmacol. 2012, 32, 1699-1717. [CrossRef]

7. Chen, M.; B, J.M. Cell Swelling and a Nonselective Cation Channel Regulated by Internal Ca ${ }^{2+}$ and ATP in Native Reactive Astrocytes from Adult Rat Brain. J. Neurosci. 2001, 21, 6512-6521. [CrossRef] [PubMed]

8. Chen, M.; Dong, Y.; Simard, J.M. Functional Coupling between Sulfonylurea Receptor Type 1 and a Nonselective Cation Channel in Reactive Astrocytes from Adult Rat Brain. J. Neurosci. 2003, 23, 8568-8577. [CrossRef] [PubMed]

9. Simard, J.M.; Woo, S.K.; Aarabi, B.; Gerzanich, V. The Sur1-Trpm4 Channel in Spinal Cord Injury. J. Spine 2013. [CrossRef] 
10. Sorby-Adams, A.J.; Marcoionni, A.M.; Dempsey, E.R.; Woenig, J.A.; Turner, R.J. The Role of Neurogenic Inflammation in BloodBrain Barrier Disruption and Development of Cerebral Oedema Following Acute Central Nervous System (CNS) Injury. Int. J. Mol. Sci. 2017, 18, 1788. [CrossRef] [PubMed]

11. Jha, R.M.; Bell, J.; Citerio, G.; Hemphill, J.C.; Kimberly, W.T.; Narayan, R.K.; Sahuquillo, J.; Sheth, K.N.; Simard, J.M. Role of Sulfonylurea Receptor 1 and Glibenclamide in Traumatic Brain Injury: A Review of the Evidence. Int. J. Mol. Sci. 2020, $21,409$. [CrossRef] [PubMed]

12. Stokum, J.; Gerzanich, V.; Simard, J.M. Molecular pathophysiology of cerebral edema. Br. J. Pharmacol. 2015, 36, 513-538. [CrossRef] [PubMed]

13. Yang, Y.; Rosenberg, G.A. Blood-Brain Barrier Breakdown in Acute and Chronic Cerebrovascular Disease. Stroke 2011, 42, 3323-3328. [CrossRef]

14. Griepp, D.W.; Lee, J.; Moawad, C.M.; Davati, C.; Runnels, J.; Fiani, B. BIIB093 (intravenous glibenclamide) for the prevention of severe cerebral edema. Surg. Neurol. Int. 2021, 12, 80. [CrossRef]

15. Zusman, B.E.; Kochanek, P.M.; Jha, R.M. Cerebral Edema in Traumatic Brain Injury: A Historical Framework for Current Therapy. Curr. Treat. Options Neurol. 2020, 22, 9. [CrossRef] [PubMed]

16. Simard, J.M.; Kent, T.; Chen, M.; Tarasov, K.; Gerzanich, V. Brain oedema in focal ischaemia: Molecular pathophysiology and theoretical implications. Lancet Neurol. 2007, 6, 258-268. [CrossRef]

17. Cooper, D.J.; Rosenfeld, J.V.; Murray, L.; Arabi, Y.; Davies, A.R.; D’Urso, P.; Kossmann, T.; Ponsford, J.; Seppelt, I.; Reilly, P.; et al. Decompressive Craniectomy in Diffuse Traumatic Brain Injury. N. Engl. J. Med. 2011, 364, 1493-1502. [CrossRef] [PubMed]

18. Hutchinson, P.J.; Kolias, A.G.; Timofeev, I.S.; Corteen, E.A.; Czosnyka, M.; Timothy, J.; Anderson, I.; Bulters, D.O.; Belli, A.; Eynon, C.A.; et al. Trial of Decompressive Craniectomy for Traumatic Intracranial Hypertension. N. Engl. J. Med. 2016, 375, 1119-1130. [CrossRef]

19. Kamel, H.; Navi, B.B.; Nakagawa, K.; Hemphill, J.C.; Ko, N.U. Hypertonic saline versus mannitol for the treatment of elevated in-tracranial pressure: A meta-analysis of randomized clinical trials. Crit. Care Med. 2011, 39, 554-559. [CrossRef]

20. Jha, R.M.; Kochanek, P.M. A Precision Medicine Approach to Cerebral Edema and Intracranial Hypertension after Severe Traumatic Brain Injury: Quo Vadis? Curr. Neurol. Neurosci. Rep. 2018, 18, 105. [CrossRef]

21. Nielson, J.L.; Cooper, S.R.; Yue, J.K.; Sorani, M.D.; Inoue, T.; Yuh, E.L.; Mukherjee, P.; Petrossian, T.C.; Paquette, J.; Lum, P.Y.; et al. Uncovering Precision Phenotype-Biomarker Associations in Traumatic Brain Injury Using Topological Data Analysis. PLoS ONE 2017, 12, e0169490. [CrossRef]

22. Jha, R.M.; Kochanek, P.M. Adding insight to injury: A new era in neurotrauma. Lancet Neurol. 2017, 16, 578-580. [CrossRef]

23. Stocchetti, N.; Carbonara, M.; Citerio, G.; Ercole, A.; Skrifvars, M.B.; Smielewski, P.; Zoerle, T.; Menon, D.K. Severe Traumatic Brain Injury: Targeted Management in the Intensive Care Unit. Lancet Neurol. 2017, 16, 452-464. [CrossRef]

24. Jha, R.M.; Puccio, A.M.; Chou, S.H.-Y.; Chang, C.-C.H.; Wallisch, J.S.; Molyneaux, B.J.; Zusman, B.E.; Shutter, L.A.; Poloyac, S.M.; Janesko-Feldman, K.L.; et al. Sulfonylurea Receptor-1. Crit. Care Med. 2017, 45, e255-e264. [CrossRef] [PubMed]

25. Kimberly, W.T.; Battey, T.W.K.; Pham, L.; Wu, O.; Yoo, A.J.; Furie, K.L.; Singhal, A.B.; Elm, J.J.; Stern, B.J.; Sheth, K.N. Glyburide Is Associated with Attenuated Vasogenic Edema in Stroke Patients. Neurocrit. Care 2013, 20, 193-201. [CrossRef] [PubMed]

26. Simard, J.M.; Kilbourne, M.; Tsymbalyuk, O.; Tosun, C.; Caridi, J.; Ivanova, S.; Keledjian, K.; Bochicchio, G.; Gerzanich, V. Key Role of Sulfonylurea Receptor 1 in Progressive Secondary Hemorrhage after Brain Contusion. J. Neurotrauma 2009, 26, $2257-2267$. [CrossRef] [PubMed]

27. Simard, J.M.; Woo, S.K.; Norenberg, M.D.; Tosun, C.; Chen, Z.; Ivanova, S.; Tsymbalyuk, O.; Bryan, J.; Landsman, D.; Gerzanich, V. Brief Suppression of Abcc8 Prevents Autodestruction of Spinal Cord After Trauma. Sci. Transl. Med. 2010, 2, 28-29. [CrossRef]

28. Simard, J.M.; Tsymbalyuk, O.; Ivanov, A.; Ivanova, S.; Bhatta, S.; Geng, Z.; Woo, S.K.; Gerzanich, V. Endothelial Sulfonylurea Receptor 1-Regulated NCCa-ATP Channels Mediate Progressive Hemorrhagic Necrosis Following Spinal Cord Injury. J. Clin. Invest. 2007, 117, 2105-2113. [CrossRef] [PubMed]

29. Gerzanich, V.; Stokum, J.A.; Ivanova, S.; Woo, S.K.; Tsymbalyuk, O.; Sharma, A.; Akkentli, F.; Imran, Z.; Aarabi, B.; Sahuquillo, J.; et al. Sulfonylurea Receptor 1, Transient Receptor Potential Cation Channel Subfamily M Member 4, and KIR6.2: Role in Hemorrhagic Progression of Contusion. J. Neurotrauma 2019, 36, 1060-1079. [CrossRef] [PubMed]

30. Patel, A.D.; Gerzanich, V.; Geng, Z.; Simard, J.M. Glibenclamide Reduces Hippocampal Injury and Preserves Rapid Spatial Learning in a Model of Traumatic Brain Injury. J. Neuropathol. Exp. Neurol. 2010, 69, 1177-1190. [CrossRef] [PubMed]

31. Eisenberg, H.M.; Shenton, M.E.; Pasternak, O.; Simard, J.M.; Okonkwo, D.O.; Aldrich, C.; He, F.; Jain, S.; Hayman, E.G. Magnetic Resonance Imaging Pilot Study of Intravenous Glyburide in Traumatic Brain Injury. J. Neurotrauma 2020, 37, 185-193. [CrossRef] [PubMed]

32. Jha, R.M.; Molyneaux, B.J.; Jackson, T.C.; Wallisch, J.; Park, S.-Y.; Poloyac, S.; Vagni, V.A.; Janesko-Feldman, K.L.; Hoshitsuki, K.; Minnigh, M.B.; et al. Glibenclamide Produces Region-Dependent Effects on Cerebral Edema in a Combined Injury Model of Traumatic Brain Injury and Hemorrhagic Shock in Mice. J. Neurotrauma 2018, 35, 2125-2135. [CrossRef] [PubMed]

33. Jha, R.M.; Mondello, S.; Bramlett, H.M.; Dixon, C.E.; Shear, D.A.; Dietrich, W.D.; Wang, K.K.; Yang, Z.; Hayes, R.L.; Poloyac, S.M.; et al. Glibenclamide Treatment in Traumatic Brain Injury: Operation Brain Trauma Therapy. J. Neurotrauma 2021, 38, 628-645. [CrossRef] [PubMed] 
34. Zusman, B.E.; Kochanek, P.M.; Bell, M.J.; Adelson, P.D.; Wisniewski, S.R.; Au, A.K.; Clark, R.S.; Bayır, H.; Janesko-Feldman, K.; Jha, R.M. Cerebrospinal Fluid Sulfonylurea Receptor-1 is Associated with Intracranial Pressure and Outcome after Pediatric TBI: An Exploratory Analysis of the Cool Kids Trial. J. Neurotrauma 2021, 38, 1615-1619. [CrossRef] [PubMed]

35. Tata, S.; Zusman, B.E.; Kochanek, P.M.; Gerzanich, V.; Kwon, M.S.; Woo, S.K.; Clark, R.S.B.; Janesko-Feldman, K.; Vagni, V.A.; Simard, J.M.; et al. Abcc8 (Sulfonylurea Receptor-1) Impact on Brain Atrophy after Traumatic Brain Injury Varies by Sex. J. Neurotrauma 2021, 38, 2473-2485. [CrossRef] [PubMed]

36. Tosun, C.; Kurland, D.B.; Mehta, R.; Castellani, R.J.; Dejong, J.; Kwon, M.S.; Woo, S.K.; Gerzanich, V.; Simard, J.M. Inhibition of the Sur1-Trpm4 Channel Reduces Neuroinflammation and Cognitive Impairment in Subarachnoid Hemorrhage. Stroke 2013, 44, 3522-3528. [CrossRef]

37. Dundar, T.T.; Abdallah, A.; Yurtsever, I.; Guler, E.M.; Ozer, O.F.; Uysal, O. Serum SUR1 and TRPM4 in patients with subarachnoid hemorrhage. Neurosurg. Rev. 2019, 43, 1595-1603. [CrossRef] [PubMed]

38. Martínez-Valverde, T.; Vidal-Jorge, M.; Martínez-Saez, E.; Castro, L.; Arikan, F.; Cordero, E.; Rădoi, A.; Poca, M.-A.; Simard, J.M.; Sahuquillo, J. Sulfonylurea Receptor 1 in Humans with Post-Traumatic Brain Contusions. J. Neurotrauma 2015, 32, $1478-1487$. [CrossRef]

39. Thompson, E.M.; Halvorson, K.; McLendon, R. Sulfonylurea receptor 1 expression is variable in adult and pediatric brain tumors. Clin. Neuropathol. 2018, 37, 221-227. [CrossRef] [PubMed]

40. Simard, J.M.; Geng, Z.; Woo, S.K.; Ivanova, S.; Tosun, C.; Melnichenko, L.; Gerzanich, V. Glibenclamide Reduces Inflammation, Vasogenic Edema, and Caspase-3 Activation after Subarachnoid Hemorrhage. J. Cereb. Blood Flow Metab. 2008, 29, 317-330. [CrossRef] [PubMed]

41. Thompson, E.M.; Pishko, G.L.; Muldoon, L.L.; Neuwelt, E.A. Inhibition of SUR1 decreases the vascular permeability of cerebral me-tastases. Neoplasia 2013, 15, 535-543. [CrossRef] [PubMed]

42. Zafardoost, P.; Ghasemi, A.A.; Salehpour, F.; Piroti, C.; Ziaeii, E. Evaluation of the Effect of Glibenclamide in Patients With Diffuse Axonal Injury Due to Moderate to Severe Head Trauma. Trauma Mon. 2016, 21, e25113. [CrossRef] [PubMed]

43. Zweckberger, K.; Hackenberg, K.; Jung, C.; Hertle, D.; Kiening, K.; Unterberg, A.; Sakowitz, O. Glibenclamide reduces secondary brain damage after experimental traumatic brain injury. Neuroscience 2014, 272, 199-206. [CrossRef]

44. Xu, Z.-M.; Yuan, F.; Liu, Y.-L.; Ding, J.; Tian, H.-L. Glibenclamide Attenuates Blood-Brain Barrier Disruption in Adult Mice after Traumatic Brain Injury. J. Neurotrauma 2017, 34, 925-933. [CrossRef] [PubMed]

45. Stokum, J.A.; Keledjian, K.; Hayman, E.; Karimy, J.K.; Pampori, A.; Imran, Z.; Woo, S.K.; Gerzanich, V.; Simard, J.M. Glibenclamide Pretreatment Protects against Chronic Memory Dysfunction and Glial Activation in Rat Cranial Blast Traumatic Brain Injury. Behav. Brain Res. 2017, 333, 43-53. [CrossRef]

46. Pergakis, M.; Badjatia, N.; Chaturvedi, S.; Cronin, C.A.; Kimberly, W.T.; Sheth, K.N.; Simard, J.M. BIIB093 (IV glibenclamide): An investigational compound for the prevention and treatment of severe cerebral edema. Expert Opin. Investig. Drugs 2019, 28, 1031-1040. [CrossRef] [PubMed]

47. Sheth, K.N.; Elm, J.J.; Molyneaux, B.J.; Hinson, H.; Beslow, L.A.; Sze, G.K.; Ostwaldt, A.-C.; del Zoppo, G.J.; Simard, J.M.; Jacobson, S.; et al. Safety and Efficacy of Intravenous Glyburide on Brain Swelling after Large Hemispheric Infarction (GAMES-RP): A Randomised, Double-Blind, Placebo-Controlled Phase 2 Trial. Lancet Neurol. 2016, 15, 1160-1169. [CrossRef]

48. Sheth, K.N.; Petersen, N.H.; Cheung, K.; Elm, J.J.; Hinson, H.E.; Molyneaux, B.J.; Beslow, L.A.; Sze, G.K.; Simard, J.M.; Kimberly, W.T. Long-Term Outcomes in Patients Aged $\leq 70$ Years With Intravenous Glyburide From the Phase II GAMES-RP Study of Large Hemispheric Infarction. Stroke 2018, 49, 1457-1463. [CrossRef] [PubMed]

49. Sheth, K.N.; Kimberly, W.T.; Elm, J.J.; Kent, T.A.; Yoo, A.J.; Thomalla, G.; Campbell, B.; Donnan, G.A.; Davis, S.M.; Albers, G.W.; et al. Exploratory analysis of glyburide as a novel therapy for preventing brain swelling. Neurocrit. Care 2014, $21,43-51$. [CrossRef] [PubMed]

50. Hayman, E.G.; Patel, A.P.; Kimberly, W.T.; Sheth, K.N.; Simard, J.M. Cerebral edema after cardiopulmonary resuscitation: A thera-peutic target following cardiac arrest? Neurocrit. Care 2018, 28, 276-287. [CrossRef]

51. Aguilar-Bryan, L.; Nichols, C.G.; Wechsler, S.W.; Clement, J.P., IV; Boyd, A.E., III; González, G.; Herrera-Sosa, H.; Nguy, K.; Bryan, J.; Nelson, D.A. Cloning of the $\beta$ Cell High-Affinity Sulfonylurea Receptor: A Regulator of Insulin Secretion. Science 1995, 268, 423-426. [CrossRef] [PubMed]

52. Thomas, C.; Tampé, R. Multifaceted structures and mechanisms of ABC transport systems in health and disease. Curr. Opin. Struct. Biol. 2018, 51, 116-128. [CrossRef]

53. Tusnády, G.E.; Bakos, É.; Váradi, A.; Sarkadi, B. Membrane topology distinguishes a subfamily of the ATP-binding cassette (ABC) transporters. FEBS Lett. 1997, 402, 1-3. [CrossRef]

54. Matsuo, M.; Kioka, N.; Amachi, T.; Ueda, K. ATP Binding Properties of the Nucleotide-binding Folds of SUR1. J. Biol. Chem. 1999, 274, 37479-37482. [CrossRef]

55. Launay, P.; Fleig, A.; Perraud, A.-L.; Scharenberg, A.M.; Penner, R.; Kinet, J.-P. TRPM4 Is a Ca ${ }^{2+}$-Activated Nonselective Cation Channel Mediating Cell Membrane Depolarization. Cell 2002, 109, 397-407. [CrossRef]

56. Nilius, B.; Prenen, J.; Tang, J.; Wang, C.; Owsianik, G.; Janssens, A.; Voets, T.; Zhu, M.X. Regulation of the Ca ${ }^{2+}$ Sensitivity of the Nonselective Cation Channel TRPM4. J. Biol. Chem. 2005, 280, 6423-6433. [CrossRef] [PubMed]

57. Song, M.Y.; Yuan, J.X.-J. Introduction to TRP Channels: Structure, Function, and Regulation. In Membrane Receptors, Channels and Transporters in Pulmonary Circulation; Springer: Berlin/Heidelberg, Germany, 2009; pp. 99-108. [CrossRef] 
58. Vennekens, R.; Nilius, B. Insights into TRPM4 Function, Regulation and Physiological Role. In Handbook of Experimental Pharmacology; Transient Receptor Potential (TRP) Channels; Humana Press: Totowa, NJ, USA, 2007; pp. 269-285. [CrossRef]

59. Zerangue, N.; Schwappach, B.; Jan, Y.N.; Jan, L.Y. A new ER trafficking signal regulates the subunit stoichiometry of plasma membrane K(ATP) channels. Neuron 1999, 22, 537-548. [CrossRef]

60. Luo, Z.-W.; Ovcjak, A.; Wong, R.; Yang, B.-X.; Feng, Z.-P.; Sun, H.-S. Drug development in targeting ion channels for brain edema. Acta Pharmacol. Sin. 2020, 41, 1272-1288. [CrossRef]

61. Bryan, J.; Muñoz, A.; Zhang, X.; Düfer, M.; Drews, G.; Krippeit-Drews, P.; Aguilar-Bryan, L. ABCC8 and ABCC9: ABC transporters that regulate $\mathrm{K}^{+}$channels. Pflügers Arch.-Eur. J. Physiol. 2007, 453, 703-718. [CrossRef]

62. Burke, M.A.; Mutharasan, R.K.; Ardehali, H. The Sulfonylurea Receptor, an Atypical ATP-Binding Cassette Protein, and Its Regulation of the KATPChannel. Circ. Res. 2008, 102, 164-176. [CrossRef]

63. Yamada, K.; Inagaki, N. Neuroprotection by KATP channels. J. Mol. Cell. Cardiol. 2005, 38, 945-949. [CrossRef]

64. Haider, S.; Antcliff, J.F.; Proks, P.; Sansom, M.S.; Ashcroft, F.M. Focus on Kir6.2: A key component of the ATP-sensitive potassium channel. J. Mol. Cell. Cardiol. 2005, 38, 927-936. [CrossRef] [PubMed]

65. Simard, J.M.; Chen, M.; Tarasov, K.V.; Bhatta, S.; Ivanova, S.; Melnitchenko, L.; Tsymbalyuk, N.; West, G.A.; Gerzanich, V. Newly Expressed SUR1-Regulated NCCa-ATP Channel Mediates Cerebral Edema after Ischemic Stroke. Nat. Med. 2006, 12, 433-440. [CrossRef] [PubMed]

66. ̈̈mmälä, C.; Moorhouse, A.; Gribble, F.; Ashfleld, R.; Proks, P.; Smith, P.A.; Sakura, H.; Coles, B.; Ashcroft, S.J.H.; Ashcroft, F.M.; et al. Promiscuous coupling between the sulphonylurea receptor and inwardly rectifying potassium channels. Nature 1996, 379, 545-548. [CrossRef] [PubMed]

67. Clement, J.P., IV; Kunjilwar, K.; Gonzalez, G.; Schwanstecher, M.; Panten, U.; Aguilar-Bryan, L.; Bryan, J. Association and Stoichiometry of KATP Channel Subunits. Neuron 1997, 18, 827-838. [CrossRef]

68. Mehta, R.I.; Tosun, C.; Ivanova, S.; Tsymbalyuk, N.; Famakin, B.M.; Kwon, M.S.; Castellani, R.J.; Gerzanich, V.; Simard, J.M. Sur1-Trpm4 Cation Channel Expression in Human Cerebral Infarcts. J. Neuropathol. Exp. Neurol. 2015, 74, 835-849. [CrossRef]

69. Tsymbalyuk, O.; Gerzanich, V.; Mumtaz, A.; Andhavarapu, S.; Ivanova, S.; Makar, T.K.; Sansur, C.; Keller, A.; Nakamura, Y.; Bryan, J.; et al. SUR1, newly expressed in astrocytes, mediates neuropathic pain in a mouse model of peripheral nerve injury. Mol. Pain 2021, 17, 17448069211006603. [CrossRef] [PubMed]

70. Hayman, E.G.; Wessell, A.; Gerzanich, V.; Sheth, K.N.; Simard, J.M. Mechanisms of Global Cerebral Edema Formation in Aneurysmal Subarachnoid Hemorrhage. Neurocrit. Care 2016, 26, 301-310. [CrossRef]

71. Jha, R.M.; Kochanek, P.M.; Simard, J.M. Pathophysiology and treatment of cerebral edema in traumatic brain injury. Neuropharmacology 2018, 145, 230-246. [CrossRef]

72. Simard, J.M.; Sheth, K.N.; Kimberly, W.T.; Stern, B.J.; Del Zoppo, G.J.; Jacobson, S.; Gerzanich, V. Glibenclamide in cerebral ischemia and stroke. Neurocrit. Care 2013, 20, 319-333. [CrossRef]

73. Simard, J.M.; Kahle, K.T.; Gerzanich, V. Molecular mechanisms of microvascular failure in central nervous system injurysynergistic roles of NKCC1 and SUR1/TRPM4. J. Neurosurg. 2010, 113, 622-629. [CrossRef] [PubMed]

74. Cartier, E.A.; Conti, L.R.; Vandenberg, C.A.; Shyng, S.L. Defective trafficking and function of KATP channels caused by a sulfonyl-urea receptor 1 mutation associated with persistent hyperinsulinemic hypoglycemia of infancy. Proc. Natl. Acad. Sci. USA 2001, 98, 2882-2887. [CrossRef] [PubMed]

75. Yan, F.-F.; Casey, J.; Shyng, S.-L. Sulfonylureas Correct Trafficking Defects of Disease-causing ATP-sensitive Potassium Channels by Binding to the Channel Complex. J. Biol. Chem. 2006, 281, 33403-33413. [CrossRef] [PubMed]

76. Partridge, C.J.; Beech, D.; Sivaprasadarao, A. Identification and Pharmacological Correction of a Membrane Trafficking Defect Associated with a Mutation in the Sulfonylurea Receptor Causing Familial Hyperinsulinism. J. Biol. Chem. 2001, 276 , 35947-35952. [CrossRef]

77. Findlay, I. Effects of $\mathrm{pH}$ upon the inhibition by sulphonylurea drugs of ATP-sensitive $\mathrm{K}^{+}$channels in cardiac muscle. J. Pharmacol. Exp. Ther. 1992, 262, 71-79.

78. Nelson, D.A.; Bryan, J.; Wechsler, S.; Clement, J.P.; Aguilar-Bryan, L. The High-Affinity Sulfonylurea Receptor: Distribution, Glycosylation, Purification, and Immunoprecipitation of Two Forms from Endocrine and Neuroendocrine Cell Lines. Biochemistry 1996, 35, 14793-14799. [CrossRef] [PubMed]

79. Nedergaard, M.; Kraig, R.P.; Tanabe, J.; Pulsinelli, W.A. Dynamics of interstitial and intracellular pH in evolving brain infarct. Am. J. Physiol. Integr. Comp. Physiol. 1991, 260, R581-R588. [CrossRef] [PubMed]

80. Simard, J.M.; Woo, S.K.; Bhatta, S.; Gerzanich, V. Drugs acting on SUR1 to treat CNS ischemia and trauma. Curr. Opin. Pharmacol. 2008, 8, 42-49. [CrossRef] [PubMed]

81. Ashfield, R.; Ashcroft, S.J. Cloning of the promoters for the beta-cell ATP-sensitive K-channel subunits Kir6.2 and SUR1. Diabetes 1998, 47, 1274-1280. [CrossRef] [PubMed]

82. Hernández-Sánchez, C.; Ito, Y.; Ferrer, J.; Reitman, M.; LeRoith, D. Characterization of the Mouse Sulfonylurea Receptor 1 Promoter and Its Regulation. J. Biol. Chem. 1999, 274, 18261-18270. [CrossRef]

83. Kim, J.-W.; Seghers, V.; Cho, J.-H.; Kang, Y.; Kim, S.; Ryu, Y.; Baek, K.; Aguilar-Bryan, L.; Lee, Y.-D.; Bryan, J.; et al. Transactivation of the Mouse Sulfonylurea Receptor I Gene by BETA2/NeuroD. Mol. Endocrinol. 2002, 16, 1097-1107. [CrossRef] [PubMed] 
84. Gorogawa, S.; Fujitani, Y.; Kaneto, H.; Hazama, Y.; Watada, H.; Miyamoto, Y.; Takeda, K.; Akira, S.; Magnuson, M.A.; Yamasaki, Y.; et al. Insulin Secretory Defects and Impaired Islet Architecture in Pancreatic $\beta$-Cell-Specific STAT3 Knockout Mice. Biochem. Biophys. Res. Commun. 2004, 319, 1159-1170. [CrossRef] [PubMed]

85. Lantz, K.A.; Vatamaniuk, M.Z.; Brestelli, J.E.; Friedman, J.R.; Matschinsky, F.M.; Kaestner, K.H. Foxa2 regulates multiple pathways of insulin secretion. J. Clin. Investig. 2004, 114, 512-520. [CrossRef] [PubMed]

86. Woo, S.K.; Kwon, M.S.; Geng, Z.; Chen, Z.; Ivanov, A.; Bhatta, S.; Gerzanich, V.; Simard, J.M. Sequential Activation of HypoxiaInducible Factor 1 and Specificity Protein 1 Is Required for Hypoxia-Induced Transcriptional Stimulation of Abcc8. J. Cereb. Blood Flow Metab. 2011, 32, 525-536. [CrossRef] [PubMed]

87. Helton, R.; Cui, J.; Scheel, J.; Ellison, J.A.; Ames, C.; Gibson, C.; Blouw, B.; Ouyang, L.; Dragatsis, I.; Zeitlin, S.; et al. Brain-Specific Knock-Out of Hypoxia-Inducible Factor-1 Reduces Rather Than Increases Hypoxic-Ischemic Damage. J. Neurosci. 2005, 25, 4099-4107. [CrossRef] [PubMed]

88. Chen, C.; Hu, Q.; Yan, J.; Lei, J.; Qin, L.; Shi, X.; Luan, L.; Yang, L.; Wang, K.; Han, J.; et al. Multiple Effects of 2 ME2 and D609 on the Cortical Expression of HIF- $1 \alpha$ and Apoptotic Genes in a Middle Cerebral Artery Occlusion-Induced Focal Ischemia Rat Model. J. Neurochem. 2007, 102, 1831-1841. [CrossRef] [PubMed]

89. Chen, C.; Ostrowski, R.P.; Zhou, C.; Tang, J.; Zhang, J.H. Suppression of hypoxia-inducible factor- $1 \alpha$ and its downstream genes reduces acute hyperglycemia-enhanced hemorrhagic transformation in a rat model of cerebral ischemia. J. Neurosci. Res. 2010, 88, 2046-2055. [CrossRef]

90. Chen, W.; Jadhav, V.; Tang, J.; Zhang, J.H. HIF-1 $\alpha$ inhibition ameliorates neonatal brain injury in a rat pup hypoxic-ischemic model. Neurobiol. Dis. 2008, 31, 433-441. [CrossRef] [PubMed]

91. Chen, W.; Jadhav, V.; Tang, J.; Zhang, J.H. HIF-1 alpha inhibition ameliorates neonatal brain damage after hypoxic-ischemic injury. In Handbook of Experimental Pharmacology; Springer: Vienna, Austria, 2008; Volume 102, pp. 395-399. [CrossRef]

92. Kurland, D.B.; Gerzanich, V.; Karimy, J.K.; Woo, S.K.; Vennekens, R.; Freichel, M.; Nilius, B.; Bryan, J.; Simard, J.M. The Sur1-Trpm4 channel regulates NOS2 transcription in TLR4-activated microglia. J. Neuroinflamm. 2016, 13, 1-23. [CrossRef] [PubMed]

93. Laird, M.D.; Shields, J.S.; Sukumari-Ramesh, S.; Kimbler, D.E.; Fessler, R.D.; Shakir, B.; Youssef, P.; Yanasak, N.; Vender, J.R.; Dhandapani, K.M. High mobility group box protein-1 promotes cerebral edema after traumatic brain injury via activation of toll-like receptor 4. Glia 2013, 62, 26-38. [CrossRef]

94. Trotta, T.; Porro, C.; Calvello, R.; Panaro, M.A. Biological role of Toll-like receptor-4 in the brain. J. Neuroimmunol. 2014, 268, 1-12. [CrossRef]

95. Stokum, J.A.; Kwon, M.S.; Woo, S.K.; Tsymbalyuk, O.; Vennekens, R.; Gerzanich, V.; Simard, J.M. SUR1-TRPM4 and AQP4 Form a Heteromultimeric Complex That Amplifies Ion/Water Osmotic Coupling and Drives Astrocyte Swelling. Glia 2017, 66, 108-125. [CrossRef] [PubMed]

96. Gerzanich, V.; Kwon, M.S.; Woo, S.K.; Ivanov, A.; Simard, J.M. SUR1-TRPM4 channel activation and phasic secretion of MMP-9 induced by tPA in brain endothelial cells. PLoS ONE 2018, 13, e0195526. [CrossRef] [PubMed]

97. Makar, T.K.; Gerzanich, V.; Nimmagadda, V.K.C.; Jain, R.; Lam, K.; Mubariz, F.; Trisler, D.; Ivanova, S.; Woo, S.K.; Kwon, M.S.; et al. Silencing of Abcc8 or Inhibition of Newly Upregulated Sur1-Trpm4 Reduce Inflammation and Disease Progression in Experimental Autoimmune Encephalomyelitis. J. Neuroinflamm. 2015, 12. [CrossRef]

98. Gerzanich, V.; Makar, T.K.; Guda, P.R.; Kwon, M.S.; Stokum, J.A.; Woo, S.K.; Ivanova, S.; Ivanov, A.; Mehta, R.I.; Morris, A.B.; et al. Salutary effects of glibenclamide during the chronic phase of murine experimental autoimmune encephalomyelitis. $J$. Neuroinflamm. 2017, 14, 177. [CrossRef]

99. Clément, T.; Rodriguez-Grande, B.; Badaut, J. Aquaporins in brain edema. J. Neurosci. Res. 2018, 98, 9-18. [CrossRef]

100. Manley, G.T.; Fujimura, M.; Ma, T.; Noshita, N.; Filiz, F.; Bollen, A.W.; Chan, P.; Verkman, A. Aquaporin-4 deletion in mice reduces brain edema after acute water intoxication and ischemic stroke. Nat. Med. 2000, 6, 159-163. [CrossRef] [PubMed]

101. Papadopoulos, M.C.; Manley, G.T.; Krishna, S.; Verkman, A.S. Aquaporin-4 facilitates reabsorption of excess fluid in vasogenic brain edema. FASEB J. 2004, 18, 1291-1293. [CrossRef]

102. Iliff, J.J.; Wang, M.; Liao, Y.; Plogg, B.A.; Peng, W.; Gundersen, G.A.; Benveniste, H.; Vates, G.E.; Deane, R.; Goldman, S.A.; et al. A Paravascular Pathway Facilitates CSF Flow Through the Brain Parenchyma and the Clearance of Interstitial Solutes, Including Amyloid $\beta$. Sci. Transl. Med. 2012, 4, 147ra111. [CrossRef]

103. Mestre, H.; Mori, Y.; Nedergaard, M. The Brain's Glymphatic System: Current Controversies. Trends Neurosci. 2020, 43, 458-466. [CrossRef] [PubMed]

104. Mestre, H.; Du, T.; Sweeney, A.M.; Liu, G.; Samson, A.J.; Peng, W.; Mortensen, K.N.; Stæger, F.F.; Bork, P.A.R.; Bashford, L.; et al. Cerebrospinal fluid influx drives acute ischemic tissue swelling. Science 2020, 367, 6483. [CrossRef]

105. Kitchen, P.; Salman, M.M.; Halsey, A.M.; Clarke-Bland, C.; MacDonald, J.A.; Ishida, H.; Vogel, H.J.; Almutiri, S.; Logan, A.; Kreida, S.; et al. Targeting Aquaporin-4 Subcellular Localization to Treat Central Nervous System Edema. Cell 2020, 181, 784-799.e19. [CrossRef]

106. Sylvain, N.J.; Salman, M.M.; Pushie, M.J.; Hou, H.; Meher, V.; Herlo, R.; Peeling, L.; Kelly, M.E. The effects of trifluoperazine on brain edema, aquaporin-4 expression and metabolic markers during the acute phase of stroke using photothrombotic mouse model. Biochim. Biophys. Acta Biomembr. 2021, 1863, 183573. [CrossRef]

107. Salman, M.M.; Kitchen, P.; Halsey, A.; Wang, M.X.; Tornroth-Horsefield, S.; Conner, A.C.; Badaut, J.; Iliff, J.J.; Bill, R.M. Emerging roles for dynamic aquaporin-4 subcellular relocalization in CNS water homeostasis. Brain 2021. [CrossRef] 
108. MacAulay, N. Molecular mechanisms of brain water transport. Nat. Rev. Neurosci. 2021, 22, 326-344. [CrossRef] [PubMed]

109. Salman, M.M.; Kitchen, P.; Iliff, J.J.; Bill, R.M. Aquaporin 4 and glymphatic flow have central roles in brain fluid homeostasis. Nat. Rev. Neurosci. 2021, 22, 650-651. [CrossRef]

110. Fang, Y.; Shi, H.; Ren, R.; Huang, L.; Okada, T.; Lenahan, C.; Gamdzyk, M.; Travis, Z.D.; Lu, Q.; Tang, L.; et al. Pituitary Adenylate Cyclase-Activating Polypeptide Attenuates Brain Edema by Protecting Blood-Brain Barrier and Glymphatic System After Subarachnoid Hemorrhage in Rats. Neurotherapeutics 2020, 17, 1954-1972. [CrossRef] [PubMed]

111. Simard, J.M.; Geng, Z.; Silver, F.L.; Sheth, K.N.; Kimberly, W.T.; Stern, B.J.; Colucci, M.; Gerzanich, V. Does Inhibiting Sur1 Complement Rt-PA in Cerebral Ischemia? Ann. N. Y. Acad. Sci. 2012, 1268, 95-107. [CrossRef] [PubMed]

112. Simard, J.M.; Yurovsky, V.; Tsymbalyuk, N.; Melnichenko, L.; Ivanova, S.; Gerzanich, V. Protective Effect of Delayed Treatment With Low-Dose Glibenclamide in Three Models of Ischemic Stroke. Stroke 2009, 40, 604-609. [CrossRef] [PubMed]

113. Simard, J.M.; Tsymbalyuk, N.; Tsymbalyuk, O.; Ivanova, S.; Yurovsky, V.; Gerzanich, V. Glibenclamide Is Superior to Decompressive Craniectomy in a Rat Model of Malignant Stroke. Stroke 2010, 41, 531-537. [CrossRef] [PubMed]

114. Abdallah, D.M.; Nassar, N.N.; El Salam, R.A. Glibenclamide ameliorates ischemia-reperfusion injury via modulating oxidative stress and inflammatory mediators in the rat hippocampus. Brain Res. 2011, 1385, 257-262. [CrossRef]

115. Simard, J.M.; Woo, S.K.; Tsymbalyuk, N.; Voloshyn, O.; Yurovsky, V.; Ivanova, S.; Lee, R.; Gerzanich, V. Glibenclamide-10-h Treatment Window in a Clinically Relevant Model of Stroke. Transl. Stroke Res. 2012, 3, 286-295. [CrossRef]

116. Ortega, F.J.; Gimeno-Bayon, J.; Espinosa-Parrilla, J.F.; Carrasco, J.; Batlle, M.; Pugliese, M.; Mahy, N.; Rodriguez, M.J. ATPdependent potassium channel blockade strengthens microglial neuroprotection after hypoxia-ischemia in rats. Exp. Neurol. 2012, 235, 282-296. [CrossRef]

117. Wali, B.; Ishrat, T.; Atif, F.; Hua, F.; Stein, N.G.; Sayeed, I. Glibenclamide Administration Attenuates Infarct Volume, Hemispheric Swelling, and Functional Impairments following Permanent Focal Cerebral Ischemia in Rats. Stroke Res. Treat. 2012, $2012,1-6$. [CrossRef] [PubMed]

118. Ortega, F.J.; Jolkkonen, J.; Mahy, N.; Rodriguez, M.J. Glibenclamide Enhances Neurogenesis and Improves Long-Term Functional Recovery after Transient Focal Cerebral Ischemia. Br. J. Pharmacol. 2012, 33, 356-364. [CrossRef]

119. Arikan Abello, F.; Martínez Valverde, T.; Sánchez Guerrero, Á.; Campos Martorell, M.; Esteves Coelho, M.; Gándara Sabatini, D.F.; Torne Torne, R.; Castro González, L.; Sahuquillo Barris, J. Malignant infarction of the middle cerebral artery in a porcine model. A pilot study. PLoS ONE 2017, 12, e0172637. [CrossRef] [PubMed]

120. Burgos, I.M.A.; Ortiz-Plata, A.; Franco-Pérez, J.; Millán, A.; Aguilera, P. Resveratrol reduces cerebral edema through inhibition of de novo SUR1 expression induced after focal ischemia. Exp. Neurol. 2020, 330, 113353. [CrossRef]

121. Luu, W.; Bjork, J.; Salo, E.; Entenmann, N.; Jurgenson, T.; Fisher, C.; Klein, A.H. Modulation of SUR1 KATP Channel Subunit Activity in the Peripheral Nervous System Reduces Mechanical Hyperalgesia after Nerve Injury in Mice. Int. J. Mol. Sci. 2019, 20, 2251. [CrossRef]

122. Mehta, R.I.; Ivanova, S.; Tosun, B.C.; Castellani, R.J.; Gerzanich, V.; Simard, J.M. Sulfonylurea Receptor 1 Expression in Human Cerebral Infarcts. J. Neuropathol. Exp. Neurol. 2013, 72, 871-883. [CrossRef]

123. Kunte, H.; Schmidt, S.; Eliasziw, M.; del Zoppo, G.J.; Simard, J.M.; Masuhr, F.; Weih, M.; Dirnagl, U. Sulfonylureas Improve Outcome in Patients With Type 2 Diabetes and Acute Ischemic Stroke. Stroke 2007, 38, 2526-2530. [CrossRef] [PubMed]

124. Favilla, C.G.; Mullen, M.T.; Ali, M.; Higgins, P.; Kasner, S.E. Virtual International Stroke Trials Archive (VISTA) Collaboration. Sul-fonylurea use before stroke does not influence outcome. Stroke 2011, 42, 710-715. [CrossRef] [PubMed]

125. Kunte, H.; Busch, M.; Trostdorf, K.; Vollnberg, B.; Harms, L.; Mehta, R.I.; Castellani, R.J.; Mandava, P.; Kent, T.; Simard, J.M. Hemorrhagic transformation of ischemic stroke in diabetics on sulfonylureas. Ann. Neurol. 2012, 72, 799-806. [CrossRef] [PubMed]

126. Horsdal, H.T.; Mehnert, F.; Rungby, J.; Johnsen, S.P. Type of Preadmission Antidiabetic Treatment and Outcome among Patients with Ischemic Stroke: A Nationwide Follow-up Study. J. Stroke Cerebrovasc. Dis. 2012, 21, 717-725. [CrossRef]

127. Zhao, J.; Yang, F.; Song, C.; Li, L.; Yang, X.; Wang, X.; Yu, L.; Guo, J.; Wang, K.; Fu, F.; et al. Glibenclamide Advantage in Treating Edema After Intracerebral Hemorrhage (GATE-ICH): Study Protocol for a Multicenter Randomized, Controlled, Assessor-Blinded Trial. Front. Neurol. 2021, 12, 579. [CrossRef]

128. da Costa, B.B.S.; Windlin, I.C.; Koterba, E.; Yamaki, V.N.; Rabelo, N.N.; Solla, D.J.F.; Teixeira, M.J.; Figueiredo, E.G. Glibenclamide in Aneurysmatic Subarachnoid Hemorrhage (GASH): Study Protocol for a Randomized Controlled Trial. Trials 2019, $20,413$. [CrossRef]

129. Simard, J.M.; Chen, M. Regulation by Sulfanylurea Receptor Type 1 of a Non-selective Cation Channel Involved in Cytotoxic Edema of Reactive Astrocytes. J. Neurosurg. Anesthesiol. 2004, 16, 98-99. [CrossRef]

130. Zhu, S.; Gao, X.; Huang, K.; Gu, Y.; Hu, Y.; Wu, Y.; Ji, Z.; Wang, Q.; Pan, S. Glibenclamide Enhances the Therapeutic Benefits of Early Hypothermia after Severe Stroke in Rats. Aging Dis. 2018, 9, 685-695. [CrossRef] [PubMed]

131. King, Z.; Sheth, K.N.; Kimberly, W.T.; Simard, J.M. Profile of intravenous glyburide for the prevention of cerebral edema following large hemispheric infarction: Evidence to date. Drug Des. Dev. Ther. 2018, 12, 2539-2552. [CrossRef]

132. Sheth, K.N.; Kimberly, W.T.; Elm, J.J.; Kent, T.A.; Mandava, P.; Yoo, A.J.; Thomalla, G.; Campbell, B.; Donnan, G.A.; Davis, S.M.; et al. Pilot Study of Intravenous Glyburide in Patients with a Large Ischemic Stroke. Stroke 2014, 45, 281-283. [CrossRef] 
133. Jha, R.; Battey, T.W.K.; Pham, L.; Lorenzano, S.; Furie, K.L.; Sheth, K.N.; Kimberly, W.T. Fluid-Attenuated Inversion Recovery Hyperintensity Correlates With Matrix Metalloproteinase-9 Level and Hemorrhagic Transformation in Acute Ischemic Stroke. Stroke 2014, 45, 1040-1045. [CrossRef]

134. Kimberly, W.T.; Bevers, M.B.; von Kummer, R.; Demchuk, A.M.; Romero, J.M.; Elm, J.J.; Hinson, H.E.; Molyneaux, B.J.; Simard, J.M.; Sheth, K.N. Effect of IV glyburide on adjudicated edema endpoints in the GAMES-RP Trial. Neurology 2018, 91, e2163-e2169. [CrossRef]

135. Jha, R.M.; Koleck, T.; Puccio, A.M.; Okonkwo, D.; Park, S.-Y.; Zusman, B.; Clark, R.S.B.; Shutter, L.; Wallisch, J.; Empey, P.; et al. Regionally clustered ABCC8 polymorphisms in a prospective cohort predict cerebral oedema and outcome in severe traumatic brain injury. J. Neurol. Neurosurg. Psychiatry 2018, 89, 1152-1162. [CrossRef]

136. Jha, R.M.; Desai, S.M.; Zusman, B.E.; Koleck, T.A.; Puccio, A.M.; Okonkwo, D.O.; Park, S.-Y.; Shutter, L.A.; Kochanek, P.M.; Conley, Y.P. DownstreamTRPM4Polymorphisms Are Associated with Intracranial Hypertension and Statistically Interact WithABCC8Polymorphisms in a Prospective Cohort of Severe Traumatic Brain Injury. J. Neurotrauma 2019, 36, 1804-1817. [CrossRef] [PubMed]

137. Jha, R.M.; Puccio, A.M.; Okonkwo, D.O.; Zusman, B.E.; Park, S.-Y.; Wallisch, J.; Empey, P.; Shutter, L.; Clark, R.S.B.; Kochanek, P.M.; et al. ABCC8 Single Nucleotide Polymorphisms are Associated with Cerebral Edema in Severe TBI. Neurocrit. Care 2016, 26, 213-224. [CrossRef]

138. Khalili, H.; Derakhshan, N.; Niakan, A.; Ghaffarpasand, F.; Salehi, M.; Eshraghian, H.; Shakibafard, A.; Zahabi, B. Effects of Oral Glibenclamide on Brain Contusion Volume and Functional Outcome of Patients with Moderate and Severe Traumatic Brain Injuries: A Randomized Double-Blind Placebo-Controlled Clinical Trial. World Neurosurg. 2017, 101, 130-136. [CrossRef]

139. Castro, L.; Noelia, M.; Vidal-Jorge, M.; Sánchez-Ortiz, D.; Gándara, D.; Martínez-Saez, E.; Cicuéndez, M.; Poca, M.A.; Simard, J.M.; Sahuquillo, J. Kir6.2, the Pore-Forming Subunit of ATP-Sensitive $\mathrm{K}^{+}$Channels, Is Overexpressed in Human Posttraumatic Brain Contusions. J. Neurotrauma 2019, 36, 165-175. [CrossRef]

140. Gorse, K.M.; Lantzy, M.K.; Lee, E.D.; Lafrenaye, A.D. Transient Receptor Potential Melastatin 4 Induces Astrocyte Swelling But Not Death after Diffuse Traumatic Brain Injury. J. Neurotrauma 2018, 35, 1694-1704. [CrossRef] [PubMed]

141. Kochanek, P.M.; Bramlett, H.M.; Dixon, C.E.; Shear, D.A.; Dietrich, W.D.; Schmid, K.E.; Mondello, S.; Wang, K.; Hayes, R.L.; Povlishock, J.T.; et al. Approach to Modeling, Therapy Evaluation, Drug Selection, and Biomarker Assessments for a Multicenter Pre-Clinical Drug Screening Consortium for Acute Therapies in Severe Traumatic Brain Injury: Operation Brain Trauma Therapy. J. Neurotrauma 2016, 33, 513-522. [CrossRef] [PubMed]

142. Kochanek, P.M.; Bramlett, H.M.; Dixon, C.E.; Dietrich, W.D.; Mondello, S.; Wang, K.K.W.; Hayes, R.L.; Lafrenaye, A.; Povlishock, J.T.; Tortella, F.C.; et al. Operation Brain Trauma Therapy: 2016 Update. Mil. Med. 2018, 183, 303-312. [CrossRef] [PubMed]

143. Xu, F.; Shen, G.; Su, Z.; He, Z.; Yuan, L. Glibenclamide ameliorates the disrupted blood-brain barrier in experimental intracerebral hemorrhage by inhibiting the activation of NLRP3 inflammasome. Brain Behav. 2019, 9, e01254. [CrossRef] [PubMed]

144. Jha, R.M.; Elmer, J.; Zusman, B.E.; Desai, S.; Puccio, A.M.; Okonkwo, D.O.; Park, S.Y.; Shutter, L.A.; Wallisch, J.S.; Conley, Y.P.; et al. Intracranial Pressure Trajectories. Crit. Care Med. 2018, 46, 1792-1802. [CrossRef] [PubMed]

145. Jha, R.M.; Zusman, B.E.; Puccio, A.M.; Okonkwo, D.O.; Pease, M.; Desai, S.M.; Leach, M.; Conley, Y.P.; Kochanek, P.M. Genetic Variants Associated With Intraparenchymal Hemorrhage Progression After Traumatic Brain Injury. JAMA Netw. Open 2021, 4, e2116839. [CrossRef]

146. Kurland, D.B.; Tosun, C.; Pampori, A.; Karimy, J.K.; Caffes, N.M.; Gerzanich, V.; Simard, J.M. Glibenclamide for the Treatment of Acute CNS Injury. Pharmaceuticals 2013, 6, 1287-1303. [CrossRef] [PubMed]

147. Hosier, H.; Peterson, D.; Tsymbalyuk, O.; Keledjian, K.; Smith, B.R.; Ivanova, S.; Gerzanich, V.; Popovich, P.G.; Simard, J.M. A Direct Comparison of Three Clinically Relevant Treatments in a Rat Model of Cervical Spinal Cord Injury. J. Neurotrauma 2015, 32, 1633-1644. [CrossRef] [PubMed]

148. Simard, J.M.; Popovich, P.G.; Tsymbalyuk, O.; Gerzanich, V. Spinal cord injury with unilateral versus bilateral primary hemorrhage-Effects of glibenclamide. Exp. Neurol. 2012, 233, 829-835. [CrossRef]

149. Simard, J.M.; Tsymbalyuk, O.; Keledjian, K.; Ivanov, A.; Ivanova, S.; Gerzanich, V. Comparative effects of glibenclamide and riluzole in a rat model of severe cervical spinal cord injury. Exp. Neurol. 2012, 233, 566-574. [CrossRef]

150. Popovich, P.G.; Lemeshow, S.; Gensel, J.C.; Tovar, C.A. Independent evaluation of the effects of glibenclamide on reducing pro-gressive hemorrhagic necrosis after cervical spinal cord injury. Exp. Neurol. 2012, 233, 615-622. [CrossRef]

151. Minnema, A.J.; Mehta, A.; Boling, W.W.; Schwab, J.; Simard, J.M.; Farhadi, H.F. SCING—Spinal Cord Injury Neuroprotection with Glyburide: A pilot, open-label, multicentre, prospective evaluation of oral glyburide in patients with acute traumatic spinal cord injury in the USA. BMJ Open 2019, 9, e031329. [CrossRef]

152. Gerzanich, V.; Woo, S.K.; Vennekens, R.; Tsymbalyuk, O.; Ivanova, S.; Ivanov, A.; Geng, Z.; Chen, Z.; Nilius, B.; Flockerzi, V.; et al. De Novo Expression of Trpm4 Initiates Secondary Hemorrhage in Spinal Cord Injury. Nat. Med. 2009, 15, 185-191. [CrossRef]

153. Yao, Y.; Xu, J.; Yu, T.; Chen, Z.; Xiao, Z.; Wang, J.; Hu, Y.; Wu, Y.; Zhu, D. Flufenamic acid inhibits secondary hemorrhage and BSCB disruption after spinal cord injury. Theranostics 2018, 8, 4181-4198. [CrossRef]

154. Simard, J.M.; Popovich, P.G.; Tsymbalyuk, O.; Caridi, J.; Gullapalli, R.P.; Kilbourne, M.J.; Gerzanich, V. MRI evidence that glibenclamide reduces acute lesion expansion in a rat model of spinal cord injury. Spinal Cord 2013, 51, 823-827. [CrossRef] [PubMed] 
155. Schwartz, G.; Fehlings, M.G. Evaluation of the neuroprotective effects of sodium channel blockers after spinal cord injury: Im-proved behavioral and neuroanatomical recovery with riluzole. J. Neurosurg. 2001, 94 (Suppl. 2), 245-256. [CrossRef]

156. Tetreault, L.A.; Zhu, M.P.; Wilson, J.R.; Karadimas, S.K.; Fehlings, M.G. The impact of riluzole on neurobehavioral outcomes in pre-clinical models of traumatic and nontraumatic spinal cord injury: Results from a systematic review of the literature. Glob. Spine J. 2020, 10, 216-229. [CrossRef] [PubMed]

157. Lee, J.Y.; Choi, H.Y.; Park, C.S.; Ju, B.G.; Yune, T.Y. Mithramycin A Improves Functional Recovery by Inhibiting BSCB Disruption and Hemorrhage after Spinal Cord Injury. J. Neurotrauma 2018, 35, 508-520. [CrossRef]

158. Lee, J.Y.; Choi, H.Y.; Na, W.H.; Ju, B.G.; Yune, T.Y. Ghrelin inhibits BSCB disruption/hemorrhage by attenuating MMP-9 and SUR1/TrpM4 expression and activation after spinal cord injury. Biochim. Biophys. Acta Mol. Basis Dis. 2014, 1842, 2403-2412. [CrossRef] [PubMed]

159. Lee, J.Y.; Choi, H.Y.; Na, W.H.; Ju, B.G.; Yune, T.Y. 17ß-estradiol inhibits MMP-9 and SUR1/TrpM4 expression and activation and thereby attenuates BSCB disruption/hemorrhage after spinal cord injury in male rats. Endocrinology 2015, 156, 1838-1850. [CrossRef] [PubMed]

160. Tosun, C.; Koltz, M.T.; Kurland, D.B.; Ijaz, H.; Gurakar, M.; Schwartzbauer, G.; Coksaygan, T.; Ivanova, S.; Gerzanich, V.; Simard, J.M. The Protective Effect of Glibenclamide in a Model of Hemorrhagic Encephalopathy of Prematurity. Brain Sci. 2013, 3, 215-238. [CrossRef]

161. Dankiewicz, J.; Cronberg, T.; Lilja, G.; Jakobsen, J.C.; Levin, H.; Ullén, S.; Rylander, C.; Wise, M.P.; Oddo, M.; Cariou, A.; et al. Hypothermia versus Normothermia after Out-of-Hospital Cardiac Arrest. N. Engl. J. Med. 2021, 384, 2283-2294. [CrossRef] [PubMed]

162. Morrison, L.J.; Thoma, B. Translating Targeted Temperature Management Trials into Postarrest Care. N. Engl. J. Med. 2021, 384, 2344-2345. [CrossRef]

163. Jackson, T.C.; Kochanek, P.M. A New Vision for Therapeutic Hypothermia in the Era of Targeted Temperature Management: A Speculative Synthesis. Ther. Hypothermia Temp. Manag. 2019, 9, 13-47. [CrossRef]

164. Lascarrou, J.-B.; Merdji, H.; Le Gouge, A.; Colin, G.; Grillet, G.; Girardie, P.; Coupez, E.; Dequin, P.-F.; Cariou, A.; Boulain, T.; et al. Targeted Temperature Management for Cardiac Arrest with Nonshockable Rhythm. N. Engl. J. Med. 2019, 381, $2327-2337$. [CrossRef] [PubMed]

165. Nielsen, N.; Wetterslev, J.; Cronberg, T.; Erlinge, D.; Gasche, Y.; Hassager, C.; Horn, J.; Hovdenes, J.; Kjaergaard, J.; Kuiper, M.; et al. Targeted Temperature Management at $33^{\circ} \mathrm{C}$ versus $36^{\circ} \mathrm{C}$ after Cardiac Arrest. N. Engl. J. Med. 2013, 369, $2197-2206$. [CrossRef] [PubMed]

166. Hypothermia after Cardiac Arrest Study Group. Mild therapeutic hypothermia to improve the neurologic outcome after cardiac arrest. N. Engl. J. Med. 2002, 346, 549-556. [CrossRef]

167. Bernard, S.A.; Gray, T.W.; Buist, M.D.; Jones, B.M.; Silvester, W.; Gutteridge, G.; Smith, K. Treatment of Comatose Survivors of Out-of-Hospital Cardiac Arrest with Induced Hypothermia. N. Engl. J. Med. 2002, 346, 557-563. [CrossRef] [PubMed]

168. Nakayama, S.; Taguchi, N.; Isaka, Y.; Nakamura, T.; Tanaka, M. Glibenclamide and Therapeutic Hypothermia Have Comparable Effect on Attenuating Global Cerebral Edema Following Experimental Cardiac Arrest. Neurocrit. Care 2017, 29, 119-127. [CrossRef]

169. Huang, K.; Gu, Y.; Hu, Y.; Ji, Z.; Wang, S.; Lin, Z.; Li, X.; Xie, Z.; Pan, S. Glibenclamide Improves Survival and Neurologic Outcome After Cardiac Arrest in Rats*. Crit. Care Med. 2015, 43, e341-e349. [CrossRef]

170. Huang, K.; Wang, Z.; Gu, Y.; Hu, Y.; Ji, Z.; Wang, S.; Lin, Z.; Li, X.; Xie, Z.; Pan, S. Glibenclamide Is Comparable to Target Temperature Management in Improving Survival and Neurological Outcome After Asphyxial Cardiac Arrest in Rats. JAHA 2016, 5, e003465. [CrossRef]

171. Huang, K.; Wang, Z.; Gu, Y.; Ji, Z.; Lin, Z.; Wang, S.; Pan, S.; Wu, Y. Glibenclamide Prevents Water Diffusion Abnormality in the Brain After Cardiac Arrest in Rats. Neurocrit. Care 2018, 29, 128-135. [CrossRef] [PubMed]

172. Jiang, B.; Li, L.; Chen, Q.; Tao, Y.; Yang, L.; Zhang, B.; Zhang, J.H.; Feng, H.; Chen, Z.; Tang, J.; et al. Role of Glibenclamide in Brain Injury After Intracerebral Hemorrhage. Transl. Stroke Res. 2016, 8, 183-193. [CrossRef] [PubMed]

173. Kung, T.F.C.; Wilkinson, C.M.; Dirks, C.A.; Jickling, G.C.; Colbourne, F. Glibenclamide does not improve outcome following severe collagenase-induced intracerebral hemorrhage in rats. PLoS ONE 2021, 16, e0252584. [CrossRef]

174. Wilkinson, C.M.; Brar, P.S.; Balay, C.J.; Colbourne, F. Glibenclamide, a Sur1-Trpm4 antagonist, does not improve outcome after collagenase-induced intracerebral hemorrhage. PLoS ONE 2019, 14, e0215952. [CrossRef]

175. Zhou, F.; Liu, Y.; Yang, B.; Hu, Z. Neuroprotective potential of glibenclamide is mediated by antioxidant and anti-apoptotic pathways in intracerebral hemorrhage. Brain Res. Bull. 2018, 142, 18-24. [CrossRef]

176. Chang, J.J.; Khorchid, Y.; Kerro, A.; Burgess, L.G.; Goyal, N.; Alexandrov, A.W.; Alexandrov, A.V.; Tsivgoulis, G. Sulfonylurea drug pretreatment and functional outcome in diabetic patients with acute intracerebral hemorrhage. J. Neurol. Sci. 2017, 381, 182-187. [CrossRef]

177. Simard, J.M.; Castellani, R.J.; Ivanova, S.; Koltz, M.T.; Gerzanich, V. Sulfonylurea Receptor 1 in the Germinal Matrix of Premature Infants. Pediatr. Res. 2008, 64, 648-652. [CrossRef]

178. Schattling, B.; Steinbach, K.; Thies, E.; Kruse, M.; Menigoz, A.; Ufer, F.; Flockerzi, V.; Brück, W.; Pongs, O.; Vennekens, R.; et al. TRPM4 cation channel mediates axonal and neuronal degeneration in experimental autoimmune encephalomyelitis and multiple sclerosis. Nat. Med. 2012, 18, 1805-1811. [CrossRef] [PubMed] 
179. Dutta, R.; Trapp, B.D. Mechanisms of neuronal dysfunction and degeneration in multiple sclerosis. Prog. Neurobiol. 2011, 93, 1-12. [CrossRef] [PubMed]

180. Sawcer, S.; Hellenthal, G.; Pirinen, M. Genetic risk and a primary role for cell-mediated immune mechanisms in multiple sclerosis. Nature 2011, 476, 214-219. [CrossRef] [PubMed]

181. Mc Guire, C.; Volckaert, T.; Wolke, U.; Sze, M.; De Rycke, R.; Waisman, A.; Prinz, M.; Beyaert, R.; Pasparakis, M.; Van Loo, G. Oligodendrocyte-Specific FADD Deletion Protects Mice from Autoimmune-Mediated Demyelination. J. Immunol. 2010, 185, 7646-7653. [CrossRef]

182. Nair, A.; Frederick, T.J.; Miller, S.D. Astrocytes in multiple sclerosis: A product of their environment. Experientia 2008, 65, 2702-2720. [CrossRef] [PubMed]

183. Brosnan, C.F.; Raine, C.S. The astrocyte in multiple sclerosis revisited. Glia 2013, 61, 453-465. [CrossRef] [PubMed]

184. Correale, J.; Farez, M.F. The role of astrocytes in multiple sclerosis progression. Front. Neurol. 2015, 6, 180. [CrossRef] [PubMed]

185. Ludwin, S.K.; Rao, V.T.; Moore, C.S.; Antel, J. Astrocytes in multiple sclerosis. Mult. Scler. J. 2016, 22, 1114-1124. [CrossRef] [PubMed]

186. Jayakumar, A.R.; Valdes, V.; Tong, X.Y.; Shamaladevi, N.; Gonzalez, W.; Norenberg, M.D. Sulfonylurea Receptor 1 Contributes to the Astrocyte Swelling and Brain Edema in Acute Liver Failure. Transl. Stroke Res. 2014, 5, 28-37. [CrossRef]

187. Betjemann, J.P.; Lowenstein, D.H. Status epilepticus in adults. Lancet Neurol. 2015, 14, 615-624. [CrossRef]

188. Lin, Z.; Huang, H.; Gu, Y.; Huang, K.; Hu, Y.; Ji, Z.; Wu, Y.; Wang, S.; Yang, T.; Pan, S. Glibenclamide ameliorates cerebral edema and improves outcomes in a rat model of status epilepticus. Neuropharmacology 2017, 121, 1-11. [CrossRef]

189. Costigan, M.; Scholz, J.; Woolf, C.J. Neuropathic Pain: A Maladaptive Response of the Nervous System to Damage. Annu. Rev. Neurosci. 2009, 32, 1-32. [CrossRef]

190. Zhang, Z.-J.; Jiang, B.-C.; Gao, Y.-J. Chemokines in neuron-glial cell interaction and pathogenesis of neuropathic pain. Cell. Mol. Life Sci. 2017, 74, 3275-3291. [CrossRef] [PubMed]

191. Vallejo, R.; Tilley, D.M.; Vogel, L.; Benyamin, R. The Role of Glia and the Immune System in the Development and Maintenance of Neuropathic Pain. Pain Pract. 2010, 10, 167-184. [CrossRef]

192. Ji, R.-R.; Chamessian, A.; Zhang, Y.-Q. Pain regulation by non-neuronal cells and inflammation. Science 2016, $354,572-577$. [CrossRef]

193. Song, J.-G.; Hahm, K.D.; Kim, Y.K.; Gil Leem, J.; Lee, C.; Jeong, S.M.; Park, P.H.; Shin, J.W. Adenosine Triphosphate-Sensitive Potassium Channel Blockers Attenuate the Antiallodynic Effect of R-PIA in Neuropathic Rats. Anesth. Analg. 2011, 112, 1494-1499. [CrossRef]

194. de Los Monteros-Zuñiga, A.E.; Izquierdo, T.; Quiñonez-Bastidas, G.N.; Rocha-González, H.I.; Godínez-Chaparro, B. Antiallodynic effect of mangiferin in neuropathic rats: Involvement of nitric oxide-cyclic GMP-ATP sensitive $\mathrm{K}^{+}$channels pathway and serotoninergic system. Pharmacol. Biochem. Behav. 2016, 150-151, 190-197. [CrossRef]

195. Longhi-Balbinot, D.T.; Rossaneis, A.C.; Ribeiro, F.P.; Bertozzi, M.M.; Cunha, F.Q.; Alves-Filho, J.C.; Cunha, T.; Peron, J.P.; Miranda, K.M.; Casagrande, R.; et al. The nitroxyl donor, Angeli's salt, reduces chronic constriction injury-induced neuropathic pain. Chem. Interact. 2016, 256, 1-8. [CrossRef]

196. Koh, W.U.; Shin, J.W.; Bang, J.-Y.; Kim, S.G.; Song, J.-G. The Antiallodynic Effects of Nefopam Are Mediated by the Adenosine Tri-phosphate-Sensitive Potassium Channel in a Neuropathic Pain Model. Anesth. Analg. 2016, 123, 762-770. [CrossRef]

197. Bertozzi, M.M.; Rossaneis, A.C.; Fattori, V.; Longhi-Balbinot, D.T.; Freitas, A.; Cunha, F.Q.; Alves-Filho, J.C.; Cunha, T.M.; Casagrande, R.; Verri, W.A. Diosmin reduces chronic constriction injury-induced neuropathic pain in mice. Chem. Interact. 2017, 273, 180-189. [CrossRef]

198. Zulazmi, N.A.; Gopalsamy, B.; Min, J.C.S.; Farouk, A.A.O.; Sulaiman, M.R.; Bharatham, B.H.; Perimal, E.K. Zerumbone Alleviates Neuropathic Pain through the Involvement of 1-Arginine-Nitric Oxide-cGMP-K ${ }^{+}$ATP Channel Pathways in Chronic Constriction Injury in Mice Model. Molecules 2017, 22, 555. [CrossRef] [PubMed]

199. Mata-Bermudez, A.; Izquierdo, T.; Monteros-Zuñiga, E.D.L.; Coen, A.; Godínez-Chaparro, B. Antiallodynic effect induced by 6-gingerol in neuropathic rats is mediated by activation of the serotoninergic system and the nitric oxide-cyclic guanosine monophosphate-adenosine triphosphate-sensitive $\mathrm{K}^{+}$channel pathway. Phytother. Res. 2018, 32, 2520-2530. [CrossRef] [PubMed]

200. Pastrana-Quintos, T.; Salgado-Moreno, G.; Pérez-Ramos, J.; Coen, A.; Godínez-Chaparro, B. Anti-allodynic effect induced by cur-cumin in neuropathic rat is mediated through the NO-cyclic-GMP-ATP sensitive $\mathrm{K}^{+}$channels pathway. BMC Complement. Med. Ther. 2020, 20, 83. [CrossRef] [PubMed]

201. Li, G.; Makar, T.; Gerzanich, V.; Kalakonda, S.; Ivanova, S.; Pereira, E.F.R.; Andharvarapu, S.; Zhang, J.; Simard, J.M.; Zhao, R.Y. HIV-1 Vpr-Induced Proinflammatory Response and Apoptosis Are Mediated through the Sur1-Trpm4 Channel in Astrocytes. mBio 2020, 11, e02939-20. [CrossRef] [PubMed]

202. Berdugo, M.; Delaunay, K.; Naud, M.-C.; Guegan, J.; Moulin, A.; Savoldelli, M.; Picard, E.; Radet, L.; Jonet, L.; Djerada, Z.; et al. The antidiabetic drug glibenclamide exerts direct retinal neuroprotection. Transl. Res. 2020, 229, 83-99. [CrossRef] 